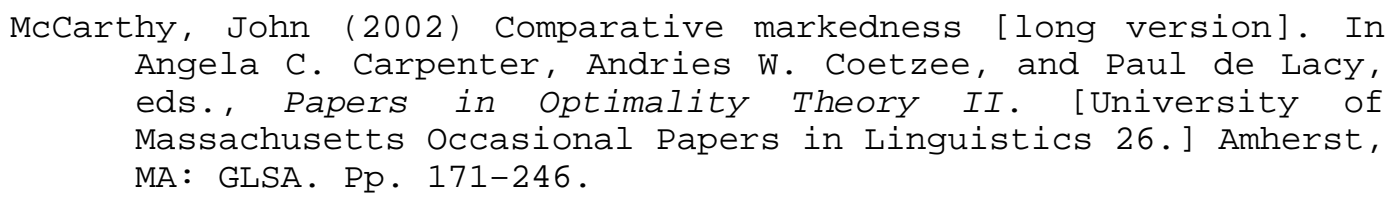

\title{
Comparative Markedness
}

\author{
John J. McCarthy \\ University of Massachusetts, Amherst
}

The beauty we find is from the comparison we make.... Beauty therefore is a relation, and the apprehension of it a comparison.

Gerard Manley Hopkins, SJ

\begin{abstract}
The markedness constraints of classic Optimality Theory assign violationmarks to output candidates without reference to the input or to other candidates. This paper explores an alternative conception of markedness that is comparative: markedness constraints compare the candidate under evaluation with another candidate, the most faithful one. Comparative constraints distinguish two situations: the candidate under evaluation contains an instance of a marked structure that is also present in the fullyfaithful candidate; or the candidate under evaluation contains an instance of a marked structure that is not present in the fully faithful candidate. The empirical consequences of comparative markedness are explored, including grandfather effects (i.e., blocking by emergent markedness constraints), derived environment effects, non-iterating processes, coalescence paradoxes, and counterfeeding opacity. Theoretical questions concerning harmonic ascent and other topics will also be discussed. Comparative markedness is found to have some advantages and some disadvantages in comparison with classic OT and alternatives like local conjunction, stratal OT, sympathy, and targeted constraints.
\end{abstract}

\section{$\$ 1$. Introduction}

Optimality Theory (Prince and Smolensky 1993) has two types of constraints, faithfulness and markedness. Faithfulness constraints militate against input-output disparity, while markedness constraints impose restrictions on the output without reference to the input. For example, the input-output mapping /ab/ $\rightarrow$ Pab violates the faithfulness constraint DEP (no epenthesis), and the output form $7 a b$ violates the markedness constraints No-CODA and NoVCDOB $(\equiv *[-$ son, +voice $])$.

In this article, I explore a different approach to markedness. The idea is that markedness constraints assign violation-marks to output candidates by comparing 
them to the fully faithful candidate (FFC), which is present in every candidate set. ${ }^{1}$ These novel markedness constraints distinguish between:

-Mappings that fail to correct a marked configuration in the FFC. E.g., the mapping /ab/ $\rightarrow$ Pab fails to correct the marked voiced obstruent in the FFC $a b$. That is, the NoVCDOB violation in $7 a b$ is "old" because the fully faithful candidate $a b$ has the same violation.

and

-Mappings that introduce new marked configurations. E.g., the mapping /ampa/ $\rightarrow$ amba (i.e., post-nasal voicing) introduces a voiced obstruent that is not present in the FFC ampa. That is, the NOVCDOB violation in amba is "new" because the fully faithful candidate ampa doesn't have this violation.

In other words, every traditional markedness constraint $\mathrm{M}$ is replaced by two freely rankable constraints, ${ }_{0} \mathrm{M}$ and ${ }_{\mathbf{N}} \mathrm{M}$. The notation ${ }_{\mathbf{0}} \mathrm{M}$ is a reminder that these markedness constraints only refer to violations that are old, in the sense that they are shared with the FFC. The notation ${ }_{\mathrm{N}} \mathrm{M}$ is similarly a reminder that these markedness constraints only refer to violations that are new, in the sense that they are not shared with the FFC. For example, ${ }_{0}$ NoVCDOB is violated by the /ab/ $\rightarrow$ ?ab mapping, while ${ }_{\mathbf{N}} \mathrm{NoVCDOB}$ is violated by the /ampa/ $\rightarrow$ amba mapping. Dividing traditional $\mathrm{M}$ up in this way yields some new results, as we will see below. I call this approach comparative markedness.

Taken together, ${ }_{\mathbf{O}} \mathrm{M}$ and ${ }_{\mathrm{N}} \mathrm{M}$ assign the same violation-marks as a traditional, non-comparative markedness constraint $\mathrm{M}$. This is best seen with a Venn diagram:

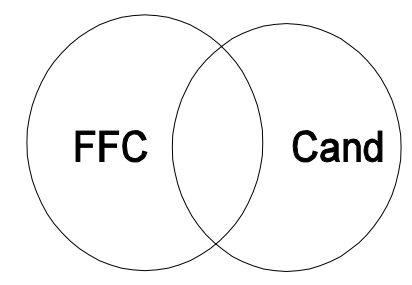

The circle on the left stands for all the violations of standard OT markedness constraints incurred by the FFC. The circle on the right stands for all the violations of standard OT markedness constraints incurred by the candidate under evaluation, Cand. Cand's violation-marks can be partitioned into two subsets: those shared with the FFC (Cand FFC) and those that are not shared with the FFC (Cand-FFC). The shared violations, the region in the middle, are the ones that I will be calling, somewhat imprecisely, "old" or "inherited". Comparative markedness theory counts them as ${ }_{0} \mathrm{M}$ violations. Cand's violation-marks that are not shared with the FFC the portion of the right circle that does not overlap with the left circle - can be (loosely) described as new, since they refer to something about Cand that is different from the FFC. Comparative markedness theory counts them as ${ }_{\mathbf{N}} \mathrm{M}$ violations. From

\footnotetext{
${ }^{1}$ Candidates are compared with the FFC, rather than the input itself, because inputs may lack syllabification or other fully predictable structure. See $\$ 6.2$ for further discussion.
} 
this, it's clear that all of Cand's traditional markedness violations are accounted for, some being assigned to ${ }_{0} \mathrm{M}$ constraints and some to ${ }_{\mathrm{N}} \mathrm{M}$ constraints.

The next section looks informally at one consequence of comparative markedness, the analysis of grandfather effects, where a marked structure is permitted when it is old but forbidden when it is new. Later sections fill in the formal details of the theory as a whole and of the analysis of grandfather effects. Applications to derived environment effects, non-iterative processes, coalescence paradoxes, and counterfeeding opacity are also discussed, as are issues raised by this approach, such as determination of the fully-faithful candidate and the problem of harmonic ascent.

\section{\$2. Grandfather Effects}

Suppose that typological evidence has established that UG contains the classic OT markedness constraint M - for example, some languages permit only Mobeying forms, some languages have processes that actively eliminate M-violators, and so on. Now, suppose there is a language $\mathrm{L}$ where $\mathrm{M}$ is ranked below antagonistic faithfulness constraints, so it cannot compel unfaithful mappings. But $\mathrm{M}$ is nonetheless observed to block processes in L from creating M-violating structures. $\mathrm{M}$ is emergent in $\mathrm{L}$, in the same sense of emergence of the unmarked in McCarthy and Prince (1994). I will call this a "grandfather effect". 2

Grandfather effects are by no means uncommon. Archangeli and Pulleyblank (1994) call them "target conditions", since they specifically affect the target of a phonological process. Their relevance to comparative markedness theory was discovered by Paul de Lacy, who offers the following example (cf. Mascaró and Wetzels 2001):

(2) Mekkan Arabic [-voice] Assimilation (Abu-Mansour 1996, Bakalla 1973)

a. Voiced obstruent assimilates to following voiceless

$\begin{array}{lll}\text { /Ragsam/ } & \text { ?aksam } & \text { 'he swore an oath' } \\ \text { /mazkuir/ } & \text { maskurr } & \text { 'mentioned' }\end{array}$

b. But not vice-versa. Assimilation can't create marked voiced obstruents /Rakbar/ Takbar, * Tagbar 'older'

c. Otherwise, voiced obstruents, even codas, are treated faithfully

$\begin{array}{lll}\text { /Ribnu/ } & \text { Tibnu } & \text { 'his son' } \\ \text { /Radzuiz/ } & \text { Tadzuiz } & \text { 'old' } \\ \text { /dabdaba/ } & \text { dabdaba } & \text { 'pitter-pat (footsteps)' }\end{array}$

In this Arabic dialect, coda obstruents become voiceless before a voiceless obstruent (2a). There is no general process of coda devoicing, however, as shown by (2c).

\footnotetext{
${ }^{2}$ The term was suggested by Ellen Woolford. In American jurisprudence, a grandfather clause is a provision in a law that exempts persons who, at the time when the law was adopted, were already engaged in activities affected by that law. The term was first used to describe laws in some southern states that allowed persons whose ancestors ("grandfathers") had voted prior to 1867 to be exempt from impediments to voting, such as poll taxes and literacy tests. The intended effect was to apply these impediments only to the descendants of slaves.
} 
Significantly, voiceless coda obstruents do not become voiced before voiced obstruents (2b). In short, voiced obstruents present in the input are grandfathered (e.g., dabdaba), but new voiced obstruents cannot be created by the voicing assimilation process (/Rakbar/ $\rightarrow$ Takbar, * ?agbar). The markedness constraint NoVCDOB blocks assimilation but cannot itself compel unfaithfulness.

In comparative markedness theory, the original NoVCDOB constraint is replaced by ${ }_{\mathrm{N}} \mathrm{NoVCDOB}$ and ${ }_{\mathrm{O}} \mathrm{NoVCDOB}$. ${ }_{\mathrm{N}} \mathrm{NoVCDOB}$ is violated by new instances of voiced obstruents, those not present in the FFC. ${ }_{\mathrm{O}} \mathrm{NoVCDOB}$ is violated by old instances of voiced obstruents, those already present in the FFC. For example, * Tagbar violates each of these constraints once: ${ }_{\mathrm{N}} \mathrm{NOVCDOB}$ is violated by the $g$, whose counterpart in the FFC ?akbar is not voiced; and ${ }_{\mathrm{O}} \mathrm{NOVCDOB}$ is violated by the $b$, whose counterpart in the FFC is also voiced. Assimilation is blocked, so ${ }_{\mathrm{N}} \mathrm{NoV}$ CDOB must be ranked above the constraint responsible for assimilation, AGREE(voice), ${ }^{3}$ which is itself ranked above the faithfulness constraint IDENT(voice), as shown in (3). (The ranking arguments are surrounded by heavy lines.)

(3) Mekkan Arabic: ${ }_{N}$ NoVCDOB $\gg$ AGREE(voice) $\gg$ IDENT(voice)

\begin{tabular}{|c|c|c|c|}
\hline /Ragsam/ & ${ }_{\mathrm{N}} \mathrm{NoVCDOB}$ & AGREE(voice) & IDENT(voice) \\
\hline ?aksam & & & $*$ \\
\hline b. (FFC) ?agsam & & $* !$ & \\
\hline \multicolumn{4}{|l|}{ /2akbar/ } \\
\hline c. (FFC) ?akbar & & $*$ & \\
\hline d. $\quad$ ?agbar & $* !$ & & $*$ \\
\hline
\end{tabular}

In $(3 \mathrm{a}, \mathrm{b})$, top-ranked ${ }_{\mathrm{N}} \mathrm{NoVCDOB}$ is satisfied by both candidates because neither introduces a new voiced obstruent. This leaves the choice up to AGREE(voice), which favors the candidate with assimilation. In $(3 \mathrm{c}, \mathrm{d})$, though, there is a candidate * ?agbar with a new voiced obstruent, and its encounter with ${ }_{\mathrm{N}} \mathrm{NOVCDOB}$ is fatal. Assimilation is therefore blocked. (Another way to satisfy AGREE(voice) is by progressive assimilation: * Rakpar. I assume, as is now standard (Beckman 1998, Lombardi 1999), that the positional faithfulness constraint IDENT-ONS(voice) is ranked above AGREE.)

To show that two putatively distinct OT constraints are in fact distinct, it is sufficient to show that they are crucially ranked non-adjacently in some language's hierarchy. As required, ${ }_{0} \mathrm{NOV} C D O B$ is ranked at a different place in Mekkan Arabic's hierarchy than ${ }_{\mathrm{N}} \mathrm{NOVCDOB}$. Because some underlying voiced obstruents make it faithfully to the surface, even in coda position, IDENT(voice) must be ranked above ${ }_{0} \mathrm{NoV} C D O B$, as shown in (4).

${ }^{3}$ For now, I assume Lombardi's (1999: 272) definition of AGREE: "Obstruent clusters should agree in voicing." For discussion, see $§ 5.1$. 
(4) Mekkan Arabic: IDENT(voice) $\gg{ }_{0} \mathrm{NoVCDOB}$

\begin{tabular}{|lr||c|c|}
\hline \multicolumn{2}{|c|}{$/$ Ribnu/ } & IDENT(voice) & ${ }_{\text {ONOVCDOB }}$ \\
\hline \hline a. & Tibnu & & $*$ \\
\hline b. & Tipnu & $*$ & \\
\hline
\end{tabular}

By transitive closure of the rankings in (3) and (4), ${ }_{\mathrm{N}} \mathrm{NOVCDOB}$ and ${ }_{\mathrm{O}} \mathrm{NoVCDOB}$ are indeed ranked separately in Mekkan Arabic: ${ }_{N}$ NoVCDOB $\gg$ AgreE(voice) $\gg$ IDENT(voice) $\gg{ }_{0} \mathrm{NOVCDOB} \rrbracket$. With this ranking, ${ }_{\mathrm{N}} \mathrm{NOVCDOB}$ is visibly active on candidates derived from inputs like / $\mathrm{akbar} /$, but ${ }_{\mathrm{O}} \mathrm{NOVCDOB}$ is not visibly active on any inputs.

The key to analyzing this and other examples of grandfather effects is the ranking of the new-affecting and old-affecting versions of a markedness constraint. (Hereafter, I'll avoid the awkward locutions "new-affecting" and "old-affecting" by saying simply "new" and "old". When the chronologically prior definition of a markedness constraint is referred to, I'll use the word "classic", as in "classic OT".) The new version, ${ }_{\mathrm{N}} \mathrm{M}$, is ranked above the markedness constraint responsible for the process that is blocked. The old version, ${ }_{\mathrm{O}} \mathrm{M}$, is ranked below the relevant faithfulness constraint, so it cannot affect $\mathrm{M}$-violating structures that are already present in the input/FFC. This same schematic ranking is also at work in derived environment effects, as I will show later (\$4.2). The opposite ranking, with ${ }_{\mathrm{O}} \mathrm{M}$ high and ${ }_{\mathrm{N}} \mathrm{M}$ low, is attested as well - see $\S 5$.

In classic OT, which has only non-comparative markedness constraints, there is no general solution to the problem of grandfather effects. Consider, for example, how one might analyze Mekkan Arabic without comparative markedness. If the classic OT constraint NOVCDOB is ranked above AGREE(voice), then assimilation is correctly blocked in Rakbar. But by transitivity, NoVCDOB also dominates IDENT(voice). This predicts that Mekkan should have no voiced coda obstruents whatsoever, and that is false (see (2c)). To accommodate this language, then, the classic theory must enrich its constraint set in other ways, perhaps by dividing the AGREE and/or IDENT constraints according to values of the feature [voice]: AgreE(+voice) vs. AGREE(-voice), IDENT(+voice) vs. IDENT(-voice). Obviously, though, this is a highly localized solution to a specific problem; it does not address the issue of how to analyze grandfather effects in general (see $§ 4.1)$.

We will return to the analysis of grandfather effects in $\S 4.1$, but first it is necessary to formalize some of the ideas that have been treated intuitively up to this point.

\section{§3. Formalization}

As the discussion in $\S 2$ indicated, ${ }_{0} \mathrm{M}$ and ${ }_{\mathrm{N}} \mathrm{M}$ recognize, respectively, that a candidate retains some instance of a marked configuration and that a candidate introduces a new instance of a marked configuration, relative to the FFC. What we 
need, then, is a way of talking about a specific instance of a marked configuration in a candidate and a way of talking about what it means to inherit a marked configuration or to introduce a new one. An unambiguous characterization of the FFC is also needed; see $\S 6.2$.

The intuition to be captured is this: a constraint violation is new if the corresponding material in the FFC does not violate that constraint. For instance, the mapping /ampa/ $\rightarrow$ Tamba introduces a new NOVCDOB violation relative to the FFC ampa. Differences between candidates that are not relevant to a constraint's applicability do not make a violation new. For example, the mapping /anba/ $\rightarrow a m b a$ does not introduce a new NoVCDOB violation relative to the FFC anba. Although the underlying $/ \mathrm{b} /$ is involved in a place assimilation process in $a m b a$, that is irrelevant to evaluating NoVCDOB. Furthermore, a simple count of violation-marks is not enough to determine newness. The mapping /ampab/ $\rightarrow$ ambap, with both post-nasal voicing and final devoicing, introduces a new $\mathrm{NOVCDOB}_{\mathrm{B}}$ violation relative to the FFC ampab, even though ambap and ampab have exactly one NOVCDOB violationmark each.

To express these intuitions formally, it is necessary to explore what it means to apply a markedness constraint to a form. Two notions will be essential. One is the locus of violation of a markedness constraint in a candidate. This is the spot in the candidate where the constraint is violated; for example, the locus of violation of NoVCDOB in amba is the segment $b$. The other notion is t-correspondence. This is a version of correspondence that has been transitivized, using the shared input to link two output candidates. Together, these elements provide a foundation for defining comparative markedness.

The locus of violation of a markedness constraint $\mathrm{M}$ in a candidate cand is determined by the definition of $\mathrm{M}$ and the contents of cand. ${ }^{4}$ Every markedness constraint $\mathrm{M}_{\mathrm{i}}$ is defined in terms of its locus-of-violation function $\operatorname{Loc}_{\mathrm{i}}$. $\operatorname{Loc}_{\mathrm{i}}$ is a function from a candidate to a set of loci of violation, which are segments in that candidate.

(5) The Loc function

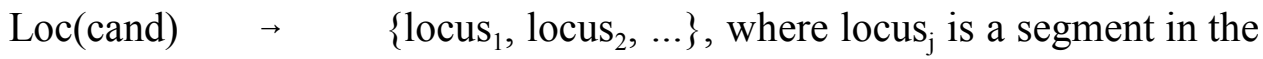
candidate cand.

Since $\operatorname{Loc}_{\mathrm{i}}$ is the definition of $\mathrm{M}_{\mathrm{i}}$, the Loc function is stipulated for each constraint. Some proposed Loc functions associated with familiar markedness constraints are given in (6):

${ }^{4}$ I am grateful to Marc van Oostendorp for suggesting an approach along these lines. Something like this is also implicit in Crowhurst and Hewitt's (1997) notion "focus" of a constraint. 
(6) Some Locus Functions

\begin{tabular}{|c|c|c|}
\hline $\operatorname{Loc}_{\mathrm{NOVCDOB}}$ & $\equiv$ & $\begin{array}{l}\text { "Return each instance of } \mathrm{C} \text {, where } \mathrm{C} \text { is [+voice, } \\
\text {-son]." }\end{array}$ \\
\hline Loc $_{\text {ONSET }}$ & $\equiv$ & $\begin{array}{l}\text { "Return each instance of } \mathrm{V} \text {, where } \mathrm{V} \text { is initial in some } \\
\text { syllable." }\end{array}$ \\
\hline $\operatorname{Loc}_{\text {No-CODA }}$ & $\equiv$ & $\begin{array}{l}\text { "Return each instance of } \mathrm{C} \text {, where } \mathrm{C} \text { is final in some } \\
\text { syllable." }\end{array}$ \\
\hline $\operatorname{Loc}_{\text {PARSE-SYLL }}$ & $\equiv$ & $\begin{array}{l}\text { "Return each instance of } \mathrm{V} \text {, where } \mathrm{V} \text { is the head of an } \\
\text { unfooted syllable." }\end{array}$ \\
\hline $\operatorname{Loc}_{\mathrm{FT}-\mathrm{BIN}}$ & $\equiv$ & $\begin{array}{l}\text { "Return each instance of } \mathrm{V} \text {, where } \mathrm{V} \text { is the head of a } \\
\text { syllable that is the head of a unary foot." }\end{array}$ \\
\hline
\end{tabular}

Since the Loc functions define markedness constraints, it is not necessary or perhaps even possible to supply a procedure for translating classic markedness constraints into Loc functions. The Loc functions are primitive in the way that all definitions are; they are not derived from something else. Nonetheless, the definitions in (6) reflect certain assumptions: loci are individual segments, not strings; and constraints on structures usually return the heads of those structures as loci.

As a first pass through comparative markedness theory, this will prove sufficient. Some further issues should not go unremarked on, however. First, because we will need to talk about corresponding loci in different candidates, loci must be elements that stand in correspondence. Segments, at least, do correspond, but it is controversial whether features or prosodic constituents do, and relations like association lines certainly do not. Whatever the elements of correspondence turn out to be (McCarthy and Prince 1995, 1999), they should also be the loci of markedness violation. Second, for contextual constraints, the choice of locus may not be obvious and it may ultimately prove necessary to allow strings of segments to be loci. Third, gradient constraints in general, and gradient alignment constraints in particular, cannot be defined in terms of a function that returns instances of a marked structure. For example, Align(Ft, Word, L), as defined in McCarthy and Prince (1993a), assigns for every foot one violation mark for every syllable standing between that foot and the left edge of the word. Elsewhere (McCarthy 2002a), I have argued that there are no gradient constraints, and so this potential impediment to redefining markedness in terms of Loc has been eliminated.

Under this new approach to defining markedness constraints, a classic constraint $M_{i}$ could be said to assign its violation marks in the following way. $M_{i}$ is defined by some locus function $\operatorname{Loc}_{\mathrm{i}}$. The result of applying $\mathrm{M}_{\mathrm{i}}$ to cand is a number of violation-marks equal to the cardinality of the set obtained by applying $\operatorname{Loc}_{\mathrm{i}}$ to cand. The comparative markedness constraints ${ }_{O} \mathrm{M}_{\mathrm{i}}$ and ${ }_{N} \mathrm{M}_{\mathrm{i}}$, which replace $\mathrm{M}_{\mathrm{i}}$, use the same function $\mathrm{Loc}_{\mathrm{i}}$. But the comparative constraints must additionallly check whether the members of the locus set are new or old violations.

Therefore, the next step in formalizing comparative markedness theory is defining what it means for two candidates from the same input to share a locus of 
violation. ${ }_{\mathrm{O}} \mathrm{M}$ constraints assign marks only for loci that are shared with the $\mathrm{FFC} ;{ }_{\mathrm{N}} \mathrm{M}$ constraints assign marks only for loci that are not shared with the FFC. This sharing relation holds between two candidates derived from the same input, so it must be mediated by correspondence. Correspondence theory relates inputs to outputs, so a correspondence relation that is transitivized by way of the input is required. This is called t-correspondence.

\section{(7) T-correspondence}

Let cand 1 and cand 2 be two candidates from input inp. Let $s 1$ be a segment in cand 1 and $s 2$ be a segment in cand 2 . Then $s 1$ t-corresponds to $s 2$ iff $s 1$ corresponds to some segment s-inp in inp and $s 2$ also corresponds to s-inp. We say then that $s 1 \Re_{\mathrm{t}} s 2$, with $\Re_{\mathrm{t}}$ standing for the correspondence relation obtained through transitivity.

In other words, the segments in different candidate forms t-correspond if they correspond to the same elements in the input. Each candidate brings with it its own correspondence relation $\Re_{\mathrm{i}}$, so different relations are involved in each link of the chain. With $s 1 \Re_{1}$ s-inp $\Re_{2} s 2$, we can sensibly compare loci of violation in different candidates. The transitive correspondence relation $\Re_{\mathrm{t}}$ is just the composition of the relations $\Re_{1}$ and $\Re_{2}$.

We are now ready to combine these two notions, the Loc function and tcorrespondence, to form a theory of comparative markedness. A comparative constraint ${ }_{\mathrm{X}} \mathrm{M}$ is a function from the 3-tuple (cand, FFC, $\Re_{t}$ ) to zero or more violation-marks. The old and new versions of a constraint are distinguished as follows:

(8) Comparative Markedness Defined

$$
\begin{aligned}
{ }_{\mathrm{N}} \mathrm{M}_{\mathrm{i}}\left(\text { cand, } \mathrm{FFC}, \Re_{\mathrm{t}}\right) \equiv & \operatorname{Let} \operatorname{Loc}_{\mathrm{i}}(\mathrm{cand})=\left\{\mathrm{c}_{1}, \mathrm{c}_{2}, \mathrm{c}_{3}, \ldots\right\} \text { and let } \operatorname{Loc}_{\mathrm{i}}(\mathrm{FFC})= \\
& \left\{\mathrm{f}_{1}, \mathrm{f}_{2}, \mathrm{f}_{3}, \ldots\right\} . \text { For each } \mathrm{c}_{\mathrm{m}} \text { that lacks a t-correspondent } \\
& \text { among } \mathrm{f}_{\mathrm{n}}, \text { assign one violation mark. } \\
{ }_{\mathrm{O}} \mathrm{M}_{\mathrm{i}}\left(\text { cand, FFC, } \Re_{\mathrm{t}}\right) \equiv & \text { Let } \operatorname{Loc}_{\mathrm{i}}(\mathrm{cand})=\left\{\mathrm{c}_{1}, \mathrm{c}_{2}, \mathrm{c}_{3}, \ldots\right\} \text { and let } \operatorname{Loc}_{\mathrm{i}}(\mathrm{FFC})= \\
& \left\{\mathrm{f}_{1}, \mathrm{f}_{2}, \mathrm{f}_{3}, \ldots\right\} . \text { For each } \mathrm{c}_{\mathrm{m}} \text { that has a t-correspondent } \\
& \text { among } \mathrm{f}_{\mathrm{n}}, \text { assign one violation mark. }
\end{aligned}
$$

For example, * 7agbar in (3d) contains two loci of $\mathrm{NOV} \mathrm{CDOB}$ violation. One of those loci is $g$. It is a voiced obstruent, but it does not t-correspond to a voiced obstruent in the FFC 7akbar. By virtue of this $g$, then, * Zagbar receives one violation-mark from ${ }_{\mathrm{N}} \mathrm{NOVCDOB}$. The other locus of violation is $b$. It too is a voiced obstruent, and moreover it t-corresponds to a voiced obstruent in the FFC. By virtue of this $b, *$ ?agbar receives a violation-mark from ${ }_{\mathrm{O}} \mathrm{NOVCDOB}$ as well.

To sum up, ${ }_{\mathrm{N}} \mathrm{M}$ and ${ }_{\mathrm{O}} \mathrm{M}$ keep track of new and old markedness violations in a candidate. A markedness violation is new if the corresponding segment in the FFC is not similarly marked; a markedness violation is old if the corresponding segment in the FFC is similarly marked. 
Before going on to review the evidence supporting and opposing this revision of OT markedness theory, I will respond to some Frequently Asked Questions about comparative markedness:

FAQ 1. Do faithfulness constraints make the same distinction? That is, are there ${ }_{\mathrm{N}} \mathrm{F}$ and ${ }_{\mathrm{O}} \mathrm{F}$ constraints to parallel ${ }_{\mathrm{N}} \mathrm{M}$ and ${ }_{\mathrm{O}} \mathrm{M}$ ?

-Such a distinction would be pointless. By definition, the FFC has no faithfulness violations. Therefore, the putative constraint ${ }_{\mathbf{o}} \mathrm{F}(\approx$ "assign one violation-mark for each locus of faithfulness violation shared with the FFC") can never be violated. A constraint that is never violated does not contribute to language typology, and so it is useless. In effect, all faithfulness constraints are ${ }_{\mathrm{N}} \mathrm{F}$ constraints.

FAQ 2. Why not compare candidates with the input itself instead of the FFC? -This would simplify the theory by eliminating the need for tcorrespondence, but it proves unworkable. Inputs may lack fully predictable structure, such as syllabification, or they may have it wrong. If so, then every ONSET violation might appear to be new even if, intuitively, it is not. The FFC, unlike the input, is guaranteed to be fully formed, and so its markedness violations can be sensibly compared to those of any other candidate. For further discussion, see $\S 6.2$.

FAQ 3. What happens when the FFC itself is the candidate under evaluation? - Given the definition of t-correspondence, every segment in the FFC corresponds with itself. This means that the FFC can never violate an ${ }_{\mathrm{N}} \mathrm{M}$ markedness constraint, since non-correspondence is a prerequisite for violating ${ }_{\mathbf{N}} \mathrm{M}$. The FFC will, of course, violate some ${ }_{\mathbf{0}} \mathrm{M}$ constraints, unless it is already perfect, like /ba/.

FAQ 4. Can faithfulness alone compel violation of an ${ }_{\mathrm{N}} \mathrm{M}$ constraint?

-No. If an ${ }_{\mathrm{N}} \mathrm{M}$ constraint is violated by a winning candidate, then at least one ${ }_{0} \mathrm{M}$ constraint must crucially dominate it. Because ${ }_{\mathrm{N}} \mathrm{M}$ constraints are only active on unfaithful candidates, there must be at least one high-ranking ${ }_{0} \mathrm{M}$ constraint to keep the unfaithful candidates in the running.

FAQ 5. Does the distinction between ${ }_{\mathbf{O}} \mathrm{M}$ and ${ }_{\mathrm{N}} \mathrm{M}$ reintroduce the Duplication Problem (cf. McCarthy 2002c: 71-76)?

${ }_{0} \mathrm{M}$ constraints might at first seem to recall the morpheme structure constraints of classic generative phonology. In fact, they are very different. By definition, morpheme structure constraints never produce alternations. But ${ }_{\mathbf{0}} \mathrm{M}$ constraints can trigger alternations, as will be made abundantly clear in $\S 5$. In fact, as I noted in the response to FAQ 4, every unfaithful winner involves crucial activity by some ${ }_{\mathrm{o}} \mathrm{M}$ constraint. What ${ }_{\mathrm{o}} \mathrm{M}$ cannot do is trigger further alternations in crucially derived contexts; that is the job of ${ }_{\mathrm{N}} \mathrm{M}$.

FAQ 6. When classic markedness constraints are in a fixed ranking, how are their comparative counterparts ranked? If we have a fixed ranking $\llbracket$ M1 $\gg$ M2 $\rrbracket$ in the classic theory, does comparative markedness 
theory require the fixed ranking $\llbracket_{N} \mathrm{M} 1,{ }_{\mathrm{O}} \mathrm{M} 1 \gg_{\mathrm{N}} \mathrm{M} 2,{ }_{\mathrm{O}} \mathrm{M} 2 \rrbracket$ or the two fixed rankings $\llbracket_{\mathrm{N}} \mathrm{M} 1 \gg_{\mathrm{N}} \mathrm{M} 2 \rrbracket$ and $\llbracket_{\mathrm{O}} \mathrm{M} 1 \gg_{\mathrm{O}_{\mathrm{O}}} \mathrm{M} 2 \rrbracket$ ?

-The answer to this question is not known to me; presumably it could go either way. In any case, the point may very well be moot. It is not clear that UG has any fixed rankings; perhaps all should be expressed by stringency relations among constraints (de Lacy 2002, Prince 1996, 1998).

\section{§4. Prohibiting New Marked Structures}

This section looks at the result of ranking an ${ }_{N} \mathrm{M}$ constraint high and its ${ }_{\mathbf{O}} \mathrm{M}$ counterpart low. There are three parts. In $\S 4.1$, grandfather effects are re-examined in light of the formalization in $\S 3$. In $\S 4.2$, I show how certain derived environment effects may be analyzed. Then $\$ 4.3$ contrasts comparative markedness with an alternative approach to some of the same phenomena, local conjunction of markedness and faithfulness constraints.

\section{\$4.1 Grandfather Effects Revisited}

The discussion in $\$ 2$ introduced grandfather effects and showed how voicing assimilation in Mekkan Arabic can be analyzed with comparative markedness constraints. This section documents the grandfather phenomenon more fully.

In a grandfather effect, a markedness constraint of UG is observed to block an otherwise general phonological process, but not to affect instances of the marked structure that are already there. In Mekkan Arabic, the markedness constraint with this force is NoVCDOB. In its two versions, it blocks assimilation when it would create voiced obstruents ${ }_{\mathrm{N}} \mathrm{NOVCDOB}$ dominates AGREE(voice)) and permits underlying voiced obstruents to emerge unscathed (IDENT(voice) dominates $\left.{ }_{\mathrm{O}} \mathrm{NoVCDOB}\right)$.

An example of the same effect, but involving a very different phenomenon, comes from the well-known case of vowel harmony in Warlpiri (Nash 1979, 1980, Steriade 1979, van der Hulst and Smith 1985). Warlpiri has four processes that produce $i / u$ alternations, but three are highly restricted morphologically. I therefore focus on the fourth, which is general in its effects. The vowel $u$ in suffixes harmonizes to a preceding $i(9 \mathrm{a})$. But this harmony process is blocked by a labial consonant, though only when it is immediately followed by $u(9 \mathrm{~b})$ :

(9) Warlpiri Vowel Harmony (examples from van der Hulst and Smith 1985)

$$
\begin{array}{lll}
\text { a. } & \text { maliki-kirli-rli-lki-ji-li } & \text { 'dog-COMIT-ERG-then-me-they' } \\
\text { minija-kurlu-rlu-lku-ju-lu } & \text { 'cat-id.' } \\
& \text { kurdu-kurlu-rlu-lku-ju-lu } & \text { 'child-id.' } \\
\text { b. } & \begin{array}{l}
\text { yamirni-puraji } \\
\text { *yamirni-piraji }
\end{array} & \text { 'uncle-your' } \\
& \text { yali-wurru } & \\
& \text { *yali-wirri } & \text { 'we two (incl.)-EMPH' }
\end{array}
$$


Words like 'cat', with root-final $a$, show that the suffixes in (9a) contain underlying $/ \mathrm{u} /$, which is changed to $i$ under the influence of root-final $i$ in 'dog'. The examples in (9b) show that suffixal $/ \mathrm{u} /$ is not affected by harmony if it is immediately preceded by a labial consonant. ${ }^{5}$

The special status of $P u$ sequences in Warlpiri harmony is related to the wellattested phenomenon of labial attraction (Campbell 1974). In various languages, a vowel after a labial consonant becomes round. In Warlpiri, the $u$ of -puraji cannot become $i$ because the pi sequence that would result is incompatible with the labial attraction requirement. But Warlpiri has no general process of labial attraction. Sequences of labial $+i$ are permitted freely in roots and suffixes (examples from Nash 1980): wapirri-mi 'ABS conceal, cover up DAT', wipi-mi 'ABS radiate out', -pirdinypa 'definite specific', -mipa 'only', -pinki 'and the like, and its ilk', etc. In short, $P i$ sequences are permitted in Warlpiri when they are already present in underlying representation, but not when they are derived by harmony. In grammar, $P i$ is grandfathered. ${ }^{6}$

Since Warlpiri has a process of harmony, SPREAD(-round) (see (46) for the definition) dominates IDENT(round):

(10) Warlpiri: SPREAD(-round) $\gg \operatorname{IDENT}($ round)

\begin{tabular}{|c||c|c|}
\hline /maliki-kurlu-rlu-lku-ju-lu/ & SPREAD(-round) & IDENT(round) \\
\hline \hline a. maliki-kirli-rli-lki-ji-li & & $* * * * * *$ \\
\hline b. maliki-kurlu-rlu-lku-ju-lu & $* * * * * * !$ & \\
\hline
\end{tabular}

Since various languages have regular labial attraction processes, we are justified in supposing that the following constraint is in UG:

(11) LABATT

Loc $_{\text {LABATT }} \quad \equiv \quad$ "Return each instance of $i$ that is immediately preceded by a labial consonant $(p, m, w) . "$

This constraint, like all other markedness constraints, comes in old and new versions. The old version is ranked below IDENT(round), since it is not active on inputs like /wipi-mi/:

${ }^{5}$ Though I focus here on harmony under suffixation, Warlpiri also has [-round] harmony, blocked by labials, root-internally. According to Nash (1980: 73), "[t]here are no underlying intramorphemic $i C u$ sequences, except where $C$ is $p$ or $w . "$

${ }^{6}$ Van der Hulst and Smith (1985: 296) propose a general labial-attraction rule for Warlpiri, but this cannot be correct because, as noted, $P i$ sequences are well-attested in this language. 
(12) Warlpiri: IDENT(round) $\gg_{\mathrm{O}}$ LABATT

\begin{tabular}{|c|c|c|}
\hline /wipi-mi/ & IDENT(round) & ${ }_{\mathrm{O}} \mathrm{LABATT}$ \\
\hline (FFC) wipimi & & $* * *$ \\
\hline b. $\quad$ wupumu & $* * * !$ & \\
\hline
\end{tabular}

The form wipimi is itself the FFC. Therefore, it violates no faithfulness constraints and any of its markedness violations must be old. Since segments in the FFC tcorrespond to themselves, wipimi incurs three marks from ${ }_{\mathrm{O}} \mathrm{LABATT}$.

The interest of Warlpiri comes from the interaction of ${ }_{\mathrm{N}}$ LABATT with the other constraints. Since it blocks harmony, it must crucially dominate SPREAD(-round):

\begin{tabular}{|c|c|c|c|c|}
\hline /yali-wurru/ & ${ }_{\mathrm{N}} \mathrm{LABATT}$ & SPREAD(-round) & IDENT(round) & ${ }_{\mathrm{O}} \mathrm{LABATT}$ \\
\hline a. (FFC) yaliwurru & & $* *$ & & \\
\hline b. $\quad$ yaliwirri & $* !$ & & $* *$ & \\
\hline
\end{tabular}

This result is key. The problem with * yaliwirri is that it has introduced a new violation of LABATT. This violation is new because the locus of violation, the postlabial $i$ of the third syllable, t-corresponds to an $u$ in the FFC paliwurru. Though * yaliwirri better satisfies SPREAD(-round), it has gotten the worse of the bargain, because ${ }_{\mathrm{N}}$ LABATT is ranked higher than SPREAD.

This argument demonstrates the main claim of comparative markedness theory, that the new and old versions of markedness constraints are distinct. In OT, to show that two constraints are distinct, it is sufficient to show that they are ranked differently in some actual grammar. In Warlpiri, ${ }_{\mathrm{N}}$ LABATT and ${ }_{\mathrm{O}}$ LABATT are indeed ranked differently: the first dominates the second through transitivity of the domination relation. This distinction is necessary to explain why labial attraction is a force to be reckoned with in harmony but is not otherwise a process of this language.

What are the alternatives to comparative markedness in analyzing Warlpiri? I can think of two. One is the more or less standard autosegmental treatment, where labial consonants block harmony because they project a feature on the [labial] tier. On this view, the blocking of harmony in Warlpiri has no connection with the existence of labial attraction processes in other languages. Already, this seems like a liability. The liability is compounded by the fact that labial consonants do not block one of the morphologically restricted Warlpiri harmony processes, regressive spreading of [+round]: 
(14) Regressive [+round] Harmony in Warlpiri (Nash 1980: 93)
/yirrpi-rnu/
yurrpurnu
'insert-Past'
cf. yirrpirni 'id.-NPast'
/kipi-rnu/
kupurnu
'winnow-Past'
cf. kipirni 'id.-NPast'

If labial consonants block [-round] harmony because they project on the labial tier, why don't they block [+round] harmony? The answer given by the comparative markedness analysis is that [+round] harmony creates $u$ 's, so it never introduces violations of ${ }_{\mathrm{N}}$ LABATT. In contrast, autosegmental approaches to blocking like the one in Nash (1980: 94) are forced to take unusual measures to deal with this difference.

Another alternative approach to Warlpiri is based on elaborating the faithfulness theory rather than the markedness theory. At the end of $\S 2$, I mentioned that Mekkan Arabic could be accounted for by positing symmetric IDENT(+F)/IDENT(-F) or MAX(F)/DEP(F) constraints (see Lombardi 2001, Pater 1999, Pulleyblank 1996 among many others). Here is how that approach plays out in Warlpiri.

The constraint IDENT(+round) is violated by $/ \mathrm{u} / \rightarrow i$ mappings but not $/ \mathrm{i} / \rightarrow u$ mappings. Since harmony changes $/ \mathrm{u} /$ to $i$, SPREAD must dominate IDENT(+round):

\section{(15) Warlpiri with IDENT(+F)/IDENT(-F) I: SPREAD(-round) $\gg \operatorname{IDENT}(+$ round $)$}

\begin{tabular}{|c||c|c|}
\hline /maliki-kurlu-rlu-lku-ju-lu/ & SPREAD(-round) & IDENT(+round) \\
\hline \hline a. maliki-kirli-rli-lki-ji-li & & $* * * * * *$ \\
\hline b. maliki-kurlu-rlu-lku-ju-lu & $* * * * * * !$ & \\
\hline
\end{tabular}

Since there is no general labial attraction process, IDENT(-round), which forbids /i/ $\rightarrow u$ mappings, must dominate LABATT:

(16)

\begin{tabular}{|c|c|c|}
\hline /wipi-mi/ & IDENT(-round) & LABATT \\
\hline wipimi & & $* * *$ \\
\hline wupumu & $* * * !$ & \\
\hline
\end{tabular}

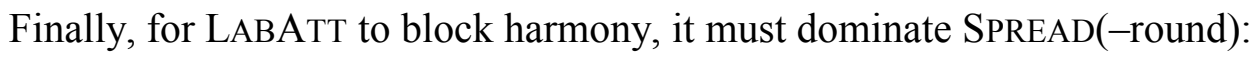

(17) Warlpiri with IDENT(+F)/IDENT(-F) III: LABATT $\gg \operatorname{SPREAD(-round)}$

\begin{tabular}{|c|c|c|c|c|}
\hline /yali-wurru/ & IDENT(-round) & LABATT & SPREAD(-round) & IDENT(+round $)$ \\
\hline a. yaliwurru & & & $*$ & \\
\hline b. $\quad$ yaliwirri & & $* !$ & & $* *$ \\
\hline
\end{tabular}


The main problem with this approach is that it fails to generalize. It analyzes grandfather effects as a specific problem in featural faithfulness rather than a broader issue in the activity of markedness constraints. To see the difference, consider the case of Sundanese, where the IDENT(+F)/IDENT(-F) approach fails because the relevant processes all involve mappings that go in the same direction.

The example comes from Cohn's (1992) analysis of Sundanese liquid dissimilation (see also Holton 1995). Sundanese has an infix /ar/ that is realized as al under certain conditions:

(18) $/ \mathrm{ar} / \rightarrow$ al in Sundanese

a. After root-initial $l$ :

1-al-itik 'little'

b. Or if there is another $r$ anywhere in the root:

$\begin{array}{ll}\text { p-al-ərceka } & \text { 'handsome' } \\ \text { c-al-ombrek } & \text { 'cold' } \\ \text { m-al-otret } & \text { 'take a picture' } \\ \text { b-al-ocor } & \text { 'leaking' } \\ \text { y-al-umbara } & \text { 'go abroad' }\end{array}$

c. Unless that other $r$ is the lone onset of the immediately preceding or following syllable:

r-ar-ahit 'wounded'

c-ar-uriga 'suspicious'

d. Other relevant data involving roots with $l$ :

$\begin{array}{ll}\text { g-ar-ilis } & \text { 'beautiful' } \\ \text { y-ar-ajləy } & \text { 'jump' } \\ \text { m-ar-ahal } & \text { 'expensive' }\end{array}$

The basic process is one of $r$-dissimilation (18b): when there are two $r$ 's in a word, the affixal $r$ dissimilates to $l$. But $r$ doesn't always dissimilate. It fails to dissimilate when it would create a $* l \mathrm{~V} r \mathrm{~V}$ sequence, as in /c-ar-uriga/ $\rightarrow$ caruriga, ${ }^{*}$ caluriga (18c). Furthermore, (18a) shows that the forbidden $* I V r V$ sequences are aggressively eliminated by assimilation of affixal $/ \mathrm{r} /$ to $l: / 1-a r-i t i k / \rightarrow$ lal tit $k$. Symmetrically, affixal $r$ fails to dissimilate when it would create a ${ }^{*} r \mathrm{~V} l \mathrm{~V}$ sequence, as in $/ \mathrm{r}$-ar-ahit $/ \rightarrow$ rarahtt, *ralahit (18c). But (18d) shows that ${ }^{*} r \mathrm{~V} l \mathrm{~V}$ sequences are not otherwise eliminated: /g-ar-ilis/ $\rightarrow$ garflis, ${ }^{*}$ galtilis. This is the grandfather effect: ${ }^{*} \mathrm{rVlV}$ sequences are not created by dissimilation, but they are not eliminated when they appear in the input.

The entire burden of the analysis in Sundanese involves accounting for the conditions under which $/ \mathrm{r} /$ does or does not map to $l$. Therefore, in terms of the $\operatorname{IDENT}(+\mathrm{F}) / \operatorname{IDENT}(-\mathrm{F})$ approach, only one faithfulness constraint is of interest, IDENT(-lateral). (The fact that the affix and never the root is affected shows that IDENT $_{\text {Roor }}(-$ lateral) is undominated.) Assuming the markedness constraints $\operatorname{OCP}(r)$, $* l \mathrm{VrV}$, and $* r \mathrm{~V} l \mathrm{~V}$, we can establish the following ranking arguments: 
(19) Sundanese with IDENT(+F)/IDENT(-F) I: OCP $(r) \gg \operatorname{IDENT}(-$ lateral $)$

\begin{tabular}{|c|c|c|}
\hline /b-ar-ocor/ & $\mathrm{OCP}(r)$ & IDENT(-lateral) \\
\hline balocor & & $*$ \\
\hline b. barocor & $* !$ & \\
\hline
\end{tabular}

(20) Sundanese with IDENT(+F)/IDENT(-F) II: * $l \mathrm{~V} r \mathrm{~V} \gg \mathrm{OCP}(r)$

\begin{tabular}{|c|c|c|}
\hline /c-ar-uriga/ & $* l \mathrm{~V} r \mathrm{~V}$ & $\mathrm{OCP}(r)$ \\
\hline a. caruriga & & $*$ \\
\hline b. caluriga & $* !$ & \\
\hline
\end{tabular}

(21) Sundanese with IDENT(+F)/IDENT(-F) III: *lV rV $\gg$ IDENT(-lateral)

\begin{tabular}{|c|c|c|}
\hline$/ 1-a r-$ titik/ & $* l \mathrm{~V} r \mathrm{~V}$ & IDENT(-lateral) \\
\hline a. & & $*$ \\
\hline b. laritik & $* !$ & \\
\hline
\end{tabular}

(22) Sundanese with IDENT(+F)/IDENT(-F) IV: ${ }^{*} r \mathrm{~V} l \mathrm{~V} \gg \mathrm{OCP}(r)$

\begin{tabular}{|lr||c|c|}
\hline \multicolumn{2}{|r||r}{-ar-ahit/ } & $* r \mathrm{VlV}$ & $\mathrm{OCP}(r)$ \\
\hline \hline a. rarahit & & $*$ \\
\hline b. & ralahit & $* !$ & \\
\hline
\end{tabular}

(23) Sundanese with IDENT $(+\mathrm{F}) / \operatorname{IDENT}(-\mathrm{F}) \mathrm{V}$ : IDENT(-lateral) $\gg * r \mathrm{~V} l \mathrm{~V}$

\begin{tabular}{|c|c|c|c|}
\hline & & IDENT(-lateral) & ${ }^{*} r \mathrm{~V} l \mathrm{~V}$ \\
\hline a. & garilis & & $*$ \\
\hline b. & galilis & $* !$ & \\
\hline
\end{tabular}

Each of these ranking arguments, taken individually, is impeccable. First, there is a general process of $r$-dissimilation (19). This process is blocked when it would create a $* l \mathrm{~V} r \mathrm{~V}$ or $* r \mathrm{~V} l \mathrm{~V}$ sequence $(20,22)$. Additionally, assimilation actively eliminates $* l \mathrm{~V} r \mathrm{~V}$ sequences $(21)$, but not $* r \mathrm{~V} l \mathrm{~V}$ sequences $(23)$.

Taken together, however, these ranking arguments are mutually inconsistent. The problem is that * $r \mathrm{~V} l \mathrm{~V}$ dominates $\mathrm{OCP}(r)$, which itself dominates IDENT(-lateral) - yet (23) also shows that IDENT(-lateral) dominates * $r \mathrm{~V} l \mathrm{~V}$. Rankings inferred from transitivity of the $\gg$ relation and rankings proven directly cannot be contradictory. This inconsistency shows that the analysis is flawed, calling into question the idea that grandfather effects can be analyzed by differentiating IDENT(+F)/IDENT(-F). 
Clearly, having both IDENT(-lateral) and IDENT(+lateral) available is of no assistance in Sundanese, since the mappings involved are all of the form $/ \mathrm{r} / \rightarrow l \mathrm{vs} . / \mathrm{r} / \rightarrow r$.

On the other hand, Sundanese presents no difficulties for comparative markedness theory. Dissimilation does not create new $* r \mathrm{~V} l \mathrm{~V}$ sequences, so ${ }_{\mathrm{N}}{ }^{*} r \mathrm{~V} l \mathrm{~V}$ must dominate $\mathrm{OCP}(r)$ :

(24) Sundanese with Comparative Markedness I: ${ }_{\mathrm{N}}{ }^{*} r \mathrm{~V} l \mathrm{~V} \gg \mathrm{OCP}(r)$

\begin{tabular}{|lr||c|c|}
\hline \multicolumn{2}{|c||}{$/$ r-ar-ahit/ } & ${ }^{*} r V l V$ & OCP $(r)$ \\
\hline \hline a. & (FFC) rarahit & & $*$ \\
\hline b. ralahit & $* !$ & \\
\hline
\end{tabular}

But $* r \mathrm{~V} l \mathrm{~V}$ sequences are not actively eliminated, so ${ }_{0}{ }^{*} r \mathrm{~V} l \mathrm{~V}$ is ranked low, below $\operatorname{IDENT}($ lateral):

(25) Sundanese with Comparative Markedness II: $\operatorname{IDENT}\left(\right.$ lateral) $\gg_{0}{ }^{*} r \mathrm{~V} l \mathrm{~V}$

\begin{tabular}{|lr||c|c|}
\hline \multicolumn{2}{|c||}{ /g-ar-tlis/ } & IDENT(lateral) & o* $r \mathrm{VlV}$ \\
\hline \hline a. & gartlis & & \\
\cline { 3 - 4 } & galtlis & $* !$ & \\
\hline
\end{tabular}

This is the familiar ranking for a grandfather effect: ${ }_{\mathrm{N}} \mathrm{M}$ high and ${ }_{\mathrm{O}} \mathrm{M}$ low. The two versions of $* l \mathrm{~V} r \mathrm{~V}$, on the other hand, need not be ranked separately, since both are active, ${ }_{\mathrm{N}} * l \mathrm{Vr} \mathrm{V}$ in blocking dissimilation and ${ }_{\mathrm{O}} * l \mathrm{VrV}$ in triggering assimilation. This sort of variation is exactly what the theory of comparative markedness predicts.

In the remainder of this section, I will present several other examples of grandfather effects. The first, whose significance for comparative markedness theory was also recognized by Paul de Lacy, comes from Sri Lankan Portuguese Creole (SLPC).

(26) Place Assimilation in Sri Lankan Portuguese Creole (Hume and Tserdanelis 1999)

a. Labials and dorsals assimilate in place

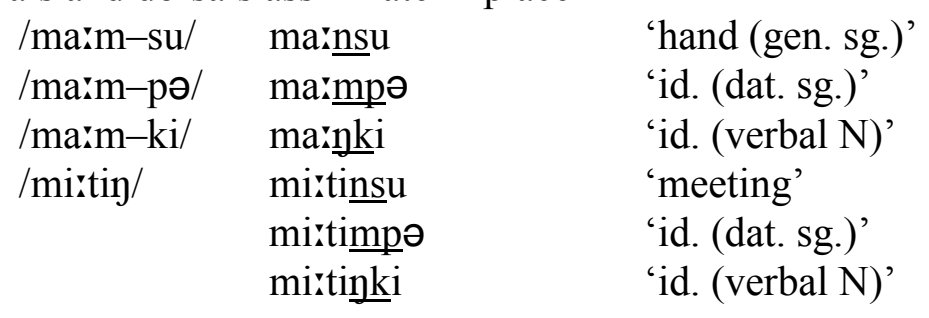

b. But coronals don't assimilate
$/ \sin /$
singsu
'bell'
siznpe, *sixmpo
'id. (dat. sg.)'
sinkki, *singki
'id. (verbal N)' 
The problem is to explain why coronals are not affected by this assimilation process. The situation is analogous to Mekkan Arabic, where voiceless obstruents are likewise not subject to assimilation. (See de Lacy (2002) for a very different analysis of SLPC and Mekkan Arabic, embedded in a far-ranging theory of assimilation and other phenomena.)

Just as voiceless obstruents are less marked than voiced, coronals are less marked than labials or velars, a claim that is extensively supported in the literature on coronal unmarkedness (Paradis and Prunet 1991). In OT, this means that there exists a markedness constraint or constraints against labials and velars, and that either the markedness constraint(s) against labials and velars are always ranked above the constraint against coronals or there is no constraint against coronals. Prince and Smolensky (1993) take the first option with their fixed hierarchy $\llbracket *$ LAB, *DORS $\gg$ *COR $\rrbracket$. De Lacy (2002) argues for the second: there is a single constraint against labials or velars (*LAB|DORS) and there is no constraint that militates against just coronals. I adopt de Lacy's approach here (see fn. 7):

$$
\begin{aligned}
& \text { *LAB|Dors } \\
& \operatorname{Loc}_{* \text { LAB } \mid \text { Dors }} \quad \equiv \quad \text { "Return every C, where C is [labial] or [dorsal]." }
\end{aligned}
$$

Since labials and velars are more marked than coronals, a grandfather effect is possible. This would be a language that has labials and velars generally, but that blocks a process from creating them when the alternative is to preserve an underlying coronal. That's the situation in SLPC. This language has consonants, including codas, at all three places of articulation. Assimilation is free to replace a labial with a velar or coronal or to replace a velar with a labial or coronal, but it will never replace a coronal with a labial or velar. This means that the comparative markedness constraint $_{\mathrm{N}}{ }^{*} \mathrm{LAB} \mid$ DORS is ranked above AGREE(place), which is itself ranked above IDENT(place). Standing at the bottom of the hierarchy, below IDENT(place), is o LAB|DORS, since there is no general process neutralizing labials and velars to coronals. Tableau (28) supplies the necessary ranking arguments (which are surrounded by heavy lines): 
(28) SLPC: ${ }_{N}{ }^{*}$ LAB $\mid$ DORS $\gg$ AGREE(place) $\gg \operatorname{IDENT}($ place $) \gg{ }_{0}^{*}$ LAB $\mid$ DORS

\begin{tabular}{|c|c|c|c|c|}
\hline /ma:m-su/ & ${ }_{N}^{*}$ LAB $\mid$ DORS & AGREE(place) & IDENT(place) & o*LAB|DORS \\
\hline ma:nsu & & & * & * \\
\hline b. (FFC) ma:msu & & $* !$ & & ** \\
\hline \multicolumn{5}{|l|}{ /ma:m-ki/ } \\
\hline ma:yki & & & * & $* * *$ \\
\hline d. $\quad$ (FFC) ma:mki & & $* !$ & & *** \\
\hline \multicolumn{5}{|l|}{$/ \mathrm{marm} /$} \\
\hline e. $\quad(\mathrm{FFC}) \circledast \mathrm{ma} m$ & & & & ** \\
\hline f. & & & $* !$ & $*$ \\
\hline \multicolumn{5}{|l|}{$/$ sinn-pə// } \\
\hline g. (FFC) sixnpə & & * & & * \\
\hline h. sismpə & $* !$ & & * & * \\
\hline
\end{tabular}

The first two candidate pairs $((28 \mathrm{a}, \mathrm{b})$ and $(28 \mathrm{c}, \mathrm{d}))$ establish the basic ranking for place assimilation: AGREE(place) dominates IDENT(place). The constraint ${ }_{N}^{*}$ LAB|DORS is not active over these candidates because none introduces a new violation of ${ }^{*} \mathrm{LAB} \mid$ DoRs. For example, ma:nki has three loci of violation of *LAB|DORS: $m, \eta$, and $k$. For each locus, we check whether its t-correspondent in the FFC is also a locus of violation of * LAB|Dors. The t-correspondents of these segments are, respectively, $m, m$, and $k$. Although the t-corresponding segments $\eta$ and $m$ differ in place of articulation, both are in the set of loci returned by $\operatorname{Loc}_{*_{\text {LABDORS }}}$ from their respective candidates, so there is no new violation to be reckoned with. Hence, ${ }_{N}{ }^{*}$ LAB|DoRS is not active on $(28 \mathrm{c}, \mathrm{d})$, as promised. ${ }^{7}$

The candidate pair in (28e, f) is evidence of the grandfather effect: dorsals and labials in coda position are not neutralized generally because ${ }_{\mathrm{O}}{ }^{*} \mathrm{LAB} \mid$ DORS is ranked below faithfulness. The candidate ma:m is the FFC and so, tautologically, its two *LAB|DORS violation loci are shared with the FFC. This candidate therefore violates only low-ranking o ${ }^{*} \mathrm{LAB} \mid \mathrm{DORS}$; indeed, any violation incurred by the FFC must be an old one.

Finally, the pair of candidates in $(28 \mathrm{~g}, \mathrm{~h})$ show how assimilation is blocked when it would change a coronal to a non-coronal. This follows from the ranking $\llbracket_{\mathrm{N}}{ }^{*} \mathrm{LAB} \mid$ DORS $\gg$ AGREE(place) $\rrbracket$ : avoidance of new violations of *LAB|Dors takes

${ }^{7}$ Paul de Lacy observes that this analysis will only work under the assumption that there is a constraint * LAB|DORS, rather than separate *LAB and *DORS. The separate constraints won't do, because mainki would wrongly violate ${ }_{\mathrm{N}}{ }^{*}$ Dors. The existence of the unified constraint is in accordance with the findings of de Lacy (2002) and Prince (1997) that harmonic scales like place markedness must be expressed by stringency (i.e., inclusion) hierarchies of constraints. 
precedence over assimilation. Because of this ranking, only grandfathered labials and dorsals are permitted in coda position. A final detail: candidates like sintə, which satisfies AGREE(place) by changing the onset $p$ into a coronal, are ruled out by the undominated positional faithfulness constraint IDENT-ONS(place).

In Optimality Theory, permuted ranking is the source of differences among languages. One possibility predicted by ranking permutation is a reversal of the positions of IDENT(place) and ${ }_{\mathrm{O}}{ }^{*} \mathrm{LAB} \mid \mathrm{DORS} .{ }^{8}$ If all else is held the same, then this predicted language should have the same medial clusters as SLPC, but only coronals word-finally. Languages like this are common in Australia; Guugu-Yimidhirr and the Pintupi dialect of the Western Desert language are typical (Dixon 1980: 161-164). Actual alternations, especially final neutralization, are not in evidence, but at least the pattern can be seen schematically in the following tableau:

\begin{tabular}{|c|c|c|c|c|}
\hline$/ \mathrm{mt} /$ & ${ }_{N}^{*}$ LAB $\mid$ DORS & AGREE(place) & o*LAB|DORS & IDENT(place) \\
\hline a. & & & & $*$ \\
\hline b. (FFC) $\mathrm{mt}$ & & $* !$ & $*$ & \\
\hline \multicolumn{5}{|l|}{$/ \mathrm{mp} /$} \\
\hline c. (FFC) $\mathrm{mp}$ & & & $* *$ & \\
\hline d. $\quad n p$ & & $* !$ & $*$ & $*$ \\
\hline \multicolumn{5}{|l|}{$/ \mathrm{m} \# /$} \\
\hline e. $\quad n \#$ & & & & $*$ \\
\hline f. $\quad(\mathrm{FFC}) \mathrm{m} \#$ & & & $* !$ & \\
\hline \multicolumn{5}{|l|}{$/ \mathrm{np} /$} \\
\hline g. (FFC) $n p$ & & $*$ & $*$ & \\
\hline h. $\quad \mathrm{mp}$ & *! & & $*$ & $*$ \\
\hline
\end{tabular}

As in the analysis of SLPC, I assume that IDENT-ONS(place) is undominated.

As I noted in $\S 2$, grandfather effects are analyzed by Archangeli and Pulleyblank (1994) under the rubric of target conditions, which are specific restrictions on the segment targeted by a phonological rule. Their book is replete with examples; I will cite one here. In Yawelmani Yokuts, a certain suffix supplies a floating glottal feature that attempts to anchor onto the preceding root.

${ }^{8}$ I am grateful to Colin Wilson for pointing out this prediction. 
(30) Yawelmani Glottal Association (Archangeli and Pulleyblank 1994: 346ff., Newman 1944)

a. Glottal feature anchors onto second root consonant if it's a sonorant:

$\begin{array}{lll}\text { /caw/ caw'aahin } & \text { 'shout' } \\ \text { /Rilk/ } & \text { ?el'kaahin } & \text { 'sing' }\end{array}$

b. Otherwise, glottal feature must segmentalize or delete:

$\begin{array}{lll}\text { /max/ } & \text { max?aahin } & \text { 'procure' } \\ \text { /hogn/ } & \text { hognaahin } & \text { 'float' }\end{array}$

Yawelmani does not in general prohibit glottalized obstruents, as shown by examples like bok'en 'will find' or hiwt'iwlaxo? 'becomes very happy'. Nonetheless, the process that docks the floating feature is prohibited from creating glottalized obstruents. This shows that the markedness constraint against new instances of [-son, $+\mathrm{glott}]$ segments is ranked high, though its old alter ego is ranked too low to matter. It seems plausible that all examples of target conditions can be reanalyzed in these terms, capturing Archangeli and Pulleyblank's insight without giving free rein to process-specific constraints (cf. Davis 1995, McCarthy 1997, 2002c: 103-6).

\section{\$4.2 Derived Environment Effects}

Lubowicz $(1999,2002 b)$ draws our attention to the problem that derived environment effects (DEE's) present for classic OT. For example, in the Austronesian language Makassarese (Aronoff et al. 1987, Broselow 1999, McCarthy 1998, McCarthy and Prince 1994), there is a process of vowel-copying epenthesis that applies after rootfinal $r, l$, and $s(31 \mathrm{a})$. In addition to the copied vowel, though, a final $?$ is epenthesized as well. Yet words with an underlying final vowel do not get an epenthetic ?:

(31) Epenthesis in Makassarese /te?ter/ /jamal/
a. /rantas/
b. /lompo/

$\begin{array}{ll}\text { rántasa? } & \text { 'dirty' } \\ \text { téttere? } & \text { 'quick' } \\ \text { jámala? } & \text { 'naughty' } \\ \text { lómpo, *lómpo? } & \text { 'big' }\end{array}$

So 7-epenthesis only affects derived vowel-final words.

Cases like Makassarese are traditionally referred to as phonologically-derived environments. In quasi-derivational terms, another phonological process, vowel epenthesis, creates the conditions for ?-epenthesis. There are also DEE's involving morphologically-derived environments: the conditions for a process are created when two morphemes come together. I will discuss each of these two types in turn.

The problem that phonological DEE's present for classic OT can be seen best by showing the mappings graphically, in a format introduced by Lubowicz: 
(32) Mappings in Makassarese

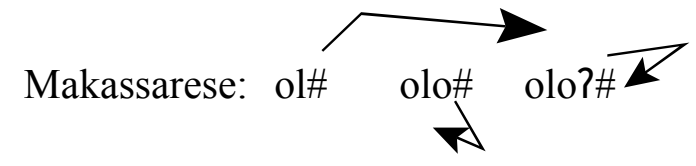

As the diagram shows, underlying /ol\#/ maps to surface olo \#\#, while underlying /olo\#/ and /olo?\#/ map to themselves (i.e., they are faithful). The diagram emphasizes that the $/ \mathrm{ol \# /} \rightarrow$ olo $\mathrm{l \#} \mathrm{mapping} \mathrm{skips} \mathrm{over} \mathrm{olo \#} \mathrm{—} \mathrm{even} \mathrm{though} \mathrm{ol \#} \mathrm{and} \mathrm{olo \#} \mathrm{are} \mathrm{closer}$ in terms of faithfulness. The problem for classic OT is how to explain why only/ol\#/ but not /olo\#/ receives epenthetic ?.

Vowel epenthesis is a consequence of undominated CODA-COND, which permits only assimilated codas medially and $?$ or $\eta$ finally. CODA-COND must, of course, dominate DEP-V (as must MAX-C):

Makassarese: CODA-COND, MAX-C $\gg$ DEP-V
\begin{tabular}{|lr||c:c|c|}
\hline \multicolumn{2}{|r|}{ /rantas/ } & CODA-COND & MAX-C & DEP-V \\
\hline \hline a. & rantasa? & & & $*$ \\
\hline b. & (FFC) rantas & $* !$ & & \\
\hline c. & ranta & & $* !$ & \\
\hline
\end{tabular}

Epenthesis of $?$ is a response to the markedness constraint FINAL-C (McCarthy and Prince 1994), defined as follows: Loc FINAL-C $_{\text {. }}$ "return every V, where $\mathrm{V}$ is final in a prosodic word." This constraint is independently justified in the Makassarese reduplicative system and in other languages (see §5.1). FINAL-C is clearly active on inputs like/rantas/, but not on inputs like /lompo/. Because only "new" V-final words show 7-epenthesis, ${ }_{N}$ FINAL-C must be the higher-ranked member of this ${ }_{\mathrm{O}} \mathrm{M} /{ }_{\mathrm{N}} \mathrm{M}$ pair:

(34) Makassarese: ${ }_{\mathbf{N}}$ FINAL-C, CODA-COND, MAX-C $\gg$ DEP-V, DEP-C $\gg{ }_{0}$ FINAL-C

\begin{tabular}{|c|c|c|c|c|c|c|}
\hline /rantas/ & ${ }_{\mathbf{N}}$ FINAL-C & $\begin{array}{l}\text { CODA- } \\
\text { COND }\end{array}$ & MAX-C & DEP-V & DEP-C & ${ }_{0}$ FINAL-C \\
\hline rantasa? & & & & $*$ & $*$ & \\
\hline rantasa & $* !$ & & & $*$ & & \\
\hline c. (FFC) rantas & & $* !$ & & & & \\
\hline d. $\quad$ ranta & & & $* !$ & & & \\
\hline \multicolumn{7}{|l|}{ /lompo/ } \\
\hline e. (FFC) lompo & & & & & & $*$ \\
\hline f lompo? & & & & & $* !$ & \\
\hline
\end{tabular}


First, consider a consonant-final input. Candidate (34b) contains a locus of violation of FINAL-C, the final $a$. This vowel, precisely because it is epenthetic, does not t-correspond to any segment in the FFC rantas (34c). This means that (34b) violates ${ }_{\mathrm{N}}$ FINAL-C - it contains a new FINAL-C violation, not shared with the FFC.

Now consider a vowel-final input. Candidate (34e) also contains a locus of violation of FINAL-C, the final $o$. Its competitor (34f) does not. But since (34e) is the FFC, its locus of violation of FINAL-C trivially t-corresponds to a locus in the FFC. This is a shared or old violation, which means that ${ }_{N}$ FINAL-C is satisfied by $(34 \mathrm{e})$, though ${ }_{0}$ FINAL-C is not. With this ranking, the faithful candidate triumphs over the candidate that merely satisfies low-ranking ${ }_{0}$ FINAL-C.

On the basis of this example, we can devise a basic ranking schema responsible for DEE's (and grandfather effects):

(35) Ranking Schema for a Derived Environment Effect

$$
{ }_{\mathbf{N}} \mathrm{M} \gg \text { Faith } \gg{ }_{\mathbf{O}} \mathrm{M}
$$

Informally, this says that new violations of $\mathrm{M}$ are avoided, even at the expense of being unfaithful, but old violations are tolerated. For example, Makassarese /rantas/ maps to rantasa? because the alternative, rantasa, would introduce a new instance of a marked configuration (a word-final vowel) that is not present in the FFC rantas. But Makassarese also has the mapping /lompo/ $\rightarrow$ lompo because lompo, which is itself the FFC, only has an old instance of the marked V-final configuration.

Before going on to look at morphological DEE's, it is of historical interest to note that comparative markedness comes fairly close to expressing Kiparsky's (1973) original conception of what it means for the environment of one process to be derived by another process. To paraphrase Kiparsky, rule A (V-epenthesis in Makassarese) creates a derived environment for rule B (7-epenthesis) if B's structural description would not have been met except for prior application of A. In other words, B is forced by something A does. A rough translation into comparative markedness theory goes something like this: Some new marked configuration is introduced by the unfaithful mapping that approximates process A. The unfaithful mapping that approximates process B occurs only when necessary to avoid the new instances of the marked configuration that A threatens to create. Comparative markedness theory obtains the "only when necessary" derived environment effect from its partition of traditional markedness constraints and standard OT constraint ranking. As I will show in the next section, an approach to DEE's based on the conjunction of markedness and faithfulness constraints is somewhat more distant from Kiparsky's original idea, and this distance highlights some empirical differences between constraint conjunction and comparative markedness.

Makassarese is representative of the phonological type of DEE. The other DEE type involves a process that takes place only when its conditions are crucially met by virtue of material from two different morphemes. In Korean, for example, /t/ 
neutralizes with /c/ when followed by $i$ across morpheme boundary, though not when followed by tautomorphemic $i$.

(36) Korean Palatalization' ${ }^{9}$ Ahn 1998)

\begin{tabular}{|c|c|c|c|c|}
\hline \multirow[t]{4}{*}{ a. } & $/ \mathrm{pat}^{\mathrm{h}}-\mathrm{i} /$ & $\rightarrow$ & $\operatorname{pac}^{h_{i}}$ & 'field-COP' \\
\hline & /mat-i/ & $\rightarrow$ & maci & 'eldest-NOM' \\
\hline & $/$ put $^{\mathrm{h}}-\mathrm{i} /$ & $\rightarrow$ & $\operatorname{puc}^{h_{i}}$ & 'to stick to-CAUS' \\
\hline & /tot-i/ & $\rightarrow$ & toci & 'rise-NOM' \\
\hline & /mati/ & $\rightarrow$ & mati & 'knot' \\
\hline & $/ \mathrm{kac}^{\mathrm{h}} \mathrm{i} /$ & $\rightarrow$ & $\operatorname{kac}^{h_{i}}$ & 'value' \\
\hline
\end{tabular}

In short, there is palatalization only when the coronal $+i$ sequence is heteromorphemic.

Comparative markedness will also account for morphological DEE's like Korean, through a very natural generalization of the theory we've been working with thus far. ${ }^{10}$ Correspondence theory asserts that faithfulness is not just a relation between inputs and outputs; it also extends to base/reduplicant pairs (McCarthy and Prince 1995, 1999) and to morphologically-related output forms (Benua 1997 and others). Since comparative markedness theory is based on correspondence, comparative markedness can also be applied to these other faithfulness relations. A markedness violation is new relative to the output-output faithfulness relation if the locus of violation in the derived form is not matched in the simple form (which Benua calls the "base"). For example, Korean *mati from /mat-i/ contains an unpalatalized $t i$ sequence that is new relative to the base mat, but the $t i$ sequence in mati from /mati/ 'knot' is old, since there is no simpler base form from which /mati/ is derived by adding $i$.

Assume there is a markedness constraint PAL associated with the function $\operatorname{Loc}_{\mathrm{PAL}} \equiv$ "return every coronal that immediately precedes $i$ ". In addition to the old/new distinction, we will now recognize the possibility of specifying PAL for particular correspondence relations: $\mathrm{IO}-{ }_{\mathrm{N}} \mathrm{PAL}, \mathrm{IO}-{ }_{\mathrm{O}} \mathrm{PAL}, \mathrm{OO}-{ }_{\mathrm{N}} \mathrm{PAL}, \mathrm{OO}{ }_{\mathrm{O}} \mathrm{PAL}$. Palatalization is restricted to morphologically-derived environments because only OO- ${ }_{\mathrm{N}} \mathrm{PAL}$ is ever active - it assigns a mark to $t$ preceding $i$ if $t$ 's OO correspondent does not precede $i$. The ranking responsible for this state of affairs is given in (37):

${ }^{9}$ Korean has a fully automatic process of post-vocalic voicing of plain obstruents. For clarity, I abstract away from it in this discussion.

${ }^{10}$ Thanks to John Alderete and Ken Safir for discussion of this point. 
(37) Korean: OO- ${ }_{\mathrm{N}} \mathrm{PAL} \gg \mathrm{IDENT} \gg \mathrm{IO}-{ }_{\mathrm{O}} \mathrm{PAL}, \mathrm{OO}{ }_{{ }_{\mathrm{O}}} \mathrm{PAL}$

\begin{tabular}{|c|c|c|c|c|}
\hline /tot/ & $\mathrm{OO}_{-}{ }_{\mathrm{N}} \mathrm{PAL}$ & IDENT & $\mathrm{IO}-{ }_{\mathrm{O}} \mathrm{PAL}$ & $\mathrm{OO}-{ }_{\mathrm{O}} \mathrm{PAL}$ \\
\hline \multicolumn{5}{|l|}{ a. $(\mathrm{FFC})$ tot } \\
\hline b. toc & & $* !$ & & \\
\hline \multicolumn{5}{|l|}{ /tot-i/ } \\
\hline c. & & $*$ & & \\
\hline d. (FFC) toti & $* !$ & & $*$ & \\
\hline \multicolumn{5}{|l|}{ /mati/ } \\
\hline e. (FFC) mati & & & $*$ & $*$ \\
\hline f. & & $* !$ & & \\
\hline
\end{tabular}

Obviously, there is no palatalization in the base tot (37a). (Not only is toc (37b) gratuitously unfaithful, but it also violates an undominated coda condition.) This lack of palatalization in the base is, in a sense, responsible for the presence of palatalization in the derived form, since it is the reason behind *toti's crucial violation of OO- ${ }_{N} \mathrm{PAL}(37 \mathrm{~d})$. The final pair of candidates $(37 \mathrm{e}, \mathrm{f})$ shows why there is no general palatalization process in Korean: faithfulness dominates the remaining PAL constraints. ${ }^{11}$

This analysis of Korean suggests a general approach to DEE's involving morpheme concatenation. The constraint $\mathrm{OO}-{ }_{N} \mathrm{M}$ is violated only by those loci of $\mathrm{M}$ violation that are not shared with the base form in OO correspondence. Violations are "new" relative to this other output form, rather than the input. In effect, a process occurs only if it will create visible alternations in output forms. ${ }^{12}$

Because $\mathrm{OO}-{ }_{\mathrm{N}} \mathrm{M}$ and $\mathrm{IO}{ }_{\mathrm{N}} \mathrm{M}$ are distinct constraints, this approach to DEE's decouples the phonological and morphological types from one another. Through ranking permutation, a language can, in principle, show only a DEE by another process, only a DEE by morpheme concatenation, both, or neither. For instance, if Korean had a process that created $i$ 's without producing alternations, this process

${ }^{11}$ It has been proposed (Bradley 2002, Cho 1998) that Korean and similar cases can be accounted for under the assumption that gestural timing is lexically specified for tautomorphemic sequences but not heteromorphemic sequences. This allows greater gestural overlap - e.g., palatalization -in heteromorphemic sequences. This approach, though couched in OT terms, does not seem compatible with the core OT postulate called richness of the base (for explanation and references, see the discussion of (63) in §5.4). Under richness of the base, the lexicon cannot be relied on to consistently and reliably encode predictable details of structure, such as the timing of gestures (cf. §6.2). (I am grateful to Travis Bradley for discussion of this point. See Hall (2003) for parallel discussion.)

${ }^{12}$ The (deduced) requirement that a process create visible alternations is reminiscent of Alderete's $(1998,2001)$ anti-faithfulness constraints, whose function is the signaling of morphological distinctions. ${ }_{\mathrm{N}} \mathrm{M}$ and anti-faithfulness are in general different, however - see $\S 6.1$. 
could or could not feed palatalization, depending on how IO- ${ }_{\mathrm{N}} \mathrm{PAL}$ is ranked. By treating the two types of DEE separately, comparative markedness puts itself in good company. There is a recent consensus that unifying the phonological and morphological types of DEE under the Alternation Condition (Kiparsky 1973) or the Strict Cycle Condition (Mascaró 1976) was probably a mistake (Hammond 1992, Kiparsky 1993, Lubowicz 2002b).

One final remark. Grandfather effects and DEE's are both obtained from rankings modeled on the schema (35). In grandfathering and DEE's, ${ }_{N} M$ dominates some relevant faithfulness constraint, while its ${ }_{\mathrm{O}} \mathrm{M}$ counterpart is dominated by the same faithfulness constraint. This is not an accident. Though grandfather effects and DEE's seem rather different when first encountered, they are really the same thing. This is perhaps easiest to see when a grandfather effect is analyzed with a rule-based derivation. For example, the analysis of Mekkan Arabic could be done with a process that devoices only derived voiced obstruents in coda position:

(38) Mekkan Arabic Derivationally

Underlying

Regressive [avoice] assimil.

Coda devoicing (DEE)

$\begin{array}{ccc}\text { Ragsam/ } & \text { /Rakbar/ } & \text { /Ribnu/ } \\ \text { ?aksam } & \text { ?agbar } & - \\ - & \text { Takbar } & \text { Blocked }\end{array}$

In this sort of analysis, coda devoicing applies only in a derived environment, so it is limited to undoing the effects of regressive voicing assimilation. The result is a Duke-of-York derivation (McCarthy 2002b, Pullum 1976): /k/ $\rightarrow g \rightarrow k$. In rule-based phonology, a grandfather effect is exactly the result of combining a Duke-of-York derivation with blocking in underived environments.

I have approached grandfather effects and DEE's separately because they are functionally somewhat different. Grandfather effects are static: a process like assimilation is blocked by the ${ }_{\mathrm{N}} \mathrm{M}$ constraint. DEE's are dynamic: a process is triggered by the ${ }_{\mathrm{N}} \mathrm{M}$ constraint. But there is no real difference. OT makes no distinction between static restrictions and dynamic processes; the same markedness constraints are responsible for both. Grandfather effects and DEE's have similar rankings because the static and dynamic come from the same source, by a fundamental tenet of OT.

\section{$\$ 4.3$ Grandfather Effects, DEE's, and Constraint Conjunction}

The core of comparative markedness theory is the idea that markedness constraints can look simultaneously at the candidate under evaluation and at the fully faithful candidate. A roughly similar notion is involved in another approach to DEE's, conjunction of markedness and faithfulness constraints. This section compares the two theories.

In the local conjunction approach to DEE's developed by Lubowicz (1999, 2002b), markedness and faithfulness constraints can be locally conjoined in the sense of Smolensky (1995). (The local conjunction of constraints $\mathrm{A}$ and $\mathrm{B},[\mathrm{A} \& \mathrm{~B}]_{\delta}$, is a 
constraint that is violated once for every constituent $\delta$ that violates both A and B.) With the right ranking, it is possible to ensure that the markedness constraint in the conjunction is active only when and where the faithfulness constraint is violated. In Makassarese, for instance, the markedness constraint FINAL-C is active - that is, able to compel unfaithful analysis - only in segments that are epenthetic. For example, /rantas/maps to rantasa ? and not * rantasa because the final $a$ is epenthetic and so FINAL-C is activated. But FINAL-C is not active over candidates whose final segment is unchanged from the input, such as /lompo/ $\rightarrow$ lompo?. The following tableau illustrates:

(39) Makassarese via Local Conjunction: [DEP-V\&FINAL-C $]_{\mathrm{Seg}} \gg$ DEP-C $\gg$ FINAL-C

\begin{tabular}{|c|c|c|c|}
\hline /rantas/ & {$[\mathrm{DEP}-\mathrm{V} \& \text { FINAL-C }]_{\mathrm{Seg}}$} & DEP-C & FINAL-C \\
\hline rantasa? & & $*$ & \\
\hline rantasa & $* !$ & & $*$ \\
\hline \multicolumn{4}{|l|}{ /lompo/ } \\
\hline L lompo & & & $*$ \\
\hline lompo? & & $* !$ & \\
\hline
\end{tabular}

In the $(39 a) /(39 b)$ comparison, the conjoined constraint [DEP-V\&FINAL-C $]_{\text {Seg }}$ is decisive. By the logic of local conjunction, this constraint is violated by any candidate that simultaneously bears violation-marks from both constraints within the domain of conjunction (here, a segment). And * rantasa has exactly that problem: its final $a$ is epenthetic, so it bears a violation-mark from DEP-V. The conjoined constraint is not active over the (39c)/(39d) comparison because the final o of lompo is underlying, so it is not in violation of DEP-V. In short, local conjunction of markedness with faithfulness allows the markedness constraint to be active only when the faithfulness constraint is violated.

The similarity between this model and comparative markedness theory should be apparent: both allow markedness constraints, indirectly or directly, to get access to the input or something like the input. But there are also important differences that emerge when we look more closely at how these two approaches deal with DEE's.

In comparative markedness theory, as I noted in $\S 4.2$, the nature of a derived environment comes rather close to Kiparsky's (1973) original idea. For Kiparsky, rule A (vowel epenthesis in Makassarese) creates a derived environment for rule B (7-epenthesis) if B's structural description would not have been met except for prior application of $\mathrm{A}$. That is, rule $\mathrm{B}$ is made possible and therefore necessary because of something that rule A did. The way this is understood in comparative markedness theory is that one unfaithful mapping ( $\approx$ process $A$ ) has the potential to introduce some new marked configuration and another unfaithful mapping ( $\approx$ process $B)$ is necessary to avoid it. 
The approach to derived environment effects via local conjunction is more remote from Kiparsky's original idea, and this is arguably to its detriment. The nearest thing to a derived environment is the domain of conjunction, in which the conjoined faithfulness constraint is violated. Otherwise, there is no necessary connection between the faithfulness constraint and the conjoined markedness constraint that it activates. For this reason, local conjunction can produce some impossible-looking derived environment effects that comparative markedness cannot. Two examples are given in (40).

(40) Some Predicted Effects of Markedness and Faithfulness Conjunction

a. Conjunction of unrelated constraints

-Assume the ranking:

$\left[\operatorname{IDENT}(\text { back) \&NOVCDOB }]_{\sigma} \gg \operatorname{IDENT}(\right.$ voice) $\gg \mathrm{NOVCDOB}$ and assume an umlaut process independently motivated.

-Then /boti/ $\rightarrow$ pöti but /beta/ $\rightarrow$ beta, /bota/ $\rightarrow$ bota, /böta/ $\rightarrow$ böta. Local conjunction captures an implausible generalization: obstruents are devoiced before fronted vowels.

b. Conjunction in wrong domain

-Assume ranking

$$
[\text { DEP-V\&FINAL-C }]_{\mathrm{PrWd}} \gg \text { DEP-C } \gg \text { FINAL-C }
$$

This is the same as Makassarese, but with the Seg domain replaced by PrWd.

-Then hypothetical /tarpa/ $\rightarrow$ tarapa , but hypothetical /tara/ $\rightarrow$ tara . Local conjunction captures an implausible generalization: epenthesize final $?$ if there is epenthesis anywhere in the word.

Neither (40a) nor (40b) is a derived environment in Kiparsky's sense. In (40a), the process of umlaut does not produce conditions that encourage devoicing; rather, the process of umlaut is irrelevant to the process of devoicing. But the theory of local conjunction does not impose any conditions of relevance or relatedness on the constraints that it combines, beyond the intrinsic requirement that both be evaluable within some domain. ${ }^{13}$ As for (40b), remote vowel epenthesis should not have any effect on the phonology of the end of the word; the derived environment created by epenthesis should be local to the affected segment and not extend beyond that. But the theory of local conjunction allows the domain of conjunction to be specified independently of the constraints conjoined in that domain, allowing for a domain that is too big, as in this case.

\footnotetext{
${ }^{13}$ Ito and Mester's (2002) analysis of forms like Honig [honic] 'honey' in standard German exploits this property of local conjunction. They argue that a constraint against dorsal stop codas is active only in segments that violate IDENT(voice), so final $/ \mathrm{g} /$ becomes the fricative $[\mathrm{c}] /[\mathrm{x}]$ but final $/ \mathrm{k} /$ does not (Plastik [plastik], *[plaastic]). As Ito and Mester observe, this is a type of derived environment effect that does not come within the scope of Kiparsky's original idea. At present, this example seems to be unique (though Andries Coetzee informs me that the facts are much the same in Afrikaans: $/ \mathrm{kerk} / \rightarrow$ [kerk] 'church', /bærg/ $\rightarrow$ [bærx] 'mountain'), but if more cases emerge, then the argument in the text will not stand.
} 
Lubowicz recognizes both of these issues and proposes to address them by imposing additional conditions on constraint conjunction. Nonetheless, the point is clear that local conjunction does not really capture Kiparsky's original idea of a derived environment and this may lead to unwanted empirical predictions. Comparative markedness, in contrast, comes closer to expressing the original derived environment notion. In fact, by its very nature, without the need for additional conditions, comparative markedness theory is unable to express absurd generalizations like those in (40). Recall the ranking schema for DEE's in (35): $\llbracket_{\mathbf{N}} \mathrm{M} \gg$ Faith $\gg{ }_{\mathbf{0}} \mathrm{M} \rrbracket$. This schema says that new loci of $\mathrm{M}$-violation are avoided at the expense of unfaithfulness, but old loci remain. In (40a), the mapping /boti/ $\rightarrow$ böti does not introduce a new locus of NOVCDOB violation, so this more faithful mapping wins over /boti/ $\rightarrow$ *pöti. And in (40b), the mapping /tarpa/ $\rightarrow$ tarapa beats /tarpa/ $\rightarrow$ tarapa $?$ because the final $a$ is not a new locus of FINAL-C violation. (Formally, $a_{5}$ of $t_{1} a_{2} r_{3} a p_{4} a_{5}$ t-corresponds to $a_{5}$ of the FFC $t_{1} a_{2} r_{3} p_{4} a_{5}$.) Cases like these, where another process is occurring either irrelevantly (40a) or remotely (40b) should not be possible derived environment effects, and indeed they aren't in comparative markedness theory.

Similar remarks can be made about grandfather effects. Bakovic (2000) proposes to analyze dominant/recessive tongue-root harmony in Kalenjin as a kind of grandfather effect: the vowels in a word should agree in their value of the feature [ATR], but harmony cannot create marked [-ATR] vowels. This perspective explains why only [+ATR] spreads, even from non-root morphemes. In the following

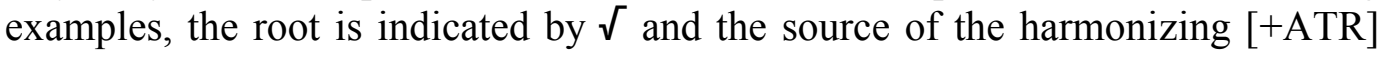
feature is in boldface.

(41) Dominant/Recessive [ATR] Harmony in Kalenjin (Bakovic 2000, B. Hall and et al. 1974)

$\begin{array}{llll} & / \mathrm{kI}-\mathrm{a}-\sqrt{\mathrm{ke} r}-\mathrm{In} / & \text { kiegerrin } & \text { 'I saw you }(\mathrm{sg} .) \\ & / \mathrm{kI}-\mathrm{a}-\sqrt{\mathrm{k} \varepsilon \mathrm{r}-\mathrm{e} /} & \text { kiegere } & \text { 'I was shutting it' } \\ \text { cf. } & / \mathrm{kI}-\mathrm{a}-\sqrt{\mathrm{k} \varepsilon \mathrm{r} /} & \text { kIager } & \text { 'I shut it' }\end{array}$

[-ATR] doesn't spread, because it would create new instances of marked [-ATR] vowels. But Kalenjin has [-ATR] vowels - though only in words that contain no underlying [+ATR] morphemes, like 'I shut it'. There is a similar but more complex case in Lango (Archangeli and Pulleyblank 1994, Benua and Smolensky 2001, Prince and Smolensky 1991, Smolensky 1997).

Bakovic proposes to analyze Kalenjin with local conjunction of markedness and faithfulness constraints. The conjoined constraint [IDENT(ATR)\&*-ATR $]_{\text {Seg }}$, ranked above IDENT(ATR), rules out the creation of [-ATR] vowels from [+ATR] vowels. The constraint AGREE(ATR), also ranked above IDENT, favors words with harmony: 
(42) Kalenjin (after Bakovic 2000)

\begin{tabular}{|c|c|c|c|c|}
\hline$/ \mathrm{kI}-\mathrm{a}-\sqrt{\mathrm{k} \varepsilon \mathrm{r}-\mathbf{e} /}$ & $\begin{array}{c}{[\mathrm{IDENT}(\mathrm{ATR}) \&} \\
*-\mathrm{ATR}]_{\mathrm{Seg}} \\
\end{array}$ & AgreE(ATR) & IDENT(ATR) & *-ATR \\
\hline a. kiegere & & & $* * *$ & \\
\hline kIakere & & $* !$ & & $* * *$ \\
\hline kIakere & $* !$ & & $*$ & $* * * *$ \\
\hline \multicolumn{5}{|l|}{$/ \mathrm{kI}-\mathrm{a}-\sqrt{\mathrm{k} \varepsilon \mathrm{r} /}$} \\
\hline kIager & & & & $* * *$ \\
\hline e. kieger & & & $* * * !$ & \\
\hline
\end{tabular}

Together, AGREE(ATR) and [IDENT(ATR)\&*-ATR $]_{\text {Seg }}$ ensure that harmony will be achieved by creating unmarked [+ATR] vowels rather than marked [-ATR] vowels ((42a) vs. (42c)). But IDENT(ATR) is ranked above unconjoined *-ATR, so that inputs containing only [-ATR] vowels will survive intact ((42d) vs. (42e)).

This case too is subject to reanalysis under the comparative markedness regime. The markedness-faithfulness conjunction is replaced by the comparative constraint ${ }_{\mathrm{N}}^{*}$-ATR, which is violated by any new [-ATR] vowel. Its counterpart ${ }^{*}$-ATR is ranked below IDENT(ATR), so it cannot compel unfaithfulness to the input.

It seems likely that all cases of markedness and faithfulness conjunction can be similarly reanalyzed (though see footnote 13). Going the other way, it appears that there is at least one case of a grandfather effect that cannot be analyzed with local conjunction, although it submits to analysis with comparative markedness. (Thanks to Paul de Lacy for pointing this out.) As shown in (28c, d), the mapping /maim-ki/ $\rightarrow$ ma:yki in SLPC does not violate the comparative constraint ${ }_{\mathrm{N}}{ }^{*} \mathrm{LAB} \mid$ DorS. The $/ \mathrm{m} /$ $\rightarrow \eta$ mapping does not introduce a new markedness violation because there is a single constraint against both labials and velars. Yet $\eta$ is unfaithful to its underlying place specification, so there is no way to translate this analysis into the local conjunction model. Conjunction of markedness and faithfulness activates the markedness constraint whenever a faithfulness violation is detected. This is fine when the mapping threatens to change a coronal into something else, as in /sirn-ki/ $\rightarrow *$ si.nki, but it is wrong when the mapping merely exchanges one marked element for another, as in /ma:m-ki/ $\rightarrow$ ma:yki. Comparative markedness rules out /si:n-ki/ $\rightarrow *$ si:nki because it introduces a new marked thing; local conjunction wrongly rules out /ma:m-ki/ $\rightarrow$ ma:yki because the output of an unfaithful mapping is a marked thing, even though the unfaithful mapping did not make it more marked.

To sum up, the local conjunction of markedness and faithfulness constraints, though it can deal with DEE's and some kinds of grandfather effects, is both too rich and too poor a theory. Markedness-faithfulness conjunction says, in essence, that an environment is derived if some process - some faithfulness violation - has 
occurred nearby. There is no requirement that the process be relevant (cf. (40a)) nor that it happen close enough to matter (cf. (40b)). The analyses of Makassarese and Kalenjin highlight this problem: the processes that create the derived environments in these languages are both relevant and near enough to interact, but the underlying theory treats this as an accident. The SLPC example points toward the same problem: an unfaithful mapping creates a derived environment, but not always in a relevant way. Comparative markedness theory encounters no such difficulties (though it has plenty of its own - see $\S 5.4$ and $\S 6.1$ ). Relevance and locality are assured by the nature of the comparison mechanism.

\section{§5. Eliminating Old Marked Structures}

In $\S 4$, we looked at hierarchies where ${ }_{\mathrm{N}} \mathrm{M}$ is ranked high and ${ }_{\mathrm{O}} \mathrm{M}$ low. The opposite is also possible. In this section, I present three situations where high ${ }_{\mathrm{O}} \mathrm{M} / \mathrm{low}$ ${ }_{\mathrm{N}} \mathrm{M}$ is required: non-iterative processes, such as apocope and local tone spreading; coalescence paradoxes, where coalescence produces segments that are otherwise forbidden; and counterfeeding opacity, where the output of one process unexpectedly fails to undergo another process. All three cases involve the active elimination of old M-violating structures while tolerating new ones.

\section{\$5.1 Non-iterating Processes}

In the context of research on iterative rules in the 1970's (e.g., Kenstowicz and Kisseberth 1977: 155-229), a class of processes was identified that should be able to iterate but do not. For example, rules of apocope typically delete the final vowel mora, but they do not then continue to nibble off additional vowel morae until they run into a consonant (Vago and Battistella 1982). The Siouan language Hidatsa forms the imperative in this way (Harris 1942):

(43) Hidatsa imperative

$\begin{array}{llll}\text { /cixi/ } & \text { cix } & \text { 'jump!' } & \text { cf. cixic 'jumped' } \\ \text { /kikua/ } & \text { kiku } & \text { 'set a trap! } & \text { cf. kikuac '(did) set a trap' } \\ \text { /ikaa/ } & \text { ika } & \text { 'look! } & \text { cf. ika:c 'looked' }\end{array}$

If the process fed itself, we would expect $/ \mathrm{kikua} / \rightarrow k i k u \rightarrow * k i k$. Similar examples can be found in Latvian (Halle and Zeps 1966), Lithuanian (Lightner 1972), Odawa (Piggott 1975), Ponapean (Howard 1972: 179-81), and Woleaian (Sohn 1975). Some, like Hidatsa, are morphologized, but others are not.

Perhaps the best-known case of this type is Lardil (K. Hale 1973, Kenstowicz and Kisseberth 1979, Klokeid 1976, Prince and Smolensky 1993, Wilkinson 1988). In nominative-case nouns containing at least three morae, a root-final vowel is apocopated. Apocope exposes consonants to word-final position, where some of them (the non-apicals) are deleted in conformity with Lardil phonotactics. (The rightmost column is there to prove the underlying form by showing the final vowel protected by the non-future accusative suffix $-n$.) 
(44) Lardil Apocope

/pulumunitami/

/kurumpuwa/

/pulnarpa/

/munkumunku/

/tipitipi/ pulumunita

kurumpu

pulyar

muykumu

tipiti 'young f. dugong'

'tata-spear'

'huge'

'wooden axe'

'rock-cod' cf. pulumunitamin

cf. kurumpuwan

cf. pulyarpan

cf. muykumunkun

cf. tipitipin

In /pulumunitami/, for example, the final vowel $i$ is apocopated and the preceding consonant, $m$, deletes also, since labials are prohibited word-finally. In /pulyarpa/, apocope and deletion of $/ \mathrm{p} /$ leave a final apical, $r$, which is permitted.

Apocope does not feed itself; in terms of a serial derivation, we don't find /kurumpuwa/ $\rightarrow$ kurumpuw $\rightarrow$ kurumpu $\rightarrow *$ kurump $\rightarrow * k$ kurum $\rightarrow * k u r u$, as final vowels are successively truncated, each time exposing a new consonant that is prohibited word-finally, until the bimoraic word minimum finally puts a halt to the process. To prevent apocope from chewing its way through the word like this, Prince and Smolensky (1993: 101) propose that apocope is not the result of an ordinary, outputevaluating markedness constraint. They adopt instead a kind of anti-faithfulness constraint, FREE-V, that requires non-parsing of the word-final vowel. ${ }^{14}$ By the representational assumptions of the PARSE/FILL faithfulness model current at that time, the unparsed final vowel was present but unpronounced in the output form kurumpu\{wa $\rangle$. FREE-V demands a final unparsed vowel, and that's what it gets. Further vowel deletion is neither desired nor predicted.

This sort of analysis is not possible under the representational assumptions of correspondence theory, which regards apocope as literal deletion rather than underparsing. Reanalysis of Lardil apocope must proceed either in the direction of a full-blown anti-faithfulness theory (Alderete 1998, 2001, Horwood 1999) or along the following lines. We have already seen that there is a markedness constraint prohibiting word-final vowels, FINAL-C (\$4.2). According to the assumptions of comparative markedness theory, this constraint has two parallel forms, ${ }_{0}$ FINAL-C and ${ }_{N}$ FINAL-C. The constraint ${ }_{0}$ FINAL-C is violated by any candidate that contains a wordfinal vowel, if that vowel stands in correspondence with a vowel that is final in the FFC. The constraint ${ }_{N}$ FINAL-C is violated by any candidate that introduces a new final vowel, one not present in the FFC. This is precisely the difference between the candidates *pulumunitami and pulumunita in Lardil. The first candidate, *pulumunitami, shares a FINAL-C violation with the FFC - trivially, since it is the FFC. The second candidate, pulumunita, also has a FINAL-C violation, but in a locus that is not shared with the locus of violation in the FFC, since the $a$ of $t a$ and the $i$ of $m i$ are not in t-correspondence. The following tableau tells the tale:

\footnotetext{
${ }^{14}$ Prince and Smolensky also describe FREE-V as morphologized because it is limited to nominative nouns (see also Kirchner 1992). But Klokeid (1976) makes a fairly good case that apocope is not morphologized. The main problem for a phonological apocope process is the absence of apocope in verbs. Klokeid argues that all verbs end in an underlying final $/ \mathrm{t} /$, a kind of verbmarking morpheme, that protects the final vowel from apocope but itself deletes because it is not apical. This $/ \mathrm{t} /$ is overtly present with monomoraic roots, where it is followed by the usual Lardil augment $a$ : neța 'burn, cook', beta 'bite', wuta 'give'.
} 
(45) Lardil: ${ }_{0}$ FINAL-C $\gg$ MAX $\gg{ }_{N}$ FINAL-C

\begin{tabular}{|c|c|c|c|c|}
\hline \multicolumn{2}{|c|}{ /pulumunitami/ } & ${ }_{\mathrm{o}}$ FINAL-C & MAX & ${ }_{\mathbf{N}}$ FINAL-C \\
\hline a. & (FFC) pulumunitami & $* !$ & & \\
\hline b. & pulumunita & & $* *$ & $*$ \\
\hline c. & pulumun & & $* * * * !$ & \\
\hline
\end{tabular}

Apocope only affects underlying final vowels because the responsible markedness constraint, ${ }_{0}$ FINAL-C, only detects loci of violation that are shared with the FFC. The other markedness constraint, ${ }_{\mathrm{N}}$ FINAL-C, detects the final vowel of pulumunita, since this violation locus is not shared with the FFC. It is, moreover, irrelevant, because ${ }_{\mathbf{N}}$ FINAL-C is ranked below MAX. Apocope never takes a vowel other than the underlying final one because only an underlying final vowel can violate ${ }_{0}$ FINAL-C. This holds true even when further apocope would produce a form that is consonantfinal, such as * pulumun.

This analysis further explains why apocope has no effect on underlying consonant-final roots. For example, underlying/tukuyuy/ 'lungs' (cf. tukuyuy-in) and /wuykunuy/ 'queenfish' come out as tukuyu and wugkunu, with the last vowel of the root preserved intact. The root-final segment is not a vowel but the consonant $\eta$, which deletes because it is non-apical. This then exposes $u$ to word-final position. Since the $u$ is not word-final in the FFC, it does not violate high-ranking ${ }_{0}$ FINAL-C. The effect is like Prince and Smolensky's FrEE-V, but comparative markedness uses an independently motivated markedness constraint, FINAL-C, rather than an ad hoc anti-faithfulness constraint.

Another situation where a process could in principle iterate but does not is local spreading. In local spreading, assimilation of tone or a feature affects an immediately adjacent syllable or segment, but it goes no further. Research in OT on tone spreading, vowel harmony, and other assimilation processes has tended to focus on long-distance effects, which have sometimes been attributed to constraints of the Alignment family (Kirchner 1993 et al.). Alignment is not of obvious help, though, in analyzing local spreading. ${ }^{15}$ Once the ranking $\llbracket$ Align(Tone, Edge) $\gg$ Faith $\rrbracket$ has been established, there is no obvious way to limit the tone to spreading just one syllable toward the edge. For this reason, the sporadic treatments of local spreading in the literature (Alderete 1998, Bickmore 1996, Myers 1997) have invoked constraints of a somewhat ad hoc character, such as special faithfulness constraints against spreading too far.

\footnotetext{
${ }^{15}$ Some cases of alleged local spreading may be purely implementational, involving anticipation or delay in reaching the pitch peak rather than true phonological spreading (cf. Myers 2001).
} 
Comparative markedness offers a different approach to local and longdistance spreading. ${ }^{16}$ The idea is to derive both types of spreading from pre-existing harmony constraints under the comparative regime. The constraint AGREe(F) (Bakovic 2000, Lombardi 1999, 2001) requires adjacent segments or syllables to agree in the feature or tone F. The constraint SPREAD(F) (Padgett 1995) says that, if any segment or syllable in a domain bears $F$, then all must. The Loc functions associated with the tonal versions of these constraints can be defined as follows:

(46) Agree(H) and Spread(H)

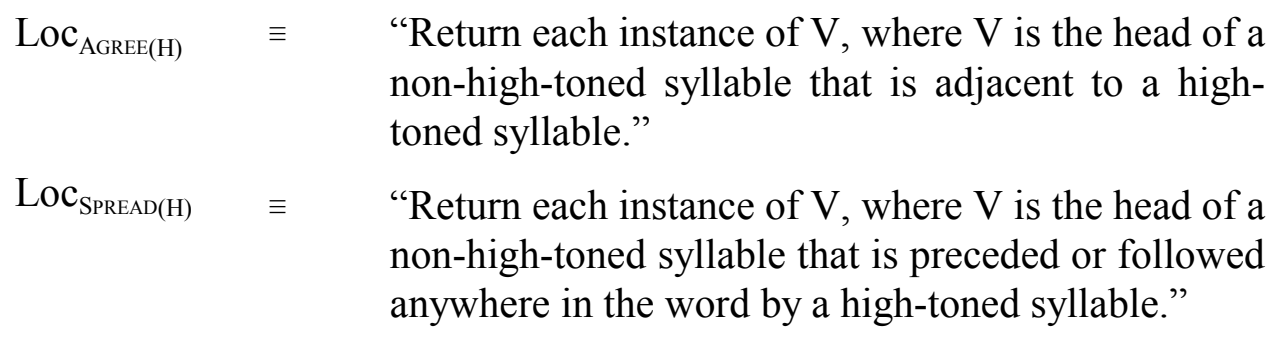

Ultimately, something must be said about directionality effects in spreading, but this will suffice for present purposes.

In comparative markedness theory, these constraints come in two flavors, old and new. The constraint ${ }_{0} \operatorname{AgREE}(\mathrm{H})$ is violated by a HL tone sequence already present in the input; eliminating this sequence — by local spreading, for instance will satisfy this constraint. The constraint ${ }_{\mathbf{N}} \mathrm{AGREE}(\mathrm{H})$ is violated by any $\mathrm{HL}$ sequence created by, say, tone spreading. The constraint ${ }_{0} \operatorname{SPREAD}(\mathrm{H})$ is violated by all lowtoned syllables in a word with an underlying high tone, whereas the constraint ${ }_{N} \operatorname{SPREAD}(\mathrm{H})$ is violated by, inter alia, low-toned syllables in a word with a syllable whose high tone derives from docking of an underlying high tone.

To show how these constraints work under somewhat realistic circumstances,

\begin{tabular}{|c|c|c|c|c|c|c|}
\hline /HLLLL/ & ${ }_{\mathrm{O}} \mathrm{AGREE}(\mathrm{H})$ & ${ }_{\mathrm{N}} \mathrm{AGREE}(\mathrm{H})$ & ${ }_{\mathrm{O}} \mathrm{SPR}(\mathrm{H})$ & ${ }_{N} \mathrm{SPR}(\mathrm{H})$ & FAITH & NONFIN \\
\hline a. (FFC) HLLLL & * & & $* * * *$ & & & \\
\hline HHLLL & & * & $* * *$ & & * & \\
\hline HHHLL & & * & ** & & $* *$ & \\
\hline HHHHL & & $*$ & * & & $* * *$ & \\
\hline HHHHH & & & & & $* * * *$ & * \\
\hline
\end{tabular}
I will embed them in a system that includes a faithfulness constraint (FAITH) and a non-finality requirement (NON-FIN), which bans high tone from final syllables. The following unranked quasi-tableau shows how this system may dispose of an input with an initial high tone followed by four syllables with low tones:

(47) Some Typological Consequences I section.

${ }^{16}$ I am grateful to Bert Vaux for challenges that fostered various improvements in this 
Since the input contains at least one $\mathrm{H}$ and no candidates have epenthesized syllables, there are no violation-marks in the ${ }_{N} \mathrm{SPR}(\mathrm{H})$ column. In $(47 \mathrm{~b}-\mathrm{d})$, less-than-total spreading has introduced non-agreeing sequences, so $_{N} \mathrm{AGREE}(\mathrm{H})$ is violated. The FFC (47a) can only violate old comparative constraints, so its non-agreeing sequence is charged against ${ }_{\mathrm{O}} \mathrm{AGREE}(\mathrm{H})$. The final candidate $(47 \mathrm{e})$ has extended high tone onto the final syllable, a violation of NONFIN.

Of the five candidates, the shaded one $(47 \mathrm{c})$ is unattainable because it is harmonically bounded within this constraint-set. This candidate has neither local spreading, like (47b), nor long-distance spreading up to a limit, like (47d, e). This result seems correct: spreading shows a basically dichotomous behavior, either strictly bounded or thoroughly unbounded. The other four candidates are all possible winners, depending on the details of ranking.

Though ${ }_{N} \operatorname{SPR}(\mathrm{H})$ has nothing to say about (47), it is relevant when the input contains a floating tone. Consider an input that consists of a floating $\mathrm{H}$ plus a word without high tone. Assume that the floating tone is compelled to dock by undominated *FLOAT (Myers 1997: 867). The possibilities are these:

(48) Some Typological Consequences II

\begin{tabular}{|c|c|c|c|c|c|c|}
\hline & ${ }_{\mathrm{O}} \mathrm{AGREE}(\mathrm{H})$ & ${ }_{\mathrm{N}} \mathrm{AgREE}(\mathrm{H})$ & ${ }_{\mathrm{O}} \mathrm{SPR}(\mathrm{H})$ & ${ }_{N} \mathrm{SPR}(\mathrm{H})$ & FAITH & NONFIN \\
\hline a. $(\mathrm{FFC})\langle\mathrm{H}\rangle \mathrm{LLLLL}$ & \multicolumn{6}{|c|}{ Ruled out by undominated *FLOAT } \\
\hline HLLLL & & $*$ & & $* * * *$ & $*$ & \\
\hline HHLLL & & * & & $* * *$ & $* *$ & \\
\hline HHHLL & & $*$ & & $* *$ & $* * *$ & \\
\hline HHHHL & & $*$ & & $*$ & $* * * *$ & \\
\hline НHНHН & & & & & $* * * * *$ & * \\
\hline
\end{tabular}

Interestingly, local spreading of a floating tone (48c) is harmonically bounded by (48b) and (48e). (This is collective harmonic bounding (Samek-Lodovici and Prince 1999).) The reason is clear: ${ }_{0} \operatorname{AgREE}(\mathrm{H})$ is responsible for local spreading of underlying linked tones, but it has no effect on underlying floating tones. If these constraints are right, then floating tones should never spread locally. They should either not spread at all or spread long-distance. ${ }^{17}$

This prediction seems to reflect a genuine pattern of floating-tone behavior. I know of no counterexamples, and autosegmental theory has emphasized the longdistance spreading of floating tones, with principles like a preference for floating (vs. linked) tones to spread (Clements and Ford 1979: 185) or automatic spreading of floating tones only (Odden (1995: 458) citing Halle and Vergnaud (1982)).

${ }^{17}$ Thanks to Mark Baker for a question about this. 


\section{$\$ 5.2$ Coalescence Paradoxes}

Gnanadesikan (1997) identifies a class of phenomena that she calls coalescence paradoxes. Coalescence is phonological fusion: two input segments unite into a single output segment $\varsigma$ that shares characteristics of both its parents. In a coalescence paradox, $\varsigma$ has no source other than coalescence; in particular, when $\varsigma$ appears in inputs, it is treated unfaithfully. The paradox is that the same faithfulness constraints that are satisfied when coalescence produces $\varsigma$ are also violated when input $/ \varsigma /$ is treated unfaithfully. ${ }^{18}$

The best known example of a coalescence paradox comes from Sanskrit. Sequences of $a$ immediately followed by $i$ or $u$ merge into long $e^{\prime}$ or $o{ }^{\prime}$, respectively.

(49) Coalescence in Sanskrit

$$
\begin{aligned}
& / \mathrm{a}+\mathrm{i} / \rightarrow \mathrm{e}: \\
& / \mathrm{ca}_{1}+\mathrm{i}_{2} \mathrm{ha} / \quad \rightarrow \quad \mathrm{cer}_{1,2} \text { ha 'and here' } \\
& / \mathrm{a}+\mathrm{u} / \rightarrow \mathrm{o:} \\
& / \mathrm{ca}_{1}+\mathrm{u}_{2} \mathrm{ktam} / \rightarrow \quad \operatorname{co}_{1,2} \mathrm{ktam} \quad \text { 'and said' }
\end{aligned}
$$

The input-output correspondence relations are indicated by subscripts. The output vowel is mid because it is the result of fusing a low vowel with a high one; a mid vowel is a sort of compromise. The output vowel is long because it preserves the moras of both its input correspondents. Mid vowels have no other source in Sanskrit. In particular, input mid vowels are not mapped onto surface mid vowels. Surface mid vowels are always the result of coalescence, as shown by the fact that surface mid vowels are always long.

The Austronesian language Rotuman has a similar phenomenon involving vowel color rather than height.

(50) Umlaut in Rotuman (Churchward 1940, McCarthy 2000 and references there)

$$
\begin{array}{llll}
/ \mathrm{mo}_{1} \mathrm{se}_{2} / & \rightarrow & \mathrm{mö}_{1,2} \mathrm{~s} & \text { 'to sleep' } \\
/ \mathrm{fu}_{1} \mathrm{ti}_{2} / & \rightarrow & \mathrm{fü}_{1,2} \mathrm{t} & \text { 'to pull' }
\end{array}
$$

In the so-called incomplete phase, the final vowel can delete entirely, metathesize with the preceding consonant, or coalesce with the preceding vowel, as in (50). Coalescence of $/ \mathrm{o}+\mathrm{e} /$ or $/ \mathrm{u}+\mathrm{i} /$ produces the front rounded vowels $\ddot{o}$ and $\ddot{u}$, compromising on the color of the two input vowels. But front rounded vowels are impossible in all other circumstances in Rotuman; they only occur in the incomplete phase of $/ \mathrm{CoCe} /$ and $/ \mathrm{CuCi} /$ roots because they only arise as a result of coalescence.

Finally, the Bantu language Luganda supplies a case of consonant coalescence with the same property. Sequences of a nasal followed by a consonant coalesce into a prenasalized stop, with compensatory lengthening of the preceding vowel.

\footnotetext{
${ }^{18}$ On the analysis of coalescence in OT, see Causley (1997), Gnanadesikan (1995/to appear, 1997), Keer (1999), Lamontagne and Rice (1995), McCarthy (2000), McCarthy and Prince (1995), and Pater (1999).
} 
(51) Prenasalization in Luganda (Clements 1986a, McCarthy 2002b, Rosenthall 1994, Wiltshire 1992)

$$
\begin{array}{llll}
/ \mathrm{ku}+\operatorname{lin}_{1} \mathrm{~d}_{2} \mathrm{a} / & \rightarrow & \text { kuli: }^{\mathrm{n}} \mathrm{d}_{1,2} \mathrm{a} & \text { 'to wait' } \\
/ \mathrm{mu}+\mathrm{n}_{1} \mathrm{t}_{2} \mathrm{u} / & \rightarrow & \mathrm{mu}^{\mathrm{n}} \mathrm{t}_{1,2} \mathrm{u} & \text { 'person' }
\end{array}
$$

Prenasalized consonants have no other source in Luganda, which is why they are always preceded by a long vowel. An input that already contains a prenasalized stop, such as $/ \mathrm{mu}^{\mathrm{n}} \mathrm{tu} /$, must be treated unfaithfully, mapping onto something like mutu or типи.

In all of these cases, coalescence introduces segments that, when present in the input, are not treated faithfully. The paradox is that the output of coalescence shows the effect of being faithful to both of the input segments, but when the same segment that is the output of coalescence is in the input, it is treated unfaithfully. The paradox can be demonstrated with some ranking arguments from Sanskrit.

Coalescence in Sanskrit produces a mid vowel by fusing a low vowel with a high vowel. I will adopt Schane's (1987) proposal that a mid vowel combines privative $[\mathrm{HI}]$ and [LO] features ("particles" in Schane's terminology). Faithfulness to those features dominates the markedness constraint NO-MID $(\equiv *[\mathrm{HI}, \mathrm{LO}]) .{ }^{19}$

(52) Sanskrit: IDENT(HI), IDENT(LO) $\gg$ No-MID

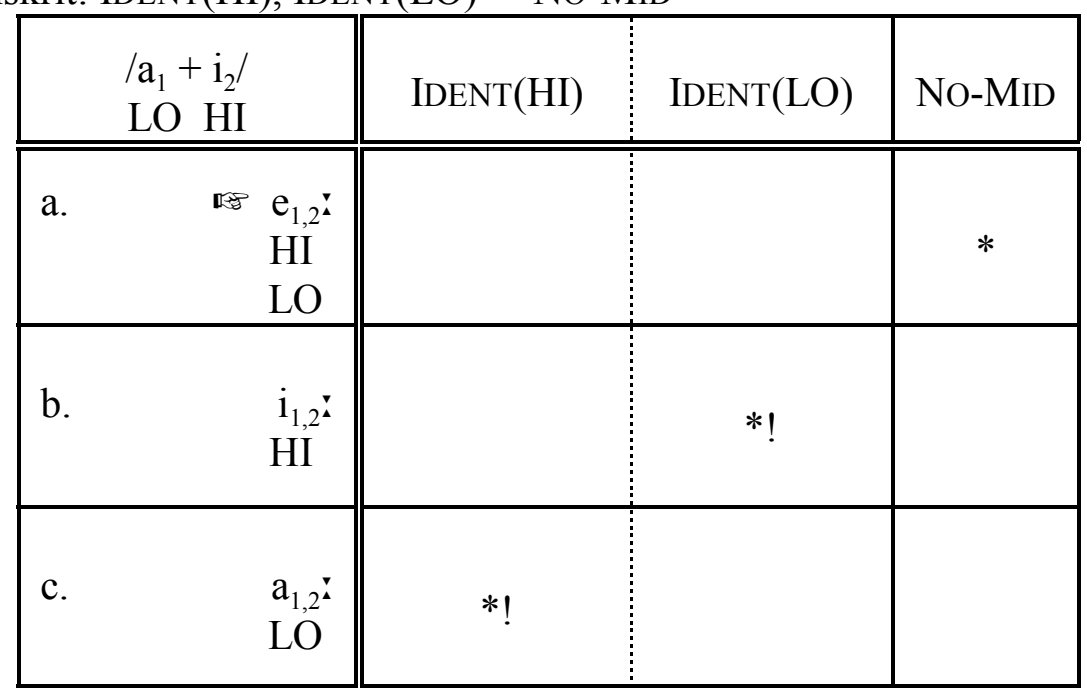

The fused segment is judged for its faithfulness to both of its input correspondents. Only one candidate, a mid vowel, satisfies both of the high-ranking IDENT constraints with respect to both correspondents.

What about input /e/ or /o/, then? They must be treated unfaithfully, but mapping them to either high or low vowels leads to a ranking paradox:

\footnotetext{
${ }^{19}$ Also see Pater (1999) on the role of IDENT constraints in coalescence.
} 
(53) Sanskrit: NO-MID $\gg$ IDENT(HI) or IDENT(LO)

\begin{tabular}{|c|c|c|c|}
\hline $\begin{array}{c}/ \mathrm{e} / \\
\mathrm{HI} \\
\mathrm{LO}\end{array}$ & No-MID & IDENT(HI) & IDENT(LO) \\
\hline $\begin{array}{ll}\text { a. } & \mathrm{i} \\
\mathrm{HI}\end{array}$ & & & * \\
\hline $\begin{array}{l}\mathrm{e} \\
\mathrm{HI} \\
\mathrm{LO}\end{array}$ & $* !$ & & \\
\hline c. & & $*$ & \\
\hline
\end{tabular}

This tableau shows what is needed to ensure that input mid vowels are treated unfaithfully. The markedness constraint NO-MID must dominate at least one of the faithfulness constraints. Which faithfulness constraint is crucially dominated depends on whether you think /e/ maps to $i$ or $a$.

To sum up, the rankings that are required for Sanskrit include 【IDENT(HI) $\gg$ NO-MID $\rrbracket$, IDENT(LO) $\gg$ NO-MID $\rrbracket$ and either $\llbracket$ NO-MID $\gg \operatorname{IDENT}(H I) \rrbracket$ or $\llbracket$ NO-MID $\gg$ IDENT(LO)』 - anyway you look at it, a contradiction. Coalescence to create surface mid vowels and unfaithfulness to input mid vowels make competing, contradictory demands on the analysis. This is a coalescence paradox.

Comparative markedness theory straightforwardly resolves the paradox. Comparative constraints can therefore distinguish between a mid vowel or other marked structure that is the product of coalescence and a mid vowel that is derived faithfully from the input. The latter is forbidden, showing that ${ }_{\mathrm{O}} \mathrm{NO}-\mathrm{MID}$ is ranked above faithfulness $(54 \mathrm{c}, \mathrm{d})$. But newly derived mid vowels are permitted, showing that faithfulness is ranked above ${ }_{\mathrm{N}} \operatorname{No}-\operatorname{Mid}(54 \mathrm{a}, \mathrm{b})$ : 
(54) Sanskrit: ${ }_{0}$ NO-MID $\gg$ IDENT( LO) (or IDENT(HI)) $\gg{ }_{N}$ NO-MID

\begin{tabular}{|c|c|c|c|}
\hline $\begin{array}{l}/ \mathrm{a}_{1}+\mathrm{i}_{2} / \\
\mathrm{LO} \mathrm{HI} \\
\end{array}$ & ${ }_{\mathrm{O}}$ NO-MID & IDENT(LO) & ${ }_{\mathrm{N}} \mathrm{NO}-\mathrm{MID}$ \\
\hline $\begin{array}{lll}\text { a. } & \mathrm{e}_{1,2}{ }^{2} \\
\mathrm{HI}\end{array}$ & & & * \\
\hline $\begin{array}{ll}\text { b. } & \mathrm{i}_{1,2^{\mathrm{i}}} \\
\mathrm{HI}\end{array}$ & & $* !$ & \\
\hline \multicolumn{4}{|l|}{ cf. FFC $a_{1} i_{2}$} \\
\hline $\begin{array}{l}/ \mathrm{e} / \\
\mathrm{HI} \\
\mathrm{LO}\end{array}$ & & & \\
\hline $\begin{array}{ll}\text { c. } & \mathrm{i} \\
& \mathrm{HI}\end{array}$ & & * & \\
\hline 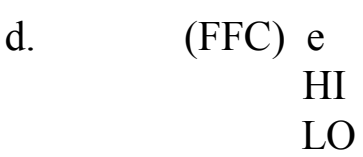 & $* !$ & & \\
\hline
\end{tabular}

The ranking here is abstractly the same as the one seen in apocope and local tone spreading. In all of these situations, marked structures already present in the input are aggressively eliminated, even as the same or different processes create the same marked structures. The key to the analysis is a hierarchy where ${ }_{0} \mathrm{M}$ is deployed above faithfulness and its ${ }_{\mathrm{N}} \mathrm{M}$ counterpart is ranked below it.

To sum up, segmental coalescence not infrequently produces outputs that are otherwise impermissible. Since coalescence itself is a manifestation of faithfulness, it can be difficult or impossible to analyze such phenomena using only the resources of classic OT. Comparative markedness theory, by distinguishing underlying from derived marked structures, is able to permit a segment to be derived by coalescence even when it is not mapped faithfully from the input.

\section{$\$ 5.3$ Counterfeeding Opacity}

Rule-based phonology of the 1970's recognized certain opaque relationships between rules. One such relationship was called counterfeeding order (Kiparsky 1965 , 1968, 1973). Suppose the outputs of process P1 include forms that look like they could undergo process P2. If in fact they do not undergo P2, then P2 must be applied before $\mathrm{P} 1$. This is counterfeeding opacity (CFO): there are surface forms that look like they should have been affected by P2, but have not. 
In some work of that era, rules like apocope or local tone assimilation were said to counterfeed themselves. The idea is that a potentially iterative process does not apply to its own output even when in principle it could. Lopping off a final vowel sometimes exposes a new final vowel, ripe for further lopping. An apocope rule that fed itself would take advantage of this new opportunity to apply; when the rule counterfeeds itself, as in Lardil, it applies once and is denied further opportunities.

It is also possible for two different processes to be in a counterfeeding relationship with one another. For example, in Barrow Inupiaq (Archangeli and Pulleyblank 1994, Kaplan 1981), palatalization of coronals is triggered by an $i$ derived from underlying / $\mathrm{i} /$, as in (55a), but it is not triggered by a phonetically identical $i$ derived from $/ \dot{t} /$ (or perhaps archisegmental $/ \mathrm{I} /$ ), as in $(55 \mathrm{~b}$ ):

(55) Barrow Inupiaq

\begin{tabular}{|c|c|c|c|c|}
\hline Stem & -lla 'be able' & -niaq 'future' & \multicolumn{2}{|c|}{-vluni '3sg realis' } \\
\hline /niRi/ & niRiКরa & niRiñiaq & niRivKuni & 'eat' \\
\hline /sisu/ & sisulla & sisuniaq & sisuvluni & 'slide' \\
\hline
\end{tabular}

In derivational terms, the absolute neutralization rule $/ \dot{t} / \rightarrow i$ follows and thereby counterfeeds the rule of palatalization. Absolute neutralization could in principle but does not in fact create inputs to the palatalization process. This is CFO.

CFO cannot be accommodated in a fully general way in classic OT (McCarthy 1999). The reasoning goes like this. In OT, a process - that is, an unfaithful mapping - is compelled by some markedness constraint. But because markedness constraints evaluate outputs alone, the same markedness constraint responsible for making niRiイKa more harmonic than *niRilla would also make

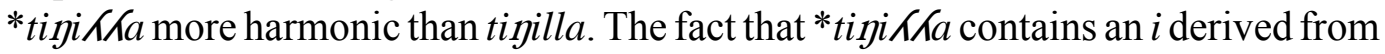
underlying $/ \dot{t} /$ can have no effect on how it performs on classic markedness constraints, which evaluate outputs only. In short, why isn't the palatalization process triggered by all surface $i$ 's, regardless of whether they are derived from $/ \mathbf{i} /$ or $/ \dot{\mathbf{t}} /$ ?

Comparative markedness theory takes a different approach to CFO. Barrow Inupiaq has palatalization only when the FFC (e.g., ni Rilla) violates the markedness constraint, PAL, defined as Loc $\mathrm{PAL}_{\mathrm{PL}} \equiv$ "Return every C, where $\mathrm{C}$ is a coronal and the preceding vowel is $i$." When the FFC satisfies this constraint (e.g., tigflla), then there is no palatalization. So the ranking for CFO conforms to the following schema:

(56) Ranking Schema for Counterfeeding Opacity

$$
{ }_{\mathrm{O}} \mathrm{M} \gg \text { Faith } \gg{ }_{\mathrm{N}} \mathrm{M}
$$

Informally, this says "unfaithfulness is compelled only to eliminate an inherited locus of $\mathrm{M}$ violation". The mapping /tin-illa/ $\rightarrow$ *tipi KKa does not eliminate an inherited locus of violation because the FFC tintlla already satisfies PAL vacuously. High- 
ranking ${ }_{0} \mathrm{PAL}$ is indifferent to the worsening palatalization situation created by the $/$ tin-tlla/ $\rightarrow$ *tini $K$ Ka map, though ${ }_{\mathrm{N}} \mathrm{PAL}$ cares about it greatly but futilely:

\begin{tabular}{|c|c|c|c|}
\hline /niRi-lla/ & ${ }_{\mathrm{O}} \mathrm{PAL}$ & IDENT(Place) & ${ }_{N}$ PAL \\
\hline niRiאKa & & $*$ & \\
\hline (FFC) niRilla & *! & & \\
\hline /tinj-1la/ & & & \\
\hline c. & & & $*$ \\
\hline d. & & $* !$ & \\
\hline
\end{tabular}

Candidate (57b) contains a locus of PAL violation - the $l$ that is preceded by $i$ - that t-corresponds with a locus of PAL violation in the FFC - trivially, since (57b) is the FFC. In candidate (57a), that violation is absent, so (57a) wins, in conformity with the $\llbracket_{0} \mathrm{PAL} \gg \mathrm{IDENT}(\mathrm{Place}) \rrbracket$ ranking.

Next, consider an input with underlying $/ \dot{t} /$. Candidate $(57 \mathrm{c})$ contains a locus of PAL violation - the $i$ before $l$ - that does not t-correspond with a locus of PAL violation in the FFC, because the t-corresponding segment in the FFC is not in a palatalizing context. So (57c) does not violate ${ }_{0} P A L$, and beating candidate $(57 \mathrm{~d})$, which satisfies low-ranking ${ }_{\mathrm{N}} \mathrm{PAL}$ at the expense of a fatal faithfulness violation.

In CFO, a general phonological process $\mathrm{P}$ fails to apply to forms that meet $\mathrm{P}$ 's conditions only by virtue of another process. For example, /tinj-lla/ $\rightarrow$ tinilla shows no effect of palatalization because the conditions for palatalization - a preceding $i$ - are only met by virtue of the $/ \dot{t} / \rightarrow i$ neutralization process. CFO, then, is the antithesis of a derived environment effect (a point made by Lubowicz 2002a). In a derived environment effect, one process applies only when its conditions are met by virtue of another process. In $\mathrm{CFO}$, one process fails to apply only when its conditions are met by virtue of another process. Comparative markedness theory expresses that antithetical quality formally: DEE's and CFO have opposite ranking schemata ((35) vs. (56)).

\section{$\$ 5.4$ Comparison with Alternatives}

No alternative approaches to non-iterating processes and coalescence paradoxes are known to me that approach the generality of comparative markedness. The study of opacity in OT, however, is a relatively rich area, with several alternatives to consider: local conjunction of faithfulness constraints, stratal OT, sympathy theory, and targeted constraints. I will try to say something about each, commenting on differences from and similarities to comparative markedness. 
Local conjunction of faithfulness constraints has been proposed as a theory of chain-shifts and other forms of CFO (Ito and Mester 2002, Kirchner 1996). For example, Barrow Inupiaq (55) could be analyzed as follows:

(58) Barrow Inupiaq with Local Conjunction

$$
\left[\operatorname{IDENT}(\text { back) \&IDENT(Place) }]_{\text {Adj- }} \gg \text { PAL } \gg \operatorname{IDENT(Place)~}\right.
$$

That is, two adjacent syllables cannot contain segments that are unfaithful in both [back] and Place.

As I noted in $\S 4.3$, conjoining constraints in the wrong domain, or even what looks like the right one, can lead to unattested interactions (McCarthy 1999: 365-6). Adj- $\sigma$ seems like the right domain for Barrow Inupiaq. The domain cannot be Adjseg because coronals are patalized even by a non-adjacent $i$, as long as only consonants intervene: /savik-lu/ $\rightarrow$ savig $K u$ 'knife-and'. But this domain predicts mappings like (hypothetical) /tini-lla/ $\rightarrow$ tinilla, $*$ timi $K$ Ka. In this case, $/ 1 /$ has failed to palatalize, even though it is preceded by underived $i$, because $/ \dot{t} /$ has fronted in an adjacent syllable. This prediction is surely wrong, and in fact seems absurd. This problem could perhaps be fixed by fine-tuning the domain of conjunction, but the global problem remains: this approach to CFO is predicting a highly implausible language typology.

Likewise, conjoining the wrong faithfulness constraints can produce equally absurd results. For example, assume a language with a general coda-devoicing process and the following ranking:

$$
\left[\operatorname{IDENT}(\text { voice }) \& \operatorname{IDENT}(\text { Place) }]_{\text {Adj-Seg }} \gg \mathrm{PAL} \gg \operatorname{IDENT}(\text { Place) }\right.
$$

This ranking prohibits adjacent segments from changing both [voice] and Place. Embedded in a language with a general coda-devoicing process, it would produce mappings like these:

$$
\begin{array}{llll}
\text { a. /batik-lu/ } & \rightarrow & \text { batik } イ \text { } \\
\text { b. /batig-lu/ } & \rightarrow & \text { batiklu }
\end{array}
$$

In (60b), although it is preceded by $i$, the $/ 1 /$ has failed to palatalize because it adjoins a devoiced segment. Again, this hypothetical example does not seem possible. The change in voicing is irrelevant to palatalization, and so coda devoicing should not block palatalization.

These unattested patterns of $\mathrm{CFO}$ are not attainable using comparative markedness (or rule ordering, for that matter). Recall the ranking schema (56): $\llbracket_{\mathbf{o}} \mathrm{M}$ $\gg$ Faith $\gg{ }_{\mathbf{N}} \mathrm{M} \rrbracket$. This says that old loci of M-violation are eliminated at a cost in faithfulness, but new loci of M-violation may be created if necessary. The blocking of palatalization in /tini-lla/ $\rightarrow$ tinilla, *tini $K$ K $a$ is not possible under this schema because fronting of $/ \mathfrak{t} /$ in the first syllable does not create a new locus of PAL violation. Nor does devoicing of $/ \mathrm{g} /$ in $(60 \mathrm{~b})$, since the voicing of the intervening 
consonant has no effect on whether or not PAL is satisfied. In the local-conjunctionbased analysis of Barrow Inupiaq (58), it is really just an accident that the faithfulness constraint IDENT(back) is included in the conjunction rather than IDENT(voice). But this can be no accident: [back] in vowels is relevant to palatalization in a way that [voice] in consonants is not. It is hard to see how this problem with conjunction can be remedied, even with the aid of formal conditions on conjoinability (Fukazawa and Lombardi to appear, Fukazawa and Miglio 1998, Lubowicz 2002b), because relevancy can in general be determined only by looking at how specific candidates are affected by a system of constraints in a hierarchy. Formal criteria for relevancy do not seem possible and are not even needed in OT except as a patch for local conjunction's tendency to overpredict.

To sum up the results of this section and §4.3, approaches to DEE's and CFO based on local conjunction do not seem to be leading us toward the right language typology. The problem is that locality and interaction are not the same thing. Local conjunction regulates the application of processes in segments that are close to each other. But in observed cases of DEE's and CFO, it is not closeness that matters it is crucial interaction of the processes, and closeness is just one of many factors that determine interaction. Comparative markedness theory, by its nature, regards interaction as a sine qua non for DEE's and CFO.

Stratal OT is another approach to CFO. Stratal OT links several OT grammars serially, like the strata of the theory of Lexical Phonology. ${ }^{20}$ Instead of rule ordering, as in $S P E$-style phonology, stratal OT attributes opaque interactions to the ordering between these strata. For example, the counterfeeding relationship between vowel neutralization and palatalization in Barrow Inupiaq would be attributed to differences in the grammars of two strata and the ordering between them, as shown in (61).

(61) Barrow Inupiaq in Stratal OT

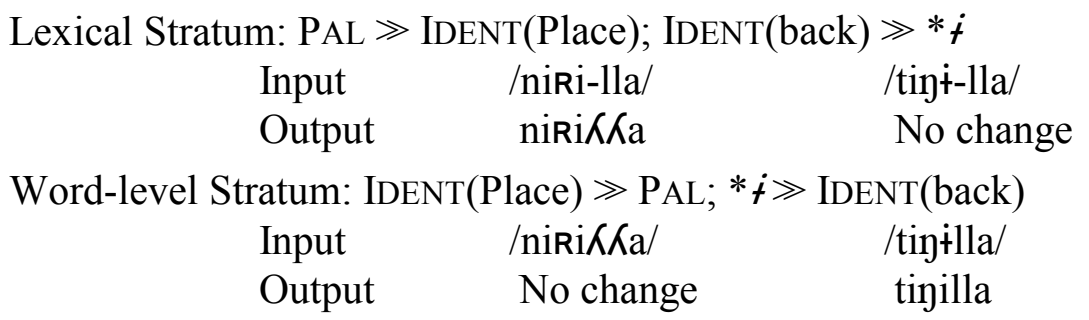

In the lexical stratum, PAL dominates IDENT(Place), so there is palatalization after $i$. But there is no neutralization of $/ \dot{t} /$ to $i$, because IDENT(back) dominates $* \dot{f}$. In the word-level stratum, both of these rankings are reversed. The constraint $* \dot{f}$ dominates IDENT(back), so input $/ \dot{t} /$ is mapped to surface $i$. But there is no palatalization before the $i$ 's derived by this process because IDENT(Place) dominates PAL. The grammars

\footnotetext{
${ }^{20}$ Some version of stratal or cyclic OT can be found in the following works, among others: Black (1993), Bermúdez-Otero (1999), Cohn and McCarthy (1994/1998), Hale and Kissock (1998), Hale, Kissock, and Reiss (1998), Ito and Mester (2002), Kenstowicz (1995), Kiparsky (2002, to appear), McCarthy (2000), McCarthy and Prince (1993b), Potter (1994), Rubach (2000), and many of the contributions to Hermans and van Oostendorp (1999) and Roca (1997).
} 
of different strata differ in the same way that the grammars of different languages do: in the ranking of the same set of constraints.

Stratal OT produces a serial derivation, so it duplicates the main effect of rule ordering, and therefore it addresses CFO in exactly the same way as rule ordering did. (Unlike classic rule ordering, stratal OT limits the number of intermediate steps to the number of strata, which is presumably fixed universally.) Concomitantly, stratal OT sheds no light on problems where rule ordering is of no help, such as grandfather effects $(\S 4.1)$, DEE’s $(\S 4.2)$, and processes that counterfeed themselves $(\$ 5.1)$.

Although comparative markedness does contribute to our understanding of these problems, it is a much more limited theory of CFO than stratal OT — probably too limited. Here I will present three differences between comparative markedness and stratal OT: in all three respects, comparative markedness comes off as more restrictive and possibly too restrictive.

In comparative markedness theory, CFO is a property of whole grammars rather than specific processes. The basic ranking $\llbracket_{0} \mathrm{M} \gg$ Faith $\gg_{N} \mathrm{M} \rrbracket$ says that Faith will not be violated solely to eliminate new violations of $M$, no matter what their source. If several processes produce M-violating structures, then all of them will be in a counterfeeding relationship with the process defined by the $\llbracket_{0} \mathrm{M} \gg$ Faith ranking. For example, Bedouin Arabic has a process raising /a/ to $i$ in an open syllable (62a). It is counterfed by two processes that create open syllables (62b), vocalization of high glides and epenthesis into rising-sonority clusters.

(62) Bedouin Arabic Raising (Al-Mozainy 1981, Johnstone 1967)

a. The vowel /a/ is raised to $i$ in an open syllable.

$/ \mathrm{katab} / \quad \rightarrow \quad$ kitab $\quad$ 'he wrote'

b. But not if the syllable is open by virtue of glide vocalization or epenthesis.

$\begin{array}{llll}/ \mathrm{badw} / & \rightarrow & \text { badu } & \text { 'Bedouin' } \\ \mathrm{gabr} / & \rightarrow & \text { gabur } & \text { 'grave' }\end{array}$

In rule-ordering theories, it is possible to order, say, glide vocalization before raising but epenthesis after raising. In stratal OT, it is likewise possible to construct the grammars of the strata so that raising and glide vocalization occur in an early stratum, with vowel epenthesis delayed until a later stratum. Either way, we get a language with $/ \mathrm{katab} / \rightarrow$ kitab,$/ \mathrm{badw} / \rightarrow$ bidu, and /gabr/ $\rightarrow$ gabur. That is, glide vocalization feeds raising, but vowel epenthesis counterfeeds raising.

If comparative markedness is the right theory of CFO, then this sort of behavior should be impossible, ceteris paribus. Without additional constraints that would render the ceteris more or less imparibus, this imagined behavior, which is readily described with rule ordering or stratal OT, is impossible to analyze with comparative markedness. Because the ranking $\llbracket$ Faith $\gg_{N} \mathrm{M} \rrbracket$ appears in the grammar, new instances of $a$ 's in open syllables, regardless of what process created them, are immune from the raising process. In general, comparative markedness predicts that, 
if a process is counterfed by at least one process, then it can never be fed by any other process in the same language. Ordering theories of CFO, including stratal OT, do not make this prediction. Is the prediction right? I don't know.

A related prediction of comparative markedness theory concerns the relationship between CFO and DEE's. ${ }^{21}$ Because the rankings for CFO and DEE's are the opposite of one another, no process can be both counterfed and restricted to applying in a phonologically derived environment. Such a situation is easy to describe in rule-based phonology (and stratal OT, if it is supplemented with a mechanism for dealing with DEE's). Suppose raising in Bedouin Arabic is restricted to applying in a derived environment, so $/ \mathrm{katab} / \rightarrow$ katab (no change), but /gabr $/ \rightarrow$ gibur (epenthesis creates derived environment). Suppose the raising rule is also followed and counterfed by glide vocalization, so /badw/ $\rightarrow$ badu. If comparative markedness theory is right, then this pattern of behavior should be impossible. Again, this is an interestingly strong claim, not obviously wrong or correct.

Another strong claim made by comparative markedness theory but not stratal OT concerns the analysis of counterfeeding opacity involving basically allophonic processes. (This class of problems was first noted by Ito and Mester (2002) in the context of their critique of sympathy theory.) The claim is best explained with an example.

Processes of nasal harmony and simplification of nasal+voiced stop clusters interact opaquely in Sea Dayak to produce sequences of a nasal followed by an oral vowel. These sequences are met with nowhere else in the language:

(63) Sea Dayak Nasal Harmony (Kenstowicz and Kisseberth 1979: 298, Scott 1957)

a. Rightward nasal harmony:

$$
\text { /naya/ - nãyã? 'straighten' }
$$

b. Blocked by oral consonants:

$$
\text { /nanga/ - nãyga? , *nãygã? 'set up a ladder' }
$$

c. Even if the blocker is optionally deleted:

$$
\text { /nayga/ } \rightarrow \text { nãyga? } \rightarrow \text { nãya?, *nãyã? id. }
$$

Nasalized vowels have no other source in Sea Dayak. In other words, nasal harmony is a basically allophonic process except for its opaque interaction with deletion of voiced stops after nasals.

OT attributes linguistic generalizations to the grammar, not the lexicon (McCarthy 2002c: 68-82, Prince and Smolensky 1993). This thesis is called "richness of the base": inputs are unrestricted, but the grammar is responsible for mapping all inputs onto pronounceable forms of the language. The grammar of Sea Dayak, then, must correctly dispose of inputs like/nãygã/, for example; it is not enough to build a grammar for /nanga/ $\rightarrow$ nãya and then retire with a deep sense of satisfaction for a job well done.

\footnotetext{
${ }^{21}$ Thanks to Paul Kiparsky for pointing this out.
} 
The problem is that there is no ranking of the relevant constraints supplied by comparative markedness theory- $0 * \mathrm{~V}_{\mathrm{NAS}}, \mathrm{N} * \mathrm{~V}_{\mathrm{NAS}}, \mathrm{O} * \mathrm{NV}_{\mathrm{ORAL}}, \mathrm{N} * \mathrm{NV}_{\mathrm{ORAL}}$, and IDENT(nasal) — that will map all of the rich-base inputs — /nanga/, /nãyga/, /nangã/, and /nãygã/ — onto the single output nãya?. (See Appendix A for the proof that no such analysis is possible.) More generally, the problem is this. In cases of allophony, richness of the base entails that the input is relatively indeterminate. But comparative markedness theory relies on the input through its surrogate, the FFC, to evaluate markedness. The problem is much the same as in Ito and Mester's (2001, 2002) critique of sympathy theory. Indeed, opacity of basically allophonic processes presents the same challenge to comparative markedness or sympathy as it did to the structuralists (e.g., writer [ı^jrə] vs. rider [ıajrə] (Chomsky and Halle 1965)): it looks as if another level of representation is required. Stratal OT, for example, supplies that level.

Two other theories of opacity in OT, sympathy and targeted constraints, bear a significant formal resemblance to comparative markedness theory. All three theories posit constraints that use one output candidate to evaluate another output candidate. In comparative markedness theory, the basis for this comparison is the FFC. In sympathy theory (McCarthy 1999, 2002b), it is the sympathetic candidate, which is defined as the most harmonic candidate among those that obey some designated faithfulness constraint. In targeted-constraints theory (Bakovic 2000, Bakovic and Wilson 2000, Wilson 2000, 2001), the basis for the comparison is determined on a constraint-by-constraint basis. For example, given the input/patka/, the constraint NOWEAKCONS compares the candidate $p a k a$ with its more faithful but otherwise identical counterpart patka:

(64) NoWEAKCONS (Wilson 2001: 160)

Let $x$ be any candidate and $\alpha$ be any consonant in $x$ that is not released by a vowel. If candidate $y$ is exactly like $x$ except that $\alpha$ has been removed, then $y$ is more harmonic than $x$ (i.e. $y>x$ ).

Like sympathy and comparative markedness, targeted constraints make intercandidate comparisons. Note too the abstract similarity with the notion "locus of violation" that was introduced in $\S 2$.

These formal resemblances are important because the three theories have incompletely overlapping empirical coverage, suggesting that some broader synthesis is needed and may even be possible. Comparative markedness applies to grandfather effects, DEE's, non-iterating processes, coalescence paradoxes, and some kinds of CFO. Sympathy theory is much more broadly applicable to opacity, including also counterbleeding opacity, but it has nothing to contribute to the analysis of DEE's, grandfather effects, or non-iterating processes. Targeted constraints are primarily relevant to the problem of explaining why some markedness constraints lead to certain unfaithful mappings and not others, ${ }^{22}$ with applications to certain cases of opacity. The hoped-for synthesis, though, is well outside my grasp at this point, though the similarities are intriguing.

${ }^{22}$ See McCarthy (to appear) for a critique of this aspect of targeted-constraints theory. 


\section{\$6 Further Issues}

This section deals with topics that arise in and around comparative markedness theory. In $\S 6.1$, I discuss the theory's implications for harmonic ascent, an important consequence of OT that comparative markedness threatens. The problem of determining the FFC is addressed in $\S 6.2$ and a preliminary but workable proposal is made. Finally, $\S 6.3$ broaches the broad question of how language learning might proceed under the comparative regime. A goal of $\S 6.3$ is to suggest how comparative markedness theory might explain the puzzling presence of chain-shifts (i.e., counterfeeding opacity) in early phonology.

\section{\$6.1 Comparative Markedness and Harmonic Ascent}

One of the most striking results of classic OT is harmonic ascent (Moreton 1996/1999). A classic OT grammar is a ranking of markedness constraints and faithfulness constraints - and nothing else. By definition, a classical markedness constraint evaluates output candidates without reference to the input, while a faithfulness constraint evaluates input-output disparity, favoring the candidate with the least disparity (i.e., none at all). From this fact, and from the further assumption that there always is a fully faithful candidate, Moreton proves the following result:

For any OT grammar $\mathrm{G}$ and any input I, the output of $\mathrm{G}$ from I, G(I), is either identical to the FFC derived from I or less marked than the FFC according to the markedness constraints as ranked in $\mathrm{G}$.

The intuition behind this is clear: the only reason to violate a faithfulness constraint is if violation leads to improvement in markedness. For details of the proof, see Moreton's work; for a fuller summary than I have provided here, see McCarthy (2002c: 101-3)

Harmonic ascent has several empirical consequences. For one thing, it means that no OT grammar can describe a process of unconditional augmentation, where every form grows in size (e.g., /ba/ $\rightarrow$ ba, , /bat $/ \rightarrow$ bat, , /bata/ $\rightarrow$ bata,$\ldots$... ). The reason: augmentation is an unfaithful mapping, and unfaithful mappings must improve markedness. Since classical markedness constraints evaluate output forms without reference to the input, and since "getting longer" is not evaluable on output forms alone, there can be no markedness constraint in CON that would compel unconditional augmentation.

Harmonic ascent also entails that no OT grammar can describe any process or set of processes that characterizes a circular chain-shift, such as $/ \mathrm{a} / \rightarrow \ldots \rightarrow i$ coexisting with $/ \mathrm{i} / \rightarrow \ldots \rightarrow a$. Circular shifts are impossible because the ranking in a grammar must be consistent: there is no way for both of the unfaithful mappings /A/ $\rightarrow B$ and $/ \mathrm{B} / \rightarrow A$ to improve markedness relative to a single constraint hierarchy, so these two processes can never coexist (in identical or overlapping contexts) within a single language.

Comparative markedness changes the basic markedness theory enough so that harmonic ascent is no longer guaranteed. For example, comparative markedness can 
be used to describe certain unconditional augmentation processes. Imagine we have a CV language, so ONSET and NO-CODA are undominated. Suppose furthermore that MAX dominates DEP. Now, assume that ${ }_{\mathrm{O}}$ FINAL-C dominates DEP as well as ${ }_{\mathrm{N}}$ FINALC. In this language, every word will grow by the addition of one syllable:

(65) Unconditional Augmentation with Comparative Markedness

\begin{tabular}{|c|c|c|c|c|c|}
\hline /pata/ & No-CODA & MAX & ${ }_{\mathrm{O}}$ FINAL-C & DEP & ${ }_{\mathrm{N}}$ FINAL-C \\
\hline pata?ə & & & & $* *$ & * \\
\hline (FFC) pata & & & $* !$ & & \\
\hline c. pata? & $* !$ & & & $*$ & \\
\hline d. & & $* * !$ & & & $*$ \\
\hline \multicolumn{6}{|l|}{ /pataka/ } \\
\hline e. pataka?ə & & & & $* *$ & $*$ \\
\hline f. $\quad$ (FFC) pataka & & & $* !$ & & \\
\hline g. pataka? & $* !$ & & & $*$ & \\
\hline h. & & $* * !$ & & & $*$ \\
\hline
\end{tabular}

In a sense, this language is the opposite of Lardil. Lardil satisfies ${ }_{\mathrm{O}}$ FINAL-C by dropping the underlying final vowel. In this hypothetical language, ${ }_{0}$ FINAL-C is satisfied by epenthesizing a final vowel. Either way, ${ }_{\mathrm{O}}$ FINAL-C is satisfied even at the expense of creating a violation of ${ }_{\mathrm{N}}$ FINAL-C.

Comparative markedness can also be applied to produce circular chainshifts. ${ }^{23}$ Consider the circular chain-shift $/ \mathrm{e} / \rightarrow i$ and $/ \mathrm{i} / \rightarrow e$. Assume that high-ranking faithfulness constraints rule out all other unfaithful mappings from these inputs and then apply the following ranking:

${ }^{23}$ I am grateful to Paul de Lacy and Elliott Moreton for their assistance on this point and for suggesting the two examples. 
(66) Circular Chain-shift: /e/ $\rightarrow i$ and $/ \mathrm{i} / \rightarrow e$.

a. Input /e/

\begin{tabular}{|lr||c:c|c|c:c|}
\hline & & o*HIGH & o*MID & IDENT(high) & N*HIGH & N*MID \\
\hline \hline i. & & & $*$ & $*$ & \\
\hline ii. & (FFC) e & & $* !$ & & & \\
\hline
\end{tabular}

b. Input /i/

\begin{tabular}{|lr||c:c|c|c:c|}
\hline & & o ${ }^{*} \mathrm{HIGH}$ & o*MID & IDENT(high) & N*HIGH & N*MID \\
\hline \hline i. & (FFC) i & $* !$ & & & & \\
\hline ii. & & & & & $*$ \\
\hline
\end{tabular}

The result is a circular chain-shift, with /e/ mapping to $i$ and /i/ mapping to $e$.

Or imagine a language that, like Barrow Inupiaq, palatalizes coronals after $i$. Imagine too that it has a top-ranked OCP-like constraint that bans sequences of identical laterals, so $* l V l$ and $* \Lambda V \Lambda$ are prohibited but $l V \Lambda$ and $\Lambda V l$ are all right (cf. Sundanese). With the (new version of the) OCP constraint at the top and with ${ }_{0} \mathrm{PAL}$ dominating ${ }_{\mathrm{N}} \mathrm{PAL}$ and faithfulness, underlying /iliK/ becomes surface $i$ Kil and, contrariwise, underlying /iKil/ becomes surface $i l i K$. In other words, palatalization neatly flips from one lateral to the other. The following tableau delivers the bad news:

\begin{tabular}{|c|c|c|c|c|}
\hline /ilik/ & $\operatorname{OCP}(l)$ & ${ }_{0}$ PAL & ${ }_{\mathbf{N}} \mathrm{PAL}$ & IDENT \\
\hline $\mathrm{i}$ îl & & & $*$ & $*$ \\
\hline b. (FFC) ilik & & $* !$ & & \\
\hline c. $\quad \mathrm{i} \wedge \mathrm{i} K$ & $* !$ & & & $*$ \\
\hline \multicolumn{5}{|l|}{ /iКil/ } \\
\hline d. $\mathrm{ili \kappa}$ & & & $*$ & $*$ \\
\hline e. $\quad($ FFC) iKil & & $* !$ & & \\
\hline f. $\quad \mathrm{i} \wedge \mathrm{i} K$ & $* !$ & & & $*$ \\
\hline
\end{tabular}

This too is a circular chain-shift, though the circularity is reckoned over strings rather than individual segments. The crucial analytic move is to deploy the OCP constraint at the top, thereby excluding the possibility of satisfying both ${ }_{\mathrm{O}} \mathrm{PAL}$ and ${ }_{\mathrm{N}} \mathrm{PAL}$. This allows ${ }_{0} \mathrm{PAL}$ to force an alternation even when there is no net gain in terms of classic OT markedness. 
This problem for comparative markedness theory is quite serious because harmonic ascent is a sound and empirically motivated deduction from classic OT. The problem also seems to be fundamental to comparative markedness theory. Unconditional augmentation and circular chain-shifts are unanalyzable in classic OT precisely because the classical markedness constraints cannot refer to the input, and so they are unable to make a distinction between new and old violations.

Here is the same reasoning presented somewhat more formally. One of the key results of Moreton's (1996/1999) work on harmonic ascent is the following lemma (paraphrased here):

(68) Assume that $\mathcal{H}$ is the constraint hierarchy of a language, and let $\mathcal{H}^{\mathrm{M}}$ and $\mathcal{H}^{\mathrm{F}}$ stand for the hierarchies of markedness and faithfulness constraints, respectively, in the same order that they have in $\mathcal{H}$. If a classic OT grammar maps /a/ to $[\mathrm{b}]$, then $\mathcal{H}^{\mathrm{M}}([\mathrm{a}])>\mathcal{H}^{\mathrm{M}}([\mathrm{b}])$.

The expression " $\mathcal{H}^{\mathrm{M}}([\mathrm{a}])>\mathcal{H}^{\mathrm{M}}([\mathrm{b}])$ " says that [a]'s markedness violation profile is worse than [b]'s. ${ }^{24}$ If some grammar maps /a/ to [b], then the markedness constraints as they are ranked in that grammar must favor output [b] over the FFC [a]. The markedness constraints must be doing this because the faithfulness constraints surely do not: they favor the FFC [a] over unfaithful [b]. Circular chain-shifts are impossible because, for the same grammar to map input /b/ to output [a], $\mathcal{H}$ would also have to say that $\mathcal{H}^{\mathrm{M}}([\mathrm{b}])>\mathcal{H}^{\mathrm{M}}([\mathrm{a}])$. This is an obvious contradiction.

Comparative markedness tosses a monkey wrench (i.e., a spanner) into this lemma. Expressions like $\mathcal{H}^{\mathrm{M}}([\mathrm{a}])$ are no longer meaningful when markedness violations cannot be determined solely by reference to outputs because they need to have access to the input/FFC as well. The existence of an $/ \mathrm{a} / \rightarrow[\mathrm{b}]$ mapping indicates that $\mathcal{H}^{\mathrm{M}}(/ \mathrm{a} /,[\mathrm{a}])>\mathcal{H}^{\mathrm{M}}(/ \mathrm{a} /,[\mathrm{b}])$. The existence of a /b/ $\rightarrow$ [a] mapping indicates that $\mathcal{H}^{\mathrm{M}}(/ \mathrm{b} /,[\mathrm{b}])>\mathcal{H}^{\mathrm{M}}(/ \mathrm{b} /,[\mathrm{a}])$. There is, then, no contradiction and so there is no proof that circular chain-shifts are impossible. In fact, the problematic grammar in (66) has exactly this property: $\mathcal{H}^{\mathrm{M}}(/ \mathrm{i} /,[\mathrm{i}])>\mathcal{H}^{\mathrm{M}}(/ \mathrm{i} /,[\mathrm{e}])$ by top-ranked ${ }_{\mathrm{o}}{ }^{*} \mathrm{HIGH}$ and $\mathcal{H}^{\mathrm{M}}(/ \mathrm{e} /,[\mathrm{e}])$ $>\mathcal{H}^{\mathrm{M}}(/ \mathrm{e} /,[\mathrm{i}])$ by top-ranked ${ }_{\mathrm{o}}^{*}$ MID.

These differences between classic OT and comparative markedness tell us something important about the latter. In classic OT, no unfaithful mapping occurs unless it improves the markedness performance of the entire candidate relative to the FFC. In comparative markedness theory, this is not true; as we have just seen, the unfaithful mapping/pata/ $\rightarrow$ pata ?əis possible even though the candidates pata? 2 and pata perform equally well on the classic markedness constraint FINAL-C. Rather, in comparative markedness theory, an ${ }_{\mathrm{O}} \mathrm{M}$ constraint can induce an unfaithful mapping even if it only improves the markedness performance of an individual segment in a candidate relative to the FFC. In the mapping /pata/ $\rightarrow$ pata 7 , the markedness performance of the second $a$ has improved: it is no longer word-final, so it doesn't

\footnotetext{
${ }^{24} \mathcal{H}^{\mathrm{M}}$ is an $n$-tuple of strings of zero or more *'s, one for each constraint, ordered as ranked in $\mathcal{H}:\langle *, 0, * *, * * *, 0, \ldots\rangle$. Then $\mathcal{H}^{\mathrm{M}}([\mathrm{a}])>\mathcal{H}^{\mathrm{M}}([\mathrm{b}])$ means that the violation profile $\mathcal{H}^{\mathrm{M}}([\mathrm{a}])$ has more *'s than $\mathcal{H}^{\mathrm{M}}([\mathrm{b}])$ in the leftmost member of the $n$-tuple where they differ.
} 
violate FINAL-C. Indeed, the whole point of the formalization in $\S 3$ is to give meaning to the notion of an individual segment's markedness status.

This property of ${ }_{\mathrm{O}} \mathrm{M}$ comparative markedness constraints is also crucial to understanding how they differ from anti-faithfulness constraints (Alderete 1998, 2001). Anti-faithfulness constraints are the negation of faithfulness; for example, $\neg$ DEP is satisfied by all and only those candidates that contain at least one epenthetic segment. Anti-faithfulness constraints can produce unconditional augmentation or circular chain-shifts; for example, in Alderete's (1998) analysis of Luo, an underlying $/ \mathrm{t} /$ is mapped to a surface $d$ and underlying /d/ to surface $t$ to satisfy the antifaithfulness constraint $\neg$ IDENT(voice).

There is an important difference between ${ }_{\mathrm{O}} \mathrm{M}$ comparative markedness constraints and anti-faithfulness constraints, however. Comparative markedness is based on the theory of markedness, while anti-faithfulness is based on the theory of faithfulness. This remark may seem a bit shallow, but it has some depth that must be appreciated. Anti-faithfulness constraints can and do favor outputs that are more marked than the FFC at the level of the entire candidate or the individual segment. That is the case, for instance, when Luo /t/ maps to $d$. But comparative markedness cannot produce this mapping because no classic markedness constraint favors the segment $d$ over the segment $t$ in the relevant context. Anti-faithfulness constraints can trigger unfaithful mappings in callous disregard of their markedness consequences. ${ }_{0} \mathrm{M}$ comparative constraints must always improve at least an individual segment's markedness performance.

\section{$\$ 6.2$ What is the FFC?}

Markedness constraints compare candidates with the FFC, not the input. Though the FFC and the input are similar, they are not necessarily identical. This section explains what the FFC is, how it differs from the input, and how it is selected in case of ambiguity.

Every candidate set emitted by GEN contains a fully faithful candidate (FFC). This assumption is more or less implicit in the basic statements of OT, and it is made explicit in Moreton (1996/1999). By definition, the FFC obeys every faithfulness constraint. If faithfulness is formalized using correspondence theory, then the relation $\Re$ between the input and the FFC is one-to-one, onto, and order-preserving (MAX, DEP, LINEARITY, INTEGRITY, and UNIFORMITY are all obeyed) with only identical elements standing in correspondence (all IDENT(feature) constraints are obeyed).

The assumption that GEN supplies an FFC for every input is not obviously correct (see Moreton). Phonologists and syntacticians sometimes posit objects in the input that, supposedly, never appear in output forms. These include floating tones or features and abstract morphemes like RED or Q. I assume, on the contrary, that these objects do appear in output candidates. If they do not appear in actual output forms, that is because constraints militate against them. See (48) for an example. 
Not only does every candidate set contain an FFC, but most candidate sets contain more than one candidate that is fully faithful. A candidate is fully faithful if it violates none of the faithfulness constraints in CON. There are, however, aspects of phonological representation that are not governed by faithfulness constraints, and so there can be ambiguity in the choice of the FFC. I will focus here on the case of syllabification.

A phonological property that is not governed by faithfulness is universally non-contrastive. Under richness of the base, the lexicon is free to make distinctions in this property, but those distinctions can never affect outputs if there are no relevant faithfulness constraints. It is widely claimed (Blevins 1995: 221, Clements 1986b: 318, Hayes 1989: 260) that syllabification of tautomorphemic sequences is never contrastive. For example, no known language has a contrast between tautomorphemic hab.la and ha.bla. In OT, a necessary condition for ensuring that syllabification is never contrastive is that syllabification is faithfulness-free, so an unsyllabified input like /maba/ or a syllabified input like /mab.a/ will be associated by GEN with all of the following fully faithful and fully syllabified candidates: m.a.b.a, ma.b.a, m.a.ba, m.aba, m.ab.a, ma.ba, mab.a, maba. Many of these candidates are sure losers for markedness reasons, such as the quadrisyllable m.a.b.a. But they are still fully faithful in the sense that they incur no faithfulness violations.

This example shows, as promised, that the existence of faithfulness-free mappings creates ambiguity in determining which candidate is the FFC. Simply to evaluate candidates using comparative markedness constraints, it is necessary to identify a unique FFC from the set of candidates that are fully faithful but diversely syllabified. The number of such candidates is finite and, indeed, not large, but it is still greater than one. ${ }^{25}$

To show that selection of the FFC has empirical consequences, I have constructed a hypothetical example that is based on real-life cases like Yiddish and some German dialects (Lombardi 1991: 98fn.) or Isthmus Nahuatl (Kenstowicz and Kisseberth 1979: 298-9). A process of syllable-final devoicing is in a counterfeeding relationship with apocope. Underlying / $\mathrm{kab} /$ maps to kap, but underlying /maba/ maps to mab rather than *map. Now, suppose that UG supplies a markedness constraint against voiced obstruents in coda position, NOVCDOB $]_{\sigma}{ }^{26}$ The ranking schema for CFO in (56) tells us how to rank the old and new versions of this constraint.

$$
\left.\left.{ }_{\mathbf{0}} \mathrm{NoVCDOB}\right]_{\sigma} \gg \operatorname{IDENT}(\text { voice }) \gg{ }_{\mathbf{N}} \mathrm{NOVCDOB}\right]_{\sigma}
$$

\footnotetext{
${ }^{25}$ There are only $2^{\mathrm{N}-1}$ ways to divide a word of $N$ segments exhaustively into syllables. (For all segments in the word except the last, there are just two options: put it into the same syllable as the following segment or not.) Structural distinctions, such as the difference between $i u$ and $i u$, add modestly to the complexity, but there is no combinatoric explosion.

${ }^{26}$ If there are no markedness constraints against voiced coda obstruents, as argued by Lombardi (2001) (see also §2), then a different process can be used. The argument in the text simply requires that there be some markedness constraint sensitive to syllable position (cf. Zoll 1998).
} 
This says that syllable-final obstruents are devoiced only if their correspondents in the FFC are also syllable-final obstruents. But syllable-final voiced obstruents derived by apocope are left alone, because their correspondents in the FFC are not syllable-final, so they violate only low-ranking $\left.{ }_{N} \mathrm{NOVCDOB}\right]_{\sigma}$.

The syllabification of the FFC is crucial to this analysis. If the FFC is ma.ba, then the intended result is obtained:

(70) $/ \mathrm{maba} / \rightarrow m a b$ with FFC ma.ba

\begin{tabular}{|c|c|c|c|}
\hline$/ \mathrm{maba} /$ & $\left.{ }_{0} \mathrm{NoVCDOB}\right]_{\sigma}$ & IDENT(voice) & $\left.{ }_{\mathbf{N}} \mathrm{NoVCDOB}\right]_{\sigma}$ \\
\hline a. $m a b$ & & & $*$ \\
\hline b. $\quad \operatorname{map}$ & & $* !$ & \\
\hline cf. FFC ma.ba & & & \\
\hline
\end{tabular}

Because $b$ is an onset in the FFC, its correspondent in the candidate mab does not violate high-ranking $\left.{ }_{0} \mathrm{NoV} C D O B\right]_{\sigma}$. Derived codas are immune from devoicing, as desired. But if the FFC is mab.a, then the opaque mapping /maba/ $\rightarrow m a b$ is impossible to obtain:

(71) $/ \mathrm{maba} / \rightarrow$ map with FFC mab.a

\begin{tabular}{|c|c|c|c|}
\hline$/ \mathrm{maba} /$ & $\left.{ }_{\mathrm{o}} \mathrm{NoVCDOB}\right]_{\sigma}$ & IDENT(voice) & $\left.{ }_{\mathbf{N}} \mathrm{NoVCDOB}\right]_{\sigma}$ \\
\hline$m a b$ & $*$ & & \\
\hline b. $\quad \operatorname{map}$ & & $* !$ & \\
\hline cf. FFC mab.a & & & \\
\hline
\end{tabular}

When the FFC is mab.a, then $\left.{ }_{0} \mathrm{NoVCDOB}\right]_{\sigma}$ is active, ruling out $m a b$ because it is a syllable-final voiced obstruent with a correspondent in the FFC that is also syllablefinal. It makes a difference, then, how the FFC is syllabified.

A natural idea is that the unique FFC is simply the most harmonic member of the set of fully faithful candidates - ma.ba, then. ${ }^{27}$ On its face, though, this definition is circular: when choosing the most harmonic fully-faithful candidate, only markedness constraints are relevant. That seems reasonable: $m a . b a$, the presumptive FFC, is surely the least marked member of the set \{m.a.b.a, ma.ba, mab.a, m.ab.a, ... . But markedness constraints are comparative, as I have argued throughout, so they cannot be evaluated without already knowing what the FFC is. It is circular, then, to use comparative markedness constraints to find the FFC.

\footnotetext{
${ }^{27}$ As I understand the proposal made in some handouts of talks of Ronald Sprouse (1997, 1998), his notion of an "enriched input" and the FFC may be the same thing.
} 
Here is an optimization procedure that unwinds the circularity. Take each of the fully faithful candidates $\{m . a . b . a, m a . b a, \ldots\}$ with itself as temporary FFC, and then evaluate it using the constraint hierarchy of the language as a whole. The true FFC will be the most harmonic candidate that emerges from this operation. That is, harmonic evaluation will optimize over the set $\{$ m.a.b.a, ma.ba, mab.a, m.ab.a,...\}, evaluating m.a.b.a as candidate relative to m.a.b.a as temporary FFC, ma.ba as candidate relative to ma.ba as temporary FFC, and so on. Because the candidates and their respective temporary FFC's are the same, neither the faithfulness constraints nor the ${ }_{\mathrm{N}} \mathrm{M}$ markedness constraints are relevant to this evaluation (see FAQ 3 at the end of $\$ 3$ ). The ${ }_{\mathrm{o}} \mathrm{M}$ markedness constraints will carry the whole burden of selecting the true FFC. In the $\{m . a . b . a, m a . b a, \ldots\}$ example, for instance, the markedness constraints ${ }_{0}$ ONSET and ${ }_{0}$ NO-CODA will favor ma.ba over the alternatives.

This procedure is somewhat reminiscent of lexicon optimization (Prince and Smolensky 1993) in using the language's independently required constraint hierarchy to select a unique member from a set of several seemingly equivalent alternatives. There are important differences, though. Lexicon optimization is charged with determining the underlying representation of non-alternating forms - that is, it chooses underlying forms only in those circumstances where they make no difference empirically (McCarthy 2002c: 76-80). Optimization of the FFC can make a difference empirically, however, as (71) shows. Concomitant with its job of picking an underlying representation, lexicon optimization uses only faithfulness constraints, while optimization of the FFC, since it chooses among faithful candidates, uses only ${ }_{\mathrm{O}} \mathrm{M}$ markedness constraints. Finally, lexicon optimization is relevant only during learning, whereas optimization of the FFC is part of harmonic evaluation.

This proposal does not resolve all questions about the FFC, however. Let's go back to hab.la vs. ha.bla. The set of fully faithful candidates associated with the input /habla/ includes \{hab.la, hab.la, habl.a, ha.bl.a, ... . Most are hopeless, but both hab.la and ha.bla are lively competitors to be the FFC. If *COMPLEX dominates No-CODA, then the FFC associated with/habla/ will be hab.la under the optimization procedure I have described. In languages with the opposite ranking, this input will be associated with the FFC ha.bla. This is fine in languages that have some codas and/or complex onsets in surface structure, but what about languages that have neither? Learners of those languages never encounter evidence for ranking *COMPLEX relative to No-CODA. What FFC do they then assign to the input $/ \mathrm{habla} /$ ? Perhaps the answer never matters empirically, but until that can be shown, there needs to be some answer or else the theory is incomplete.

There are two possible approaches to this question. ${ }^{28}$ One approach says that learners need to discover this ranking through indirect inferences based on phenomena like opaque alternations. This is, of course, the way that opaque alternations have standardly been analyzed: by some unspecified means, learners discover language-particular rules that are not surface-true or they figure out constraint rankings for strata whose outputs are never heard directly. For obvious reasons, this is unattractive. A better approach is to assume that the ranking of

\footnotetext{
${ }^{28}$ I'm grateful to Bruce Tesar for discussion of this point.
} 
*COMPLEX relative to NO-CODA is unchanged from the initial state in any language that presents learners with no direct evidence for ranking these constraints. This means that every language that disallows codas and complex onsets will assign the same FFC to the input $/$ habla/. ${ }^{29}$ Obviously, this question requires further investigation.

\section{$\$ 6.3$ Learnability and Acquisition ${ }^{30}$}

Research on the acquisition of phonology has focused almost entirely on the learning of inventories and phonotactics. Although morphophonemic alternations are the bread and butter of phonological theorizing, there are few empirical studies of the acquisition of morphophonemics (v. Kiparsky and Menn 1977) and only some preliminary results on the formal side (M. Hale and Reiss 1997, 1998, Hayes to appear, McCarthy 1998, Tesar and Smolensky 2000: 77ff.). The phenomena that reveal differences between comparative markedness and classic OT are primarily morphophonemic, such as DEE's or opacity. Examining the consequences of comparative markedness for learning, then, would seem to be premature.

Nonetheless, it is possible and even necessary to say something about how learning might proceed under the comparative regime. Does the distinction between new and old markedness constraints introduce any novel learning problems or possibilities? This section is a preliminary foray into this challenging topic, focusing on the better understood stage of early, phonotactic learning.

First some standard background assumptions (see, e.g., Prince and Tesar to appear). The input to the early learner's grammar is not an adult-like underlying representation but rather the adult surface form exactly as the learner perceives it (cf. Pater to appear). If the adult says [but] boot and the learner produces [bu], then the learner's grammar has taken as input the expression [but], with its full prosodic structure, and emitted something different, [bu]. From this evidence, inferences can be drawn about how the constraints are ranked in the learner's grammar. The goal of learning at this early stage is to get the output of the nascent grammar to match its input. The phonotactic learner has completed its task when any adult surface form, when taken as input, is mapped to an exact copy of itself.

Another fairly standard assumption is that the starting point of learning — the initial state — is a ranking where all markedness constraints dominate all faithfulness constraints. There are two independent reasons for this: on the acquisition side, early phonology shows the effects of markedness constraints that are not visibly active in

\footnotetext{
${ }^{29}$ There is suggestive evidence that these constraints are ranked $*$ COMPLEX $\gg$ NO-CODA in the initial state. Levelt's work (Levelt, Schiller, and Levelt 1999, Levelt and van de Vijver to appear) on the acquisition of Dutch shows that codas are first produced before complex onsets. (A complication: if learning is done by RCD, then having the initial state cannot give an order-ofacquisition bias. The gradual constraint ranking algorithm is different in this respect (Boersma and Levelt 2000).) A relevant typological fact is the claim that (almost?) every language with complex onsets allows codas (Baertsch 2002, Kaye 1985, Kaye and Lowenstamm 1984).

${ }^{30}$ Special thanks to Joe Pater for his help with this material.
} 
the adult system (Jakobson 1941); and on the learnability side, initial high rank of markedness is a partial solution to the subset problem (Angluin 1980, Baker 1979). ${ }^{31}$

The process of learning involves RCD, which we encountered in another context in $§ 5.4$. When the grammar gives the wrong result, it is because some constraint favoring a loser is not dominated by any constraints favoring a winner. In this case, the learner demotes the loser-favoring constraint below at least one winnerfavoring constraint. Learning proceeds like this until no further demotions are possible.

As an example of these points, consider a phonotactic learner who hears both [naw] and [naw] (e.g., if Vietnamese is the ambient language). This learner must eventually arrive at a grammar that produces the $/ \mathrm{naw} / \rightarrow[\mathrm{naw}]$ and $/ \mathrm{naw} / \rightarrow[\mathrm{naw}]$ mappings. A learner who hears only [naw] — the subset language, such as English - can never unlearn the $/ \mathrm{yaw} / \rightarrow$ [yaw] mapping of the superset language from positive data. Therefore, learners must start from the subset language. The subset language has the most restrictive grammar because all markedness constraints dominate all faithfulness constraints in the initial state. Learners exposed to an ambient language that allows initial $\eta$ will be stimulated to demote the relevant markedness constraint below some antagonistic faithfulness constraint, leading to a less restrictive grammar.

To illustrate how RCD works with comparative markedness, I have chosen a miniature phonological system modeled after the famous puzzle-puddle-puggle example produced by Amahl Smith (N. V. Smith 1973). Amahl had a chain-shift, and I will be discussing that shortly, but first we will look at the possible transparent interactions of the same processes.

Two processes are involved. Coronal fricatives become stops everywhere (zoo $\rightarrow[\mathrm{du}]$ ), and coronal stops become velar when followed by (dark) $l$ : bottle $\rightarrow$ [bokl]. For concreteness, I will assume two markedness constraints: ${ }^{*} Z$, where $\operatorname{Loc}_{{ }_{Z}}$ returns all coronal fricatives; and ${ }^{*} D l$, where $\operatorname{Loc}_{{ } D l}$ returns a coronal stop if it is immediately followed by [dorsal] $l$.

In the markedness-over-faithfulness initial state, the old and new versions of the markedness constraints are ranked above the faithfulness constraints. As a result, the beginning phonotactic learner has the most restricted inventory under this constraint set, puggle without *puzzle (no fricatives) or *puddle (no coronal stops before dark $l$ ):

\footnotetext{
${ }^{31}$ Arguments for the markedness-over-faithflness initial state can be found in the following works: Barlow (1997), Bernhardt and Stemberger (1998), Davidson, Juszcyk, and Smolensky (to appear), Demuth (1995), Gnanadesikan (1995/to appear), Goad (1997), Levelt (1996), van Oostendorp (1997), Pater (1997), Pater and Paradis (1996), Smolensky (1996), Sherer (1994), and Tesar and Smolensky (2000: Chapt. 5). For further elaboration, see Hayes (to appear), Ito and Mester (1999), McCarthy (1998), Prince and Tesar (to appear), and J. Smith (2000).
} 
(72) Initial State: puggle

\begin{tabular}{|c|c|c|c|c|c|c|}
\hline & o $Z$ & o $D l$ & $\mathrm{~N}^{*} Z$ & ${ }_{\mathrm{N}}^{*} D l$ & IDENT(cont) & IDENT(place) \\
\hline \multicolumn{7}{|l|}{$/ \mathrm{p} \wedge \mathrm{z} \mid /$} \\
\hline$(\mathrm{FFC}) \mathrm{p} \wedge \mathrm{zl}$ & W & & & & $\mathrm{L}$ & $\mathrm{L}$ \\
\hline b. & & & & $\mathrm{W}$ & & $\mathrm{L}$ \\
\hline $\mathrm{p} \wedge \mathrm{g}$ & & & & & & \\
\hline \multicolumn{7}{|l|}{$/ \mathrm{p} \wedge \mathrm{d} 1 /$} \\
\hline d. & & & W & & W & $\mathrm{L}$ \\
\hline$(\mathrm{FFC}) \mathrm{p} \wedge \mathrm{dl}$ & & W & & & & $\mathrm{L}$ \\
\hline $\mathrm{p} \wedge \mathrm{g}$ & & & & & & \\
\hline \multicolumn{7}{|l|}{$/ \mathrm{p} \wedge \mathrm{g} / /$} \\
\hline g. & & & & & $\mathrm{W}$ & $\mathrm{W}$ \\
\hline h. & & & & & & $\mathrm{W}$ \\
\hline i. $\quad(\mathrm{FFC}) \mathrm{p} \wedge \mathrm{g}$ & & & & & & \\
\hline
\end{tabular}

If the ambient language contains no coronal fricatives or unassimilated $D l$ clusters, then the learner will have no reason to deviate from this ranking; RCD will have nothing to do. Learning starts from subset languages like this.

Suppose, however, that the learner is exposed to coronal fricatives. RCD will re-rank the initial state to yield one of the superset grammars, where $/ \mathrm{p} \wedge \mathrm{z} \mid / \rightarrow[\mathrm{p} \wedge \mathrm{zl}]$ : 
(73) Inventory: puzzle, puggle

\begin{tabular}{|c|c|c|c|c|c|c|}
\hline & o $D l$ & $\mathrm{~N}^{*} Z$ & $\mathrm{~N}^{*} D l$ & IDENT(cont) & IDENT(place) & o $Z$ \\
\hline \multicolumn{7}{|l|}{$/ \mathrm{p} \wedge \mathrm{z} / /$} \\
\hline \multicolumn{7}{|l|}{ a. $\quad(\mathrm{FFC}) \mathrm{p} \wedge \mathrm{z}$} \\
\hline b. $\quad \mathrm{p} \wedge \mathrm{d} 1$ & & & $\mathrm{~W}$ & $\mathrm{~W}$ & & $\mathrm{~L}$ \\
\hline $\begin{array}{ll}\text { c. } & \text { p } \wedge \mathrm{gl}\end{array}$ & & & & W & $\mathrm{W}$ & $\mathrm{L}$ \\
\hline \multicolumn{7}{|l|}{$/ \mathrm{p} \wedge \mathrm{d} 1 /$} \\
\hline d. & & $\mathrm{W}$ & & $\mathrm{W}$ & $\mathrm{L}$ & \\
\hline$(\mathrm{FFC}) \mathrm{p} \wedge \mathrm{dl}$ & $\mathrm{W}$ & & & & $\mathrm{L}$ & \\
\hline \multicolumn{7}{|l|}{$\mathrm{p} \wedge \mathrm{gl}$} \\
\hline \multicolumn{7}{|l|}{$/ \mathrm{p} \wedge \mathrm{gl} /$} \\
\hline g. & & & & $\mathrm{W}$ & $\mathrm{W}$ & \\
\hline h. & & & & & $\mathrm{W}$ & \\
\hline i. $\quad(\mathrm{FFC}) \mathrm{p} \wedge \mathrm{gl}$ & & & & & & \\
\hline
\end{tabular}

RCD has applied in its usual fashion: the loser-favoring markedness constraint ${ }_{0}^{*} Z$ has been demoted to a stratum immediately below the initial faithfulness stratum.

If the ambient language also offers puddle, then RCD will similarly demote o $D l$. The typological possibilities, depending on what data the learner is exposed to, are these:

(74) Results of RCD Applied to Initial State (72)
a. puggle $(=(72))$$$
\text { o } * Z,{ }_{\mathrm{O}}^{*} D l,{ }_{\mathrm{N}}^{*} Z,{ }_{\mathrm{N}}^{*} D l \gg \operatorname{IDENT}(\text { cont }), \operatorname{IDENT}(\text { place })
$$
b. puzzle, puggle $(=(73))$

$$
{ }_{\mathrm{O}} * D l,{ }_{\mathrm{N}} * Z,{ }_{\mathrm{N}} * D l \gg \operatorname{IDENT}(\text { cont }), \operatorname{IDENT}(\text { place }) \gg_{\mathrm{O}} * Z
$$
c. puddle, puggle

$$
{ }_{\mathrm{O}} * Z,{ }_{\mathrm{N}} * Z,{ }_{\mathrm{N}} * D l \gg \operatorname{IDENT}(\text { cont }), \operatorname{IDENT}(\text { place }) \gg_{\mathrm{O}} * D l
$$
d. puzzle, puddle, puggle$$
{ }_{\mathrm{N}}{ }^{*} Z,{ }_{\mathrm{N}}{ }^{*} D l \gg \operatorname{IDENT}(\text { cont }), \operatorname{IDENT}(\text { place }) \gg_{\mathrm{O}} * Z,{ }_{\mathrm{o}} * D l
$$

This shows, as desired, that the basics of phonotactic typology are learnable with RCD under comparative markedness theory, starting from a markedness-overfaithfulness initial state like (72). So the learning theory for classic OT can be carried over to comparative markedness without apparent difficulty. 
There is an important difference between comparative markedness and classic markedness theory, however. Exposure to marked forms in the ambient language will cause the phonotactic learner to demote ${ }_{0} \mathrm{M}$ constraints, but ${ }_{\mathrm{N}} \mathrm{M}$ constraints remain untouched, as (74) shows. The goal of phonotactic learning is the identity mapping $/ \mathrm{X} / \rightarrow X$ for any adult form $X$. Identity mappings can never prove crucial domination of a ${ }_{N} \mathrm{M}$ constraint, because ${ }_{\mathrm{N}} \mathrm{M}$ constraints cannot be violated by fully-faithful candidates - see FAQ 3. Therefore, the various ${ }_{\mathrm{N}} \mathrm{M}$ constraints are never demoted during phonotactic learning. Demotion of these constraints must await morphophonemic learning, when learners operate with abstract underlying forms and unfaithful winning candidates.

${ }_{\mathrm{N}} \mathrm{M}$ constraints are not demoted during phonotactic learning but ${ }_{0} \mathrm{M}$ constraints may be. This difference in ranking has no observable empirical consequences at the end of phonotactic learning, but differences could emerge along the way. For example, imagine a learner who is exposed to the full puzzle/puddle/puggle inventory. Along the way toward (74d), the learner might briefly tarry at the intermediate grammar $(74 \mathrm{c})$, producing the subset inventory puddle/puggle. Under comparative markedness, the learner at this intermediate stage will pronounce puzzle as $/ \mathrm{p} \wedge \mathrm{gl} /$. This is a grandfather effect: [dl] is OK when mapped faithfully from the input, but not when derived. In fact, the ranking (74c) matches the schema for grandfather effects and DEE's given in (35).

Joe Pater suggests that real-life examples like this may indeed exist. Apparently, reduction of onset clusters (please $\rightarrow$ [piz]) is sometimes observed to affect underlying clusters but not those derived by syncope of $\partial$ (police $\rightarrow$ [plis]) (Compton and Streeter 1977, Pater 1997). This is the expected result of the ranking $\llbracket{ }_{\mathrm{N}}{ }^{*}$ COMPLEX $\gg$ MAX $\gg{ }_{0}{ }^{*}$ COMPLEX $\rrbracket$, which also matches the grandfather/DEE schema in (35). Obviously, more research needs to be done on this topic, but it is at least suggestive.

The existence of chain-shifts in child phonology is more securely established than grandfather effects (Dinnsen and Barlow 1998, Dinnsen, O'Connor, and Gierut 2001, N. V. Smith 1973). At one stage, Amahl pronounced puzzle as [p^dl] and puddle as [p^gl]. Like all chain-shifts, this is an instance of CFO because the markedness constraint that compels the $/ \mathrm{dl} / \rightarrow g l$ mapping is not active on inputs like puzzle.

The appearance of chain-shifts in phonotactic learning is difficult to explain in approaches to opacity like stratal OT, local conjunction, and sympathy. Why would a phonotactic learner make any stratal distinctions whatsoever without an inkling of the lexical phonology and morphology of English? What would motivate a phonotactic leaner to construct and appropriately rank the locally conjoined constraint [IDENT(cont)\&IDENT(place) $]_{\text {seg }}$ that is necessary to block the puzzle $\rightarrow$ *puggle mapping? Only something like Łubowicz's (2002a) theory of contrast preservation would seem to have a ready explanation for why this kind of opacity should appear in early phonology. 
Comparative markedness does not have a ready solution to this problem, but at least it suggests where to look. Under comparative markedness, the potential for $\mathrm{CFO}$ and therefore for chain-shifts is intrinsic to the theory of markedness. Chainshifts do not require an additional leap by learners because they are analyzed with the same basic stuff as all other aspects of phonology. The ranking that gives Amahl's chain shift is simply another permutation of the constraints in (74):

\begin{tabular}{|c|c|c|c|c|c|c|}
\hline & o $Z Z$ & O ${ }^{*} D l$ & ${ }_{\mathrm{N}}^{*} Z$ & IDENT(cont) & IDENT(place) & ${ }_{\mathrm{N}}^{*} D l$ \\
\hline \multicolumn{7}{|l|}{ /p^z1/ } \\
\hline$(\mathrm{FFC}) \mathrm{p} \wedge \mathrm{zl}$ & W & & & $\mathrm{L}$ & & $\mathrm{L}$ \\
\hline \multicolumn{7}{|l|}{$\mathrm{p} \wedge \mathrm{d} \mathrm{l}$} \\
\hline $\mathrm{p} \wedge \mathrm{gl}$ & & & & & W & $\mathrm{L}$ \\
\hline \multicolumn{7}{|l|}{$/ \mathrm{p} \wedge \mathrm{d} 1 /$} \\
\hline $\mathrm{p} \wedge \mathrm{zl}$ & & & W & W & $\mathrm{L}$ & \\
\hline$(\mathrm{FFC}) \mathrm{p} \wedge \mathrm{dl}$ & & $\mathrm{W}$ & & & $\mathrm{L}$ & \\
\hline $\mathrm{p} \wedge \mathrm{gl}$ & & & & & & \\
\hline \multicolumn{7}{|l|}{$/ \mathrm{p} \wedge \mathrm{gl} /$} \\
\hline g. & & & & W & W & \\
\hline h. & & & & & $\mathrm{W}$ & \\
\hline i. $\quad(\mathrm{FFC}) \mathrm{p} \wedge \mathrm{gl}$ & & & & & & \\
\hline
\end{tabular}

The real problem, to which I have no solution, is that RCD can never arrive at this ranking starting from the initial state (72). This is unsurprising, since RCD's monotonic progress toward the correct grammar is not always fully reconcilable with what is observed at intermediate stages of learning. Until this broader issue is addressed, then, these remarks necessarily remain rather speculative.

\section{$\$ 7$ Conclusion}

In this paper, I have explored a very different way of treating markedness constraints in Optimality Theory. Instead of evaluating output forms alone, comparative markedness constraints look at the markedness consequences of inputoutput mappings. The fully faithful candidate, which assumes the role of the input in this comparison, has certain markedness violations. Every other output candidate will eliminate some of those violations, add others, or stay the same. Comparative markedness constraints are sensitive to this difference: ${ }_{0} \mathrm{M}$ constraints demand elimination of markedness violations, while ${ }_{\mathbf{N}} \mathrm{M}$ constraints militate against addition of new markedness violations. 
Taken together, ${ }_{\mathbf{0}} \mathrm{M}$ and ${ }_{\mathrm{N}} \mathrm{M}$ constraints assign the same violation-marks as traditional markedness constraints. The interesting cases arise when ${ }_{\mathbf{0}} \mathrm{M}$ and ${ }_{\mathrm{N}} \mathrm{M}$ are ranked separately, with some faithfulness constraint ranked between them. If ${ }_{\mathbf{o}} \mathrm{M}$ is higher ranked, then unfaithful mappings will be possible to eliminate pre-existing markedness violations, but not to prevent the introduction of new ones. This is counterfeeding opacity: a process affects configurations present in the input, but not configurations that are produced by other processes. On the other hand, if ${ }_{\mathbf{N}} \mathrm{M}$ is higher ranked, then unfaithful mappings will be possible to prevent the introduction of new markedness violations (as a result of some other process), but not to eliminate pre-existing ones. Derived environment effects are like this: a markedness constraint is visibly active only on configurations that are the result of some other process.

These and other phenomena served as the basis for contrasting comparative markedness with classic OT, using differences between them to illuminate aspects of the comparative theory. Other enhancements to classic OT, such as local conjunction, were also considered in relation to comparative markedness. Finally, two further points of divergence between comparative markedness and classic OT were discussed: harmonic ascent, which appears to favor classic OT, and chain-shifts in acquisition, which tend to support comparative markedness.

\section{Acknowledgments}

I am grateful to the following for their comments on an earlier version of this article: Akin Akinlabi, John Alderete, Mark Baker, Eric Bakovic, Angela Carpenter, Andries Coetzee, Caroline Féry, Markus Hiller, Shigeto Kawahara, Paul Kiparsky, Amalia Gnanadesikan, Maria Gouskova, Linda Lombardi, Marc van Oostendorp, Orhan Orgun, Steve Parker, Irena Polic and the other participants in a course at UC Santa Cruz (taught by Junko Ito), Ken Safir, Bruce Tesar, Anne-Michelle Tessier, Bert Vaux, Jeroen van de Weijer and other participants in the Leiden Phonology Reading Group, Colin Wilson, Moira Yip, the students in Ling 751 at UMass, and audiences at CONSOLE X (Leiden), Rutgers University, and the Central Institute of English and Foreign Languages in Hyderabad, India. Special thanks to Paul de Lacy, Elliott Moreton, Joe Pater and Alan Prince for their valuable contributions.

\section{Appendix A: Problems with Allophony}

In $§ 5.2$, I observed that there is a problem in analyzing allophonic systems like Sea Dayak with comparative markedness. The problem is that there is no ranking of the relevant constraints supplied by comparative markedness theory- ${ }_{0} * \mathrm{~V}_{\mathrm{NAS}},{ }_{\mathrm{N}} * \mathrm{~V}_{\mathrm{NAS}}$, ${ }_{\mathrm{O}} \mathrm{NV}_{\text {ORAL }},{ }_{\mathrm{N}}{ }^{*} \mathrm{NV}_{\text {ORAL }}$, and IDENT(nasal) - that maps all of the rich-base inputs /nayga/, /nãyga/, /naygã/, and /nãygã/ — onto the single output nãya?. The easiest way to see this is to present the unranked constraints in the form of a comparative tableau (Prince 2000) and then apply Recursive Constraint Demotion (RCD) (Tesar 1995, Tesar and Smolensky 1998, 2000) until the failure becomes apparent.

We begin with an initial unranked tableau, presupposing that the phonology of post-nasal voiced stop deletion and the final $?$ is already in place: 
(76) Sea Dayak Prior to RCD

\begin{tabular}{|c|c|c|c|c|c|}
\hline & o $* \mathrm{~V}_{\mathrm{NAS}}$ & $\mathrm{N} * \mathrm{~V}_{\mathrm{NAS}}$ & o $* \mathrm{NV}_{\text {ORAL }}$ & $\mathrm{N} * \mathrm{NV}_{\text {ORAL }}$ & IDENT(nasal) \\
\hline \multicolumn{6}{|l|}{ /nayga/ } \\
\hline a. nãya $\sim$ naya & & $\mathrm{L}$ & $\mathrm{W}$ & & $\mathrm{L}$ \\
\hline b. nãya nãyã & & $\mathrm{W}$ & & $\mathrm{L}$ & $\mathrm{W}$ \\
\hline \multicolumn{6}{|l|}{ cf. FFC nayga } \\
\hline \multicolumn{6}{|l|}{ /nãnga/ } \\
\hline c. nãya $\sim$ naya & $\mathrm{L}$ & & & $\mathrm{W}$ & $\mathrm{W}$ \\
\hline d. $\quad$ nãya $\sim$ nãyã & & $\mathrm{W}$ & & $\mathrm{L}$ & $\mathrm{W}$ \\
\hline \multicolumn{6}{|l|}{ cf. FFC nãgga } \\
\hline \multicolumn{6}{|l|}{ /nãygã/ } \\
\hline e. nãya $\sim$ naya & $\mathrm{L}$ & & & $\mathrm{W}$ & $\mathrm{W}$ \\
\hline f. $\quad$ nãya $\sim$ nãyã & $\mathrm{W}$ & & & $\mathrm{L}$ & $\mathrm{L}$ \\
\hline \multicolumn{6}{|l|}{ cf. FFC nã $\eta g \tilde{a}$} \\
\hline \multicolumn{6}{|l|}{ /naygã/ } \\
\hline g. $\quad$ naya & $\mathrm{L}$ & $\mathrm{L}$ & $\mathrm{W}$ & & $\mathrm{L}$ \\
\hline h. $\quad$ nãyã & $\mathrm{W}$ & & & $\mathrm{L}$ & $\mathrm{L}$ \\
\hline cf. FFC nang $\tilde{a}$ & & & & & \\
\hline
\end{tabular}

One constraint, ${ }^{*} \mathrm{NV}_{\text {ORAL }}$, assigns only winner-favoring marks. In accordance with the RCD algorithm, this constraint is placed into the top-ranked stratum and all candidates that fare worse on this constraint than the winner $(76 \mathrm{a}, \mathrm{g})$ are eliminated. The resulting reduced tableau is the following: 
(77) Sea Dayak After First RCD Step

\begin{tabular}{|c|c|c|c|c|}
\hline & o $* \mathrm{~V}_{\mathrm{NAS}}$ & ${ }_{N} * V_{\mathrm{NAS}}$ & $\mathrm{N} * \mathrm{NV}_{\text {ORAL }}$ & IDENT(nasal) \\
\hline \multicolumn{5}{|l|}{ /nanga/ } \\
\hline nãya nãyã & & W & $\mathrm{L}$ & W \\
\hline \multicolumn{5}{|l|}{ cf. FFC nayga } \\
\hline \multicolumn{5}{|l|}{ /nãyga/ } \\
\hline nãya $\sim$ naya & $\mathrm{L}$ & & W & W \\
\hline nãya nãyã & & $\mathrm{W}$ & $\mathrm{L}$ & W \\
\hline \multicolumn{5}{|l|}{ cf. FFC nã $n g a$} \\
\hline \multicolumn{5}{|l|}{ /nãygã/ } \\
\hline nãya naya & $\mathrm{L}$ & & W & W \\
\hline nãya nãyã & W & & $\mathrm{L}$ & $\mathrm{L}$ \\
\hline \multicolumn{5}{|l|}{ cf. FFC nã $\eta g \tilde{a}$} \\
\hline \multicolumn{5}{|l|}{ /naygã/ } \\
\hline nãya nãyã & W & & $\mathrm{L}$ & $\mathrm{L}$ \\
\hline cf. FFC naygã & & & & \\
\hline
\end{tabular}

Again, we locate any constraints that favor only the winner. Finding only ${ }_{\mathrm{N}}{ }^{*} \mathrm{~V}_{\mathrm{NAS}}$, we assign it to the next highest ranking stratum, and we drop all candidates that this constraint disprefers relative to the winner $(77 \mathrm{~b}, \mathrm{~d})$. The resulting reduced tableau is the following: 
(78) Sea Dayak After Second RCD Step

\begin{tabular}{|c|c|c|c|}
\hline & o $* V_{\mathrm{NAS}}$ & $\mathrm{N} * \mathrm{NV}_{\text {ORAL }}$ & IDENT(nasal) \\
\hline \multicolumn{4}{|l|}{ /nãyga/ } \\
\hline nãya $\sim$ naya & $\mathrm{L}$ & W & W \\
\hline \multicolumn{4}{|l|}{ cf. FFC nã $g a$} \\
\hline \multicolumn{4}{|l|}{ /nãygã/ } \\
\hline nãya $\sim$ naya & $\mathrm{L}$ & W & W \\
\hline nãya nãyã & W & $\mathrm{L}$ & $\mathrm{L}$ \\
\hline \multicolumn{4}{|l|}{ cf. FFC nã $g \tilde{a}$} \\
\hline \multicolumn{4}{|l|}{ /naygã/ } \\
\hline nãya nãyã & W & $\mathrm{L}$ & $\mathrm{L}$ \\
\hline cf. FFC naygã & & & \\
\hline
\end{tabular}

Observe that there are no remaining constraints that favor only the winner. This is a nice illustration of RCD's inconsistency-detecting ability. When no grammar is possible for a certain set of constraints over a certain set of candidates, then RCD terminates with no more rankable constraints and some unresolved candidate competitions. As I said, the resources of comparative markedness theory are insufficient to deal with the full array of inputs in Sea Dayak.

\section{References}

Abu-Mansour, Mahasen Hasan (1996) Voice as a privative feature. In Perspectives on Arabic Linguistics VIII: Papers from the Eighth Annual Symposium on Arabic Linguistics, ed. Mushira Eid. Amsterdam and Philadelphia: John Benjamins.

Ahn, Sang-Cheol (1998) An Introduction to Korean Phonology. Seoul: Hanshin Publishing Company.

Alderete, John (1998) Morphologically-Governed Accent in Optimality Theory. Doctoral dissertation. Amherst, MA: University of Massachusetts, Amherst. Alderete, John (2001) Dominance effects as transderivational anti-faithfulness. Phonology 18, 201-53.

Al-Mozainy, Hamza Q. (1981) Vowel Alternations in a Bedouin Hijazi Arabic Dialect: Abstractness and Stress. Doctoral dissertation. Austin, TX: University of Texas, Austin.

Angluin, Dana (1980) Inductive inference of formal languages from positive data. Information and Control 45, 117-35.

Archangeli, Diana and Pulleyblank, Douglas (1994) Grounded Phonology. Cambridge, MA: MIT Press. 
Aronoff, Mark, Arsyad, Azhar, Basri, Hassan, and Broselow, Ellen (1987) Tier configuration in Makassarese reduplication. In CLS 23: Parasession on Autosegmental and Metrical Phonology, ed. A. Bosch, E. Schiller, and B. Need, pp. 1-15. Chicago: Chicago Linguistic Society.

Baertsch, Karen (2002) An Optimality Theoretic Approach to Syllable Structure: The Split Margin Hierarchy. Doctoral dissertation. Bloomington, IN: Indiana University.

Bakalla, Mohammed (1973) The Morphology and Phonology of Meccan Arabic. Doctoral dissertation. London: School of Oriental and African Studies, University of London.

Baker, C. L. (1979) Syntactic theory and the projection problem. Linguistic Inquiry $10,533-81$.

Bakovic, Eric (2000) Harmony, Dominance, and Control. Doctoral dissertation. New Brunswick, NJ: Rutgers University. [Available on Rutgers Optimality Archive.]

Bakovic, Eric and Wilson, Colin (2000) Transparency, strict locality, and targeted constraints. In Proceedings of the 19th West Coast Conference on Formal Linguistics, ed. Roger Billerey and Brook Danielle Lillehaugen, pp. 43-56. Somerville, MA: Cascadilla Press.

Barlow, Jessica A. (1997) A Constraint-Based Account of Syllable Onsets: Evidence from Developing Systems. Doctoral dissertation. Bloomington, IN: Indiana University.

Beckman, Jill (1998) Positional Faithfulness. Doctoral dissertation. Amherst, MA: University of Massachusetts, Amherst. [Available on Rutgers Optimality Archive. Reprinted in Optimality Theory in Phonology: A Reader, ed. by John J. McCarthy, Malden, MA and Oxford, Blackwell (2003).]

Benua, Laura (1997) Transderivational Identity: Phonological Relations between Words. Doctoral dissertation: University of Massachusetts, Amherst. [Available on Rutgers Optimality Archive. Published (2000) as Phonological Relations Between Words, New York: Garland. Reprinted in Optimality Theory in Phonology: A Reader, ed. by John J. McCarthy, Malden, MA and Oxford, Blackwell (2003).]

Benua, Laura and Smolensky, Paul (2001) Markedness and preconditions on vowel harmony. Handout. University of Massachusetts, Amherst.

Bermúdez-Otero, Ricardo (1999) Constraint Interaction in Language Change: Quantity in English and Germanic. Doctoral dissertation. Manchester, UK: University of Manchester.

Bernhardt, Barbara H. and Stemberger, Joseph P. (1998) Handbook of Phonological Development from the Perspective of Constraint-Based Nonlinear Phonology. San Diego: Academic Press.

Bickmore, Lee (1996) Bantu tone spreading and displacement as alignment and minimal misalignment. Albany, NY: University at Albany. [Available on Rutgers Optimality Archive.]

Blevins, Juliette (1995) The syllable in phonological theory. In The Handbook of Phonological Theory, ed. John A. Goldsmith, pp. 206-44. Cambridge, MA, and Oxford, UK: Blackwell. 
Boersma, Paul and Levelt, Clara C. (2000) Gradual constraint-ranking learning algorithm predicts acquisition order. In The Proceedings of the Thirtieth Annual Child Language Research Forum, ed. Eve V. Clark, pp. 229-37. Stanford, CA: CSLI Publications. [Available on Rutgers Optimality Archive.]

Bradley, Travis (2002) Gestural timing and derived environment effects in Norwegian clusters. In Proceedings of WCCFL 21, ed. L. Mikkelsen and C. Potts, pp. 101-14. Somerville, MA: Cascadilla Press. [Available on Rutgers Optimality Archive, ROA-529.]

Broselow, Ellen (1999) Stress, epenthesis, and segment transformation in Selayarese loans. In Proceedings of the Twenty-Fifth Annual Meeting of the Berkeley Linguistics Society, Feb. 12-15, 1999: General Session and Parasession on Loan Word Phenomena, ed. Steve S. Chang, Lily Liaw, and Josef Ruppenhofer. Berkeley, CA: Berkeley Linguistic Society.

Campbell, Lyle (1974) Phonological features: Problems and proposals. Language 50, 52-65.

Causley, Trisha (1997) Identity and featural correspondence: The Athapaskan case. In Proceedings of the North East Linguistic Society 27, ed. Kiyomi Kusumoto, pp. 93-105. Amherst, MA: GLSA Publications.

Cho, Taehong (1998) Intergestural timing and overlap in Korean palatalization. In Japanese/Korean Linguistics 8, ed. David Silva, pp. 261-76. Stanford, CA: CSLI Publications.

Chomsky, Noam and Halle, Morris (1965) Some controversial questions in phonological theory. Journal of Linguistics 1, 97-138.

Churchward, C. M. (1940) Rotuman Grammar and Dictionary. Sydney: Australasia Medical Publishing Co. [Repr. 1978, AMS Press, New York.].

Clements, G. N. (1986a) Compensatory lengthening and consonant gemination in Luganda. In Studies in Compensatory Lengthening, ed. L. Wetzels and E. Sezer, pp. 37-77. Dordrecht: Foris.

Clements, G. N. (1986b) Syllabification and epenthesis in the Barra dialect of Gaelic. In The Phonological Representation of Suprasegmentals, ed. Koen Bogers, Harry van der Hulst, and Maarten Mous, pp. 317-36. Dordrecht: Foris.

Clements, G. N. and Ford, K. C. (1979) Kikuyu tone shift and its synchronic consequences. Linguistic Inquiry 10, 179-210.

Cohn, Abigail (1992) The consequences of dissimilation in Sundanese. Phonology 9, 199-220.

Cohn, Abigail and McCarthy, John J. (1994/1998) Alignment and parallelism in Indonesian phonology. Working Papers of the Cornell Phonetics Laboratory 12, 53-137. [Available on Rutgers Optimality Archive, ROA-25.]

Compton, A. J. and Streeter, Mary (1977) Child phonology: Data collection and preliminary analyses. In Papers and Reports on Child Language Development 7. Palo Alto, CA: Stanford University.

Crowhurst, Megan and Hewitt, Mark (1997) Boolean operations and constraint interactions in Optimality Theory. Unpublished manuscript. Chapel Hill, NC, and Waltham, MA: University of North Carolina and Brandeis University. [Available on Rutgers Optimality Archive.]

Davidson, Lisa, Juszcyk, Peter, and Smolensky, Paul (to appear) The initial state and the final state: Theoretical implications of Richness of the Base and empirical 
explorations. In Fixing Priorities: Constraints in Phonological Acquisition, ed. René Kager, Joe Pater, and Wim Zonneveld. Cambridge: Cambridge University Press.

Davis, Stuart (1995) Emphasis spread in Arabic and Grounded Phonology. Linguistic Inquiry 26, 465-98.

Demuth, Katherine (1995) Markedness and the development of prosodic structure. In Proceedings of the North East Linguistic Society 25, ed. Jill Beckman, pp. 13-25. Amherst, MA: GLSA Publications.

Dinnsen, Daniel A. and Barlow, Jessica A. (1998) On the characterization of a chain shift in normal and delayed phonological acquisition. Journal of Child Language 25, 61-94.

Dinnsen, Daniel A., O'Connor, Kathleen, and Gierut, Judith (2001) An optimality theoretic solution to the puzzle-puddle-pickle problem. Handout from Annual Meeting, Linguistic Society of America, Washington, DC.

Dixon, Robert M. W. (1980) The Languages of Australia. Cambridge: Cambridge University Press.

Fukazawa, Haruka and Lombardi, Linda (to appear) To be simple or not to be: Constraints in Optimality Theory. In Proceedings of the First Tokyo Conference on Psycholinguistics, ed. Yukio Otsu. Tokyo: Hitsuji-Shobo.

Fukazawa, Haruka and Miglio, Viola (1998) Restricting conjunction to constraint families. In Proceedings of the Western Conference on Linguistics 9 (WECOL 96), ed. Vida Samiian, pp. 102-17. Fresno, CA: Department of Linguistics, California State University, Fresno.

Gnanadesikan, Amalia (1995/to appear) Markedness and faithfulness constraints in child phonology. In Fixing Priorities: Constraints in Phonological Acquisition, ed. René Kager, Joe Pater, and Wim Zonneveld. Cambridge: Cambridge University Press. [Available on Rutgers Optimality Archive, ROA-67.]

Gnanadesikan, Amalia (1997) Phonology with Ternary Scales. Doctoral dissertation. Amherst, MA: University of Massachusetts at Amherst. [Available on Rutgers Optimality Archive, ROA-195.]

Goad, Heather (1997) Consonant harmony in child language: An OptimalityTheoretic account. In Focus on Phonological Acquisition, ed. S.-J. Hannahs and Martha Young-Scholten, pp. 113-42. Amsterdam: John Benjamins.

Hale, Kenneth (1973) Deep-surface canonical disparities in relation to analysis and change: An Australian example. In Current Trends in Linguistics, ed. Thomas Sebeok, pp. 401-58. The Hague: Mouton.

Hale, Mark and Kissock, Madelyn (1998) The phonology-syntax interface in Rotuman. In Recent Papers in Austronesian Linguistics: Proceedings of the Third and Fourth Meetings of the Austronesian Formal Linguistics Society, UCLA Occasional Papers in Linguistics \#21, ed. Matthew Pearson, pp. 11528. Los Angeles: UCLA Department of Linguistics.

Hale, Mark, Kissock, Madelyn, and Reiss, Charles (1998) Output-output correspondence in Optimality Theory. In The Proceedings of the West Coast Conference on Formal Linguistics 16, ed. E. Curtis, J. Lyle, and G. Webster, pp. 223-36. Stanford, CA: CSLI. [Available on Rutgers Optimality Archive, ROA-202.] 
Hale, Mark and Reiss, Charles (1997) Grammar optimization: The simultaneous acquisition of constraint ranking and a lexicon. Unpublished manuscript. Concordia University, Montreal. [Available on Rutgers Optimality Archive.]

Hale, Mark and Reiss, Charles (1998) Formal and empirical arguments concerning phonological acquisition. Linguistic Inquiry 29, 656-83. [Available on Rutgers Optimality Archive.]

Hall, Beatrice and et al. (1974) African vowel harmony systems from the vantage point of Kalenjin. Afrika und Uebersee 57, 241-67.

Hall, Nancy (2003) Gestures and Segments: Vowel Intrusion as Overlap. Doctoral dissertation. Amherst, MA: University of Massachusetts, Amherst.

Halle, Morris and Vergnaud, Jean-Roger (1982) On the framework of autosegmental phonology. In The Structure of Phonological Representations, ed. Harry van der Hulst and Norval Smith, pp. 65-82. Dordrecht: Foris.

Halle, Morris and Zeps, Valdis (1966) A survey of Latvian morphophonemics. Quarterly Progress Report of the Research Laboratory of Electronics 83, 104-13.

Hammond, Michael (1992) Deriving the strict cycle condition. In CLS 28: Parasession on the Cycle in Linguistic Theory, ed. Jeannette Marshall Denton, Grace P. Chan, and Costas P. Canakis, pp. 126-40. Chicago: Chicago Linguistic Society.

Harris, Zellig (1942) Morpheme alternants in linguistic analysis. Language 18, 16980.

Hayes, Bruce (1989) Compensatory Lengthening in moraic phonology. Linguistic Inquiry 20, 253-306.

Hayes, Bruce (to appear) Phonological acquisition in Optimality Theory: The early stages. In Fixing Priorities: Constraints in Phonological Acquisition, ed. René Kager, Joe Pater, and Wim Zonneveld. Cambridge: Cambridge University Press. [Available on Rutgers Optimality Archive.]

Hermans, Ben and van Oostendorp, Marc (eds.) (1999) The Derivational Residue in Phonological Optimality Theory. Amsterdam: John Benjamins.

Holton, David B. (1995) Assimilation and dissimilation of Sundanese liquids. In Papers in Optimality Theory, ed. Jill Beckman, Laura Walsh Dickey, and Suzanne Urbanczyk, pp. 167-80. Amherst, MA: GLSA Publications.

Horwood, Graham (1999) Anti-faithfulness and subtractive morphology. Unpublished manuscript. New Brunswick, NJ: Rutgers University. [Available on Rutgers Optimality Archive, ROA-466.]

Howard, Irwin (1972) A Directional Theory of Rule Application in Phonology. Doctoral dissertation. Cambridge, MA: MIT.

Hume, Elizabeth and Tserdanelis, Georgios (1999) Nasal place assimilation in Sri Lanka Portuguese Creole: Implications for markedness. Unpublished manuscript. Columbus, OH: The Ohio State University.

Ito, Junko and Mester, Armin (1999) The phonological lexicon. In The Handbook of Japanese Linguistics, ed. Natsuko Tsujimura, pp. 62-100. Oxford: Blackwell.

Ito, Junko and Mester, Armin (2001) Structure preservation and stratal opacity in German. In Segmental Phonology in Optimality Theory, ed. Linda Lombardi, pp. 261-95. Cambridge: Cambridge University Press. 
Ito, Junko and Mester, Armin (2002) On the sources of opacity in OT: Coda processes in German. In The Optimal Syllable, ed. Caroline Féry and Ruben van de Vijver. Cambridge: Cambridge University Press. [Available on Rutgers Optimality Archive, ROA-347.]

Jakobson, Roman (1941) Kindersprache, Aphasie, und allgemeine Lautgesetze. Uppsala: Almqvist \& Wiksell. [1962 reprint in Selected Writings of Roman Jakobson, vol. 1 (Berlin: Mouton de Grutyer). 1969 reprint (Frankfurt am Main: Suhrkamp). 1968 English translation by A. Keiler (The Hague: Mouton).]

Johnstone, T. M. (1967) Aspects of syllabication in the spoken Arabic of `Anaiza. Bulletin of the School of Oriental and African Studies 30(1), 1-16.

Kaplan, Lawrence (1981) Phonological Issues in North Alaskan Inupiaq. Fairbanks, AK: Alaska Native Language Center.

Kaye, Jonathan (1985) On the syllable structure of certain West African languages. In African Linguistics: Essays in Memory of M. W. K. Semikenke, ed. Didier L. Goyvaerts. Amsterdam: John Benjamins.

Kaye, Jonathan and Lowenstamm, Jean (1984) De la syllabicité. In Forme sonore du language: structure des représentations en phonologie, ed. F. Dell, D. Hirst, and J.-R. Vergnaud, pp. 123-59. Paris: Hermann.

Keer, Edward (1999) Geminates, the OCP, and the Nature of CON. Doctoral dissertation. New Brunswick, NJ: Rutgers University. [Available on Rutgers Optimality Archive, ROA-350.]

Kenstowicz, Michael (1995) Cyclic vs. non-cyclic constraint evaluation. Phonology 12, 397-436. [Available on Rutgers Optimality Archive, ROA-31.]

Kenstowicz, Michael and Kisseberth, Charles (1977) Topics in Phonological Theory. New York: Academic Press.

Kenstowicz, Michael and Kisseberth, Charles (1979) Generative Phonology: Description and Theory. New York: Academic Press.

Kiparsky, Paul(1965) Phonological Change. Doctoral dissertation. Cambridge, MA: MIT.

Kiparsky, Paul (1968) Linguistic universals and linguistic change. In Universals in Linguistic Theory, ed. Emmon Bach and Robert Harms, pp. 170-202. New York: Holt, Rinehart and Winston.

Kiparsky, Paul (1973) Phonological representations. In Three Dimensions of Linguistic Theory, ed. O. Fujimura, pp. 3-136. Tokyo: TEC.

Kiparsky, Paul (1993) Blocking in non-derived environments. In Studies in Lexical Phonology, ed. Sharon Hargus and Ellen Kaisse. San Diego: Academic Press.

Kiparsky, Paul (2002) Syllables and moras in Arabic. In The Optimal Syllable, ed. Caroline Féry and Ruben van de Vijver. Cambridge: Cambridge University Press.

Kiparsky, Paul (to appear) Paradigmatic Effects. Stanford, CA: CSLI Publications. Kiparsky, Paul and Menn, Lise (1977) On the acquisition of phonology. In Language Learning and Thought, ed. J. Macnamara, pp. 47-78. New York: Academic Press.

Kirchner, Robert (1992) Lardil truncation and augmentation: a morphological account. Handout from Linguistic Society of America Annual Meeting, Philadelphia. 
Kirchner, Robert (1993) Turkish vowel harmony and disharmony: An Optimality Theoretic account. Unpublished manuscript. Los Angeles: UCLA. [Available on Rutgers Optimality Archive, ROA-4.]

Kirchner, Robert (1996) Synchronic chain shifts in Optimality Theory. Linguistic Inquiry 27, 341-50.

Klokeid, Terry (1976) Topics in Lardil Grammar. Doctoral dissertation. Cambridge, MA: MIT.

de Lacy, Paul (2002) The Formal Expression of Scales. Doctoral dissertation. Amherst, MA: University of Massachusetts, Amherst.

Lamontagne, Greg and Rice, Keren (1995) A correspondence account of coalescence. In University of Massachusetts Occasional Papers in Linguistics 18, ed. Jill Beckman, Laura Walsh Dickey, and Suzanne Urbanczyk, pp. 21124. Amherst, MA: GLSA Publications.

Levelt, Clara C. (1996) Consonant-vowel interactions in child language. In Proceedings of the UBC International Conference on Phonological Acquisition, ed. Barbara H. Bernhardt, John Gilbert, and David Ingram, pp. 229-39. Somerville, MA: Cascadilla Press.

Levelt, Clara C., Schiller, Niels O., and Levelt, Willem J. M (1999) A developmental grammar for syllable structure in the production of child langauge. Brain and Language 68, 291-99.

Levelt, Clara C. and van de Vijver, Ruben (to appear) Syllable types in crosslinguistic and developmental grammars. In Fixing Priorities: Constraints in Phonological Acquisition, ed. René Kager, Joe Pater, and Wim Zonneveld. Cambridge: Cambridge University Press. [Available on Rutgers Optimality Archive.]

Lightner, Theodore (1972) Problems in the Theory of Phonology. Edmonton: Linguistic Research, Inc.

Lombardi, Linda (1991) Laryngeal Features and Laryngeal Neutralization. Doctoral dissertation: University of Massachusetts, Amherst.

Lombardi, Linda (1999) Positional faithfulness and voicing assimilation in Optimality Theory. Natural Language and Linguistic Theory 17, 267-302. [Reprinted in Optimality Theory in Phonology: A Reader, ed. by John J. McCarthy, Malden, MA and Oxford, Blackwell (2003).]

Lombardi, Linda (2001) Why Place and Voice are different: Constraint-specific alternations in Optimality Theory. In Segmental Phonology in Optimality Theory: Constraints and Representations, ed. Linda Lombardi, pp. 13-45. Cambridge: Cambridge University Press. [Available on Rutgers Optimality Archive, ROA-105.]

Lubowicz, Anna (1999) Derived environment effects in OT. In The Proceedings of the West Coast Conference on Formal Linguistics 17, ed. Kimary N. Shahin, Susan J. Blake, and Eun-Sook Kim, pp. 451-65. Stanford, CA: CSLI. [Available on Rutgers Optimality Archive.]

Lubowicz, Anna (2002a) Contrast Preservation in Phonological Mappings. Doctoral dissertation. Amherst, MA: University of Massachusetts, Amherst.

Lubowicz, Anna (2002b) Derived Environment Effects in Optimality Theory. Lingua 112, 243-80. [Available on Rutgers Optimality Archive, ROA-103. Reprinted 
in Optimality Theory in Phonology: A Reader, ed. by John J. McCarthy, Malden, MA and Oxford, Blackwell (2003).]

Mascaró, Joan (1976) Catalan Phonology and the Phonological Cycle. Doctoral dissertation. Cambridge, MA: MIT.

Mascaró, Joan and Wetzels, Leo (2001) The typology of voicing and devoicing. Language 77, 207-44.

McCarthy, John J. (1997) Process-specific constraints in Optimality Theory. Linguistic Inquiry 28, 231-51.

McCarthy, John J. (1998) Morpheme structure constraints and paradigm occultation. In CLS 32, Part 2: The Panels, ed. M. Catherine Gruber, Derrick Higgins, Kenneth Olson, and Tamra Wysocki, pp. 123-50. Chicago, IL: Chicago Linguistic Society.

McCarthy, John J. (1999) Sympathy and phonological opacity. Phonology 16, 33199.

McCarthy, John J. (2000) The prosody of phase in Rotuman. Natural Language and Linguistic Theory 18, 147-97. [Preliminary version on Rutgers Optimality Archive, ROA-110.]

McCarthy, John J. (2002a) OT constraints are categorical. Unpublished manuscript. Amherst, MA: University of Massachusetts, Amherst. [Available on Rutgers Optimality Archive, ROA-510.]

McCarthy, John J. (2002b) Sympathy, cumulativity, and the Duke-of-York gambit. In The Syllable in Optimality Theory, ed. Caroline Féry and Ruben van de Vijver. Cambridge: Cambridge University Press.

McCarthy, John J. (2002c) A Thematic Guide to Optimality Theory. Cambridge: Cambridge University Press.

McCarthy, John J. (to appear) On targeted constraints and cluster simplification. Phonology.

McCarthy, John J. and Prince, Alan (1993a) Generalized Alignment. In Yearbook of Morphology, ed. Geert Booij and Jaap van Marle, pp. 79-153. Dordrecht: Kluwer. [Excerpts appear in John Goldsmith, ed., Essential Readings in Phonology. Oxford: Blackwell. Pp. 102-136, 1999.]

McCarthy, John J. and Prince, Alan (1993b) Prosodic Morphology: Constraint Interaction and Satisfaction. New Brunswick, NJ: Rutgers University Center for Cognitive Science. [Available on Rutgers Optimality Archive, ROA482.]

McCarthy, John J. and Prince, Alan (1994) The emergence of the unmarked: Optimality in prosodic morphology. In Proceedings of the North East Linguistic Society 24, ed. Mercè Gonzàlez, pp. 333-79. Amherst, MA: GLSA Publications. [Available on the Rutgers Optimality Archive. Reprinted in Optimality Theory in Phonology: A Reader, ed. by John J. McCarthy, Malden, MA and Oxford, Blackwell (2003).]

McCarthy, John J. and Prince, Alan (1995) Faithfulness and Reduplicative Identity. In University of Massachusetts Occasional Papers in Linguistics 18, ed. Jill Beckman, Laura Walsh Dickey, and Suzanne Urbanczyk, pp. 249-384. Amherst, MA: GLSA Publications.

McCarthy, John J. and Prince, Alan (1999) Faithfulness and identity in Prosodic Morphology. In The Prosody-Morphology Interface, ed. Rene Kager, Harry 
van der Hulst, and Wim Zonneveld, pp. 218-309. Cambridge: Cambridge University Press. [Reprinted in Optimality Theory in Phonology: A Reader, ed. by John J. McCarthy, Malden, MA and Oxford, Blackwell (2003).]

Moreton, Elliott (1996/1999) Non-computable functions in Optimality Theory. Unpublished manuscript. Amherst, MA: University of Massachusetts, Amherst. [Written in 1996. Revised and placed on Rutgers Optimality Archive in 1999. Reprinted in Optimality Theory in Phonology: A Reader, ed. by John J. McCarthy, Malden, MA and Oxford, Blackwell (2003).]

Myers, Scott (1997) OCP effects in Optimality Theory. Natural Language and Linguistic Theory 15, 847-92. [Reprinted in Optimality Theory in Phonology: A Reader, ed. by John J. McCarthy, Malden, MA and Oxford, Blackwell (2003).]

Myers, Scott (2001) F0 timing in Kinyarwanda. Unpublished manuscript. Austin, TX: University of Texas at Austin.

Nash, David (1979) Warlpiri vowel assimilations. MIT Working Papers in Linguistics 1, 12-24.

Nash, David (1980) Topics in Warlpiri Grammar. Doctoral dissertation. Cambridge, MA: MIT. [Published by Garland Press, New York,1986.]

Newman, Stanley (1944) Yokuts Language of California. New York: Viking Fund.

Odden, David (1995) African tone languages. In The Handbook of Phonological Theory, ed. John A. Goldsmith, pp. 444-75. Cambridge, MA, and Oxford, UK: Blackwell.

Padgett, Jaye (1995) Partial class behavior and nasal place assimilation. In Proceedings of the 1995 Southwestern Workshop on Optimality Theory (SWOT), ed. Keiichiro Suzuki and Dirk Elzinga. Tucson, AZ: Department of Linguistics, University of Arizona. [Available on Rutgers Optimality Archive. Reprinted in Optimality Theory in Phonology: A Reader, ed. by John J. McCarthy, Malden, MA and Oxford, Blackwell (2003).]

Paradis, Carole and Prunet, Jean-François (eds.) (1991) The Special Status of Coronals: Internal and External Evidence. San Diego: Academic Press.

Pater, Joe (1997) Minimal Violation and Phonological Development. Language Acquisition 6, 201-53.

Pater, Joe (1999) Austronesian nasal substitution and other NC effects. In The Prosody-Morphology Interface, ed. Rene Kager, Harry van der Hulst, and Wim Zonneveld, pp. 310-43. Cambridge: Cambridge University Press. [Reprinted in Optimality Theory in Phonology: A Reader, ed. by John J. McCarthy, Malden, MA and Oxford, Blackwell (2003).]

Pater, Joe (to appear) From phonological typology to the development of receptive and productive phonological competence: Applications of minimal violation. In Fixing Priorities: Constraints in Phonological Acquisition, ed. René Kager, Joe Pater, and Wim Zonneveld. Cambridge: Cambridge University Press.

Pater, Joe and Paradis, Johanne (1996) Truncation without templates in child phonology. In Proceedings of the 20th Annual Boston University Conference on Language Development, ed. A. Stringfellow, D. Cahana-Amitay, E. Hughes, and A. Zukowski, pp. 540-52. Somerville, MA: Cascadilla Press. 
Piggott, G. L. (1975) More on the application of phonological rules. Montreal Working Papers in Lingustics 5, 113-50.

Potter, Brian (1994) Serial optimality in Mohawk prosody. In Proceedings of the Thirtieth Annual Regional Meeting of the Chicago Linguistics Society, ed. Katharine Beals, Jeannette Denton, Robert Knippen, Lynette Melmar, Hisami Suzuki, and Erica Zeinfeld, pp. 347-61. Chicago, IL: Chicago Linguistics Society.

Prince, Alan (1996) Aspects of mapping under OT. Handout from Colloquium, University of California, Santa Cruz.

Prince, Alan (1997) Paninian relations. Unpublished manuscript. New Brunswick, NJ: Rutgers University. [Handout from talk presented at the University of Massachusetts, Amherst.]

Prince, Alan (1998) Two lectures on Optimality Theory. Handout from Phonology Forum 1998, Kobe University. [Available (9/9/00) for download from http://ling.rutgers.edu/resources/archive/kobe-all.pdf.]

Prince, Alan (2000) Comparative tableaux. Unpublished manuscript. New Brunswick, NJ: Rutgers University. [Available on Rutgers Optimality Archive.]

Prince, Alan and Smolensky, Paul (1991) Optimality. Handout from Arizona Phonology Conference, Tucson.

Prince, Alan and Smolensky, Paul (1993) Optimality Theory: Constraint interaction in generative grammar. New Brunswick, NJ: Rutgers University Center for Cognitive Science. [Reprinted in Optimality Theory in Phonology: A Reader, ed. by John J. McCarthy, Malden, MA and Oxford, Blackwell (2003). Available on Rutgers Optimality Archive, ROA-537.]

Prince, Alan and Tesar, Bruce (to appear) Learning phonotactic distributions. In Fixing Priorities: Constraints in Phonological Acquisition, ed. René Kager, Joe Pater, and Wim Zonneveld. Cambridge: Cambridge University Press. [Available on Rutgers Optimality Archive.]

Pulleyblank, Douglas (1996) Neutral vowels in Optimality Theory: A comparison of Yoruba and Wolof. Canadian Journal of Linguistics 41, 295-347.

Pullum, Geoffrey (1976) The Duke of York gambit. Journal of Linguistics 12, 83102.

Roca, Iggy (ed.) (1997) Derivations and Constraints in Phonology. Oxford: Oxford University Press.

Rosenthall, Sam (1994) Vowel/Glide Alternation in a Theory of Constraint Interaction. Doctoral dissertation. Amherst, MA: University of Massachusetts, Amherst.

Rubach, Jerzy (2000) Glide and glottal stop insertion in Slavic languages: A DOT analysis. Linguistic Inquiry 31, 271-317.

Samek-Lodovici, Vieri and Prince, Alan (1999) Optima. Unpublished manuscript. London and New Brunswick, NJ: University of London and Rutgers University. [Available on Rutgers Optimality Archive.]

Schane, Sanford (1987) The resolution of hiatus. In CLS 23: Parasession on Autosegmental and Metrical Phonology, ed. A. Bosch, B. Need, and E. Schiller, pp. 279-90. Chicago: Chicago Linguistic Society. 
Scott, N. C. (1957) Notes on the pronunciation of Sea Dayak. Bulletin of the School of Oriental and African Studies 20, 509-12.

Sherer, Tim (1994) Prosodic Phonotactics. Doctoral dissertation. Amherst, MA: University of Massachusetts, Amherst.

Smith, Jennifer (2000) Positional faithfulness and learnability in Optimality Theory. In Proceedings of ESCOL 99, ed. Rebecca Daly and Anastasia Riehl, pp. 203-14. Ithaca, NY: CLC Publications.

Smith, Neilson V. (1973) The Acquisition of Phonology: A Case Study. Cambridge: Cambridge University Press.

Smolensky, Paul (1995) On the structure of the constraint component Con of UG. Handout. UCLA. [Available on Rutgers Optimality Archive, ROA-86.]

Smolensky, Paul (1996) The initial state and 'Richness of the Base' in Optimality Theory. Baltimore, MD: Department of Cognitive Science, Johns Hopkins University. [Available on Rutgers Optimality Archive, ROA-154.]

Smolensky, Paul (1997) Constraint interaction in generative grammar II: local conjunction, or random rules in Universal Grammar. Handout from Hopkins Optimality Theory Workshop/Maryland Mayfest '97, Baltimore, MD.

Sohn, Ho-min (1975) Woleaian Reference Grammar. Honolulu: University of Hawaii Press.

Sprouse, Ronald (1997) A case for enriched inputs. Handout from TREND, Berkeley, CA.

Sprouse, Ronald (1998) Encriched input sets as a source of opacity in OT. Handout from GLOW, Tilburg.

Steriade, Donca (1979) Vowel harmony in Khalkha Mongolian, including as an appendix: The input representations to Warlpiri's vowel assimilation rules. In Papers on Syllable Structure, Metrical Structure, and Harmony Processes, ed. K. Safir, pp. 43-48. Cambridge, MA: MIT Dept. of Linguistics.

Tesar, Bruce (1995) Computational Optimality Theory. Doctoral dissertation. Boulder, CO: University of Colorado. [Available on Rutgers Optimality Archive.]

Tesar, Bruce and Smolensky, Paul (1998) Learnability in Optimality Theory. Linguistic Inquiry 29, 229-68. [Reprinted in Optimality Theory in Phonology: A Reader, ed. by John J. McCarthy, Malden, MA and Oxford, Blackwell (2003).]

Tesar, Bruce and Smolensky, Paul (2000) Learnability in Optimality Theory. Cambridge, MA: MIT Press.

Vago, Robert and Battistella, Edward (1982) Rule application in phonology. Unpublished manuscript. New York: Graduate Center, City University of New York.

van der Hulst, Harry and Smith, Norval (1985) Vowel features and umlaut in Djingili, Nyangumarda and Warlpiri. Phonology 2, 277-303.

van Oostendorp, Marc (1997) Vowel Quality and Phonological Projection. Doctoral dissertation: Katolieke Universiteit Brabant.

Wilkinson, Karina (1988) Prosodic structure and Lardil phonology. Linguistic Inquiry 19, 325-34. 
Wilson, Colin (2000) Targeted Constraints: An Approach to Contextual Neutralization in Optimality Theory. Doctoral dissertation. Baltimore, MD: Johns Hopkins University.

Wilson, Colin (2001) Consonant cluster neutralization and targeted constraints. Phonology 18, 147-97.

Wiltshire, Caroline (1992) Syllabification and Rule Application in Harmonic Phonology. Doctoral dissertation: University of Chicago.

Zoll, Cheryl (1998) Positional asymmetries and licensing. Unpublished manuscript. Cambridge, MA: MIT. [Reprinted in Optimality Theory in Phonology: A Reader, ed. by John J. McCarthy, Malden, MA and Oxford, Blackwell (2003).]

Department of Linguistics

University of Massachusetts

Amherst, MA 01003 USA

jmccarthy@linguist.umass.edu 